\title{
INSTABILITY OF DYKES AT SEVEN SISTERS GENERATING STATION
}

\author{
by \\ Blair Daniel Garinger
}

\begin{abstract}
A Thesis
Submitted to the Faculty of Graduate Studies

In Partial Fulfillment of the Requirements for the Degree of
\end{abstract}

Master of Science

Department of Civil Engineering

University of Manitoba

Winnipeg, Manitoba

(C) June, 2002 
National Library

Acquisitions and Bibliographic Services

395 Wellington Street Ottawa ON K1A ON4 Canada
Bibliothèque nationale du Canada

Acquisitions et

services bibliographiques

395, rue Wellington

Ottawa ON KIA ONA

Canada

Your tite Votre réterrence

Our file Notre rélérence

The author has granted a nonexclusive licence allowing the National Library of Canada to reproduce, loan, distribute or sell copies of this thesis in microform, paper or electronic formats.

The author retains ownership of the copyright in this thesis. Neither the thesis nor substantial extracts from it may be printed or otherwise reproduced without the author's permission.
L'auteur a accordé une licence non exclusive permettant à la Bibliothèque nationale du Canada de reproduire, prêter, distribuer ou vendre des copies de cette thèse sous la forme de microfiche/film, de reproduction sur papier ou sur format électronique.

L'auteur conserve la propriété du droit d'auteur qui protège cette thèse. $\mathrm{Ni}$ la thèse ni des extraits substantiels de celle-ci ne doivent être imprimés ou autrement reproduits sans son autorisation. 


\title{
THE UNIVERSITY OF MANITOBA
}

FACULTY OF GRADUATE STUDIES

$\star * * * *$

COPYRIGHT PERMISSION PAGE

\section{INSTABILITY OF DYKES AT SEVEN SISTERS GENERATING STATION}

\author{
BY
}

\section{BLAIR DANIEL GARINGER}

\begin{abstract}
A Thesis/Practicum submitted to the Faculty of Graduate Studies of The University of Manitoba in partial fulfillment of the requirements of the degree

of

Master of Science
\end{abstract}

BLAIR DANIEL GARINGER @ 2002

Permission has been granted to the Library of The University of Manitoba to lend or sell copies of this thesis/practicum, to the National Library of Canada to microfilm this thesis and to lend or sell copies of the film, and to University Microfilm Inc. to publish an abstract of this thesis/practicum.

The author reserves other publication rights, and neither this thesis/practicum nor extensive extracts from it may be printed or otherwise reproduced without the author's written permission. 


\begin{abstract}
The dykes at the Seven Sisters Generating Station have experienced irregular instabilities since their heightening in the late 1940's. An investigation was undertaken to compare two sections of the dykes, one that had experienced previous instability and one that had remained stable. The investigation included laboratory and pore fluid chemistry testing and computer modeling.
\end{abstract}

The laboratory testing indicated strain softening stress-strain behavior in the highly plastic foundation soil beneath the dykes. Comparison of results from the stable and unstable sections showed greater brittleness and anisotropy in the unstable section.

Pore fluid chemistry testing of cation and anion concentrations was done on samples obtained from the foundation soil. The results showed significant differences in concentrations of calcium and sulphate between a background section and sections beneath the dykes. This indicated possible leaching of gypsum in the foundation soil.

Computer modeling of the stable and unstable sections of the dykes was done using sequentially coupled seepage, stress-deformation, and slope stability computer software. Results indicated that the factor of safety at both sections 
was similar and that the dykes were marginally stable using critical state strengths in the foundation and unstable using residual strengths.

Changes in pore fluid chemistry suggest that there is leaching of gypsum in the highly plastic foundation soil, which may be causing strain softening behavior and reduced strengths. 


\section{Acknowledgements}

The author wishes to thank his advisors, Dr. Marolo Alfaro and Dr. James Graham for their support and guidance during this project.

Financial support from Manitoba Hydro and a collaborative research and development grant from the Natural Sciences and Engineering Research Council of Canada are greatly appreciated. The author also thanks Denis Dubois of Manitoba Hydro for providing information and data from previous work at Seven Sisters. The help of Dr. Tee Boon Goh from the Department of Soil Sciences for pore fluid chemistry testing and interpretation is appreciated.

Help from the numerous summer students and fellow graduate students is also appreciated. The assistance with laboratory equipment by Kerry Lynch was extremely helpful.

Finally the author would like to thank his parents and sister for their support. 


\section{Table of Contents}

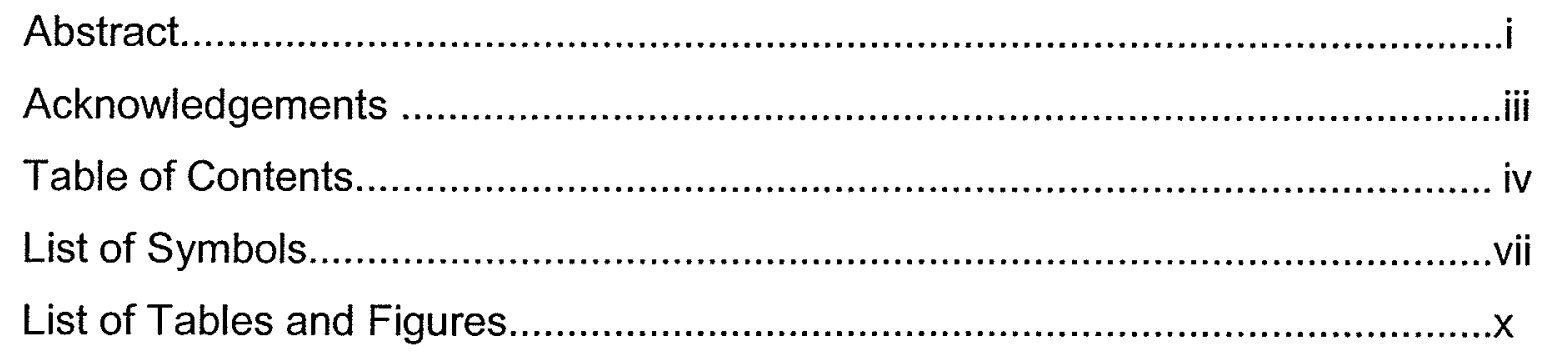

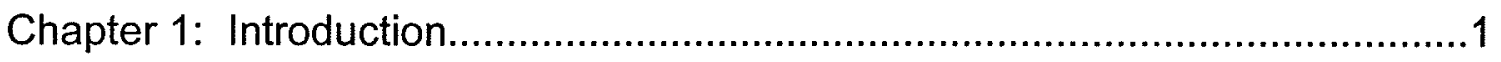

1.1 History of Seven Sisters Generating Station.................................... 1

1.2 Justification of Research Topic.................................................... 2

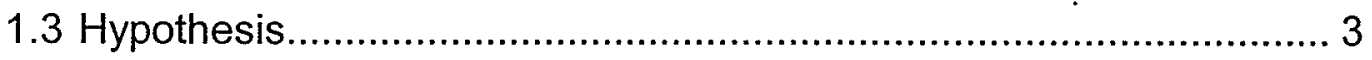

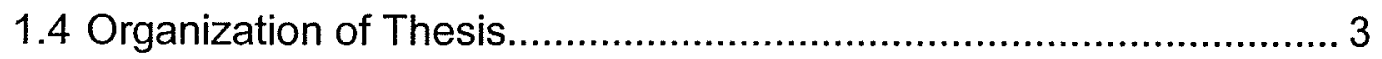

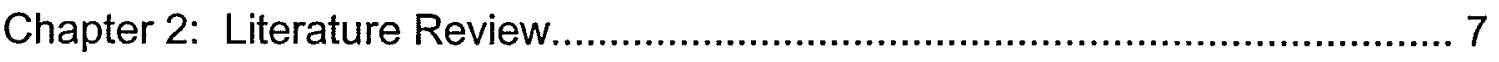

2.1 Previous Seven Sisters Research................................................... 7

2.2 Geological Background of Lake Agassiz Deposits.......................... 11

2.3 Physicochemical Investigation...................................................... 12

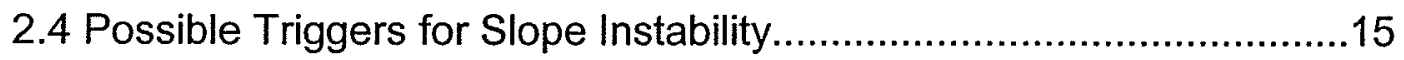

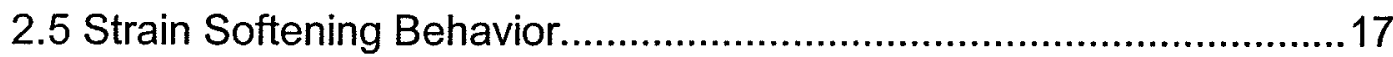

2.6 Modeling of Embankments on Soft Clays.......................................20

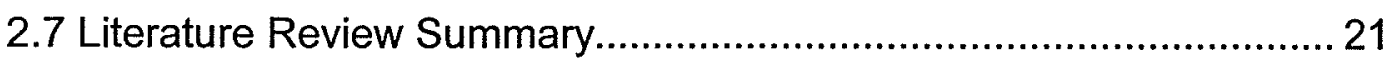

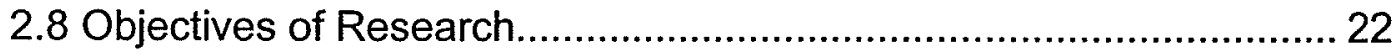

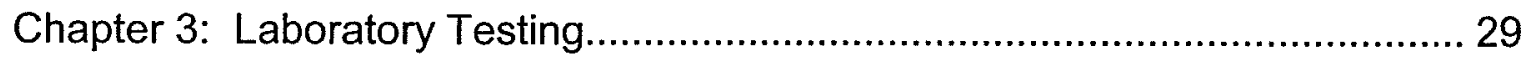

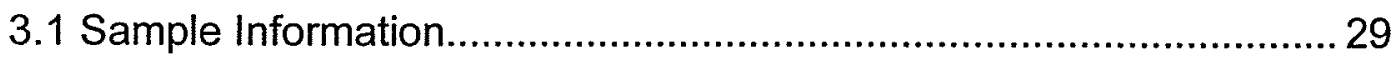

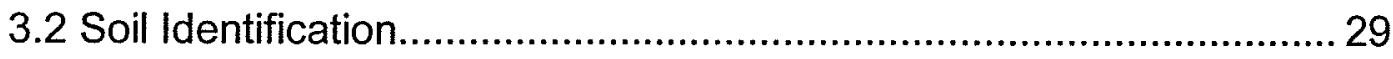

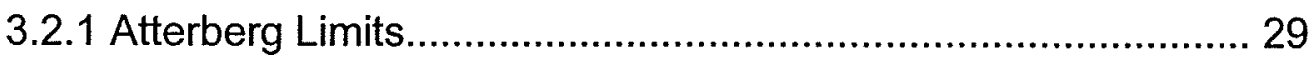

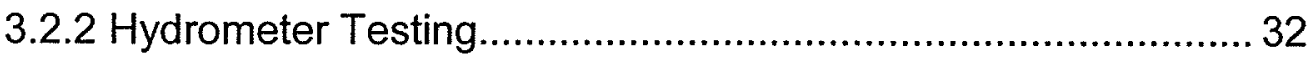

3.3 Flexible Wall Hydraulic Conductivity Testing.................................. 33 


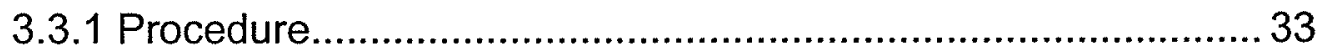

3.3.2 Saturated Hydraulic Conductivity Results............................. 34

3.3.3 Unsaturated Hydraulic Conductivity....................................... 35

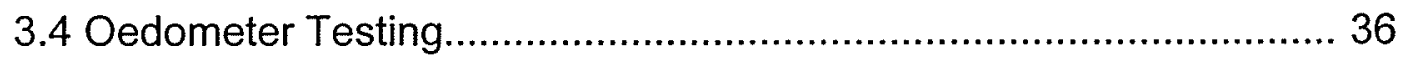

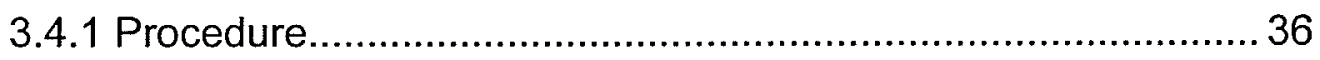

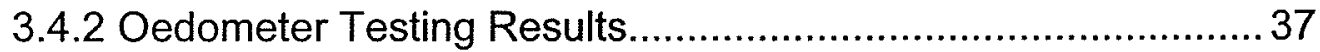

3.4.3 Oedometer Hydraulic Conductivity Testing............................ 38

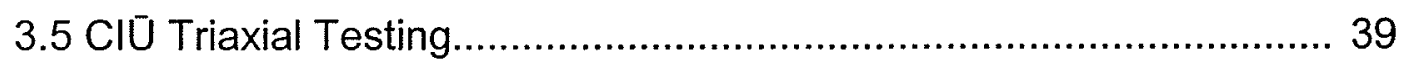

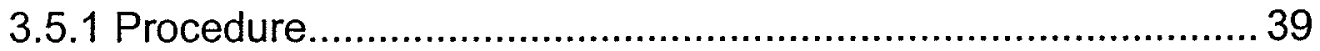

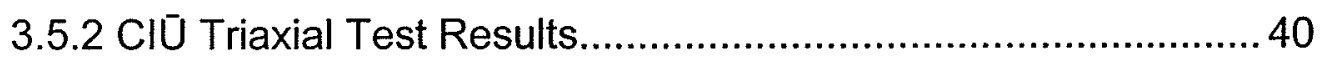

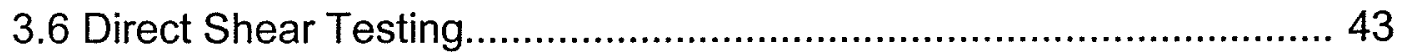

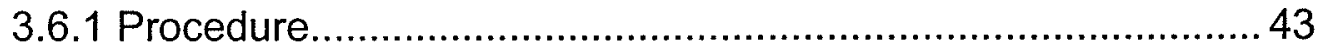

3.6.2 Direct Shear Testing Results................................................. 45

3.7 Soil Water Characteristic Curve Construction.................................. 46

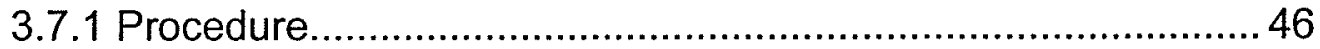

3.7.2 Soil Water Characteristic Curve Results............................... 47

3.8 Pore Fluid Chemistry Analysis..................................................... 48

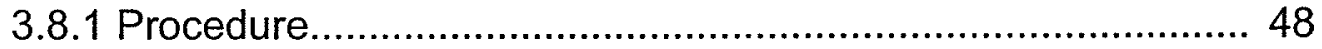

3.8.2 Pore Fluid Chemistry Analysis Results................................ 49

Chapter 4: Modeling of Seven Sisters Dykes................................................ 89

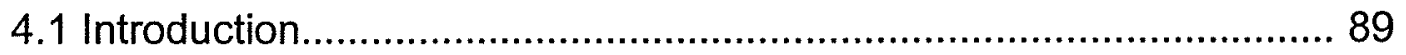

4.2 Computer Modeling Theory........................................................ 89

4.2.1 Finite Element Modeling........................................................ 90

4.2.2 Seepage Modeling Theory..................................................... 91

4.2.3 Stress-Deformation Modeling Theory................................... 92

4.2.4 Slope Stability Modeling Theory.............................................. 95

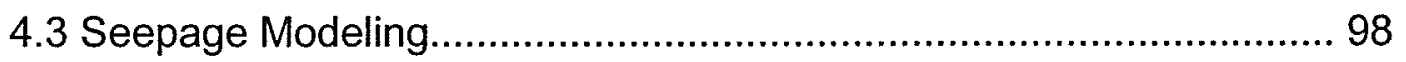

4.3.1 Seepage Model Parameters.................................................. 98

4.3.2 Seepage Model Results........................................................ 99

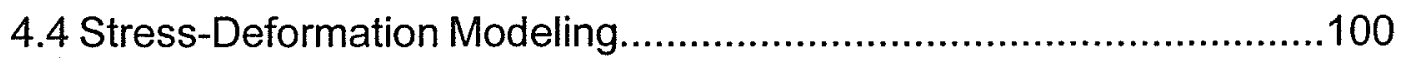


4.4.1 Stress-Deformation Model Parameters ................................100

4.4.2 Stress-Deformation Model Results........................................102

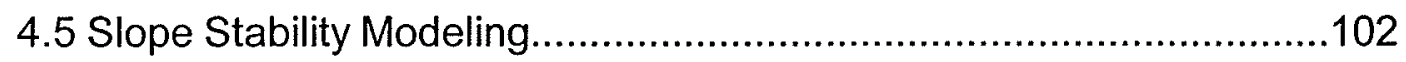

4.5.1 Slope Stability Modeling Parameters....................................102

4.5.2 Slope Stability Model Results............................................104

Chapter 5: Summary of Results and Conclusions.........................................114

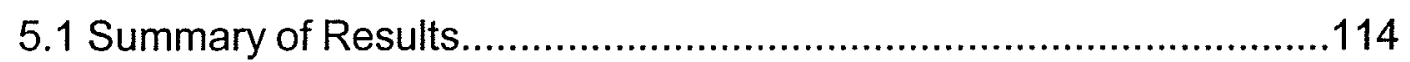

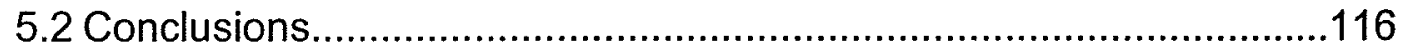

5.3 Recommendations for Further Work ............................................119

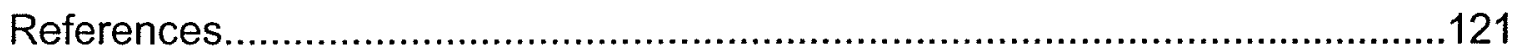




\section{List of Symbols}

\begin{tabular}{|c|c|}
\hline$\gamma_{S A T}$ & - unit weight of soil \\
\hline$\gamma_{x y}$ & - shear strain in $x-y$ plane \\
\hline$\epsilon$ & - strain \\
\hline$\epsilon^{e}$ & - elastic strain \\
\hline$\epsilon^{p}$ & - plastic strain \\
\hline$\epsilon_{p}$ & - total equivalent plastic strain \\
\hline$\epsilon_{p r}$ & - plastic strain where the softening line intersects residual line \\
\hline$\epsilon_{x}$ & - longitudinal strain in $\mathrm{x}$ - direction \\
\hline$\epsilon_{y}$ & - longitudinal strain in $y$ - direction \\
\hline$\theta$ & $\begin{array}{l}\text { - angle measured from positive } x \text {-axis to line of application of } \\
\text { normal stress (Section } 4.2 .4 \text { ) }\end{array}$ \\
\hline$\Theta$ & - volumetric water content (Section 4.2.2) \\
\hline$\nu$ & - Poisson's Ratio \\
\hline$\sigma$ & - total stress \\
\hline$\sigma^{\prime}$ & - true effective stress \\
\hline$\sigma^{*}$ & - interparticle contact stress \\
\hline$\sigma_{3}$ & - all-round stress \\
\hline$\sigma_{h c}^{\prime}$ & - effective horizontal preconsolidation pressure \\
\hline$\sigma_{n}$ & - normal stress at base center of slice \\
\hline$\sigma_{\nu c}^{\prime}$ & - effective vertical preconsolidation pressure \\
\hline
\end{tabular}




$$
\begin{aligned}
& \sigma_{x} \quad-\text { stress in } \mathrm{x} \text { - direction } \\
& \sigma_{y} \quad \text { - stress in } \mathrm{y} \text { - direction } \\
& \sigma_{z} \quad \text { - stress in } \mathrm{z} \text { - direction } \\
& \tau_{m} \quad \text { - mobilized shear stress at base center of slice } \\
& \tau_{x y} \quad-\text { shear stress in } x-y \text { plane } \\
& \phi^{b} \quad \text { - friction angle defining the increase in shear strength due to } \\
& \text { increase in matric suction } \\
& \phi^{\prime} \quad \text { - effective friction angle } \\
& \phi_{c s}^{\prime} \quad \text { - effective critical state friction angle } \\
& \phi_{n c}^{\prime} \quad \text { - effective normally consolidated friction angle } \\
& \phi_{r}^{\prime} \quad \text { - effective residual friction angle } \\
& \text { c' - effective cohesion } \\
& \mathrm{c}_{\mathrm{oc}}^{\prime} \quad \text { - effective overconsolidated cohesion } \\
& c_{p q}^{\prime} \quad-\text { effective overconsolidated cohesion in } q-p^{\prime} \text { space } \\
& c_{r}^{\prime} \quad \text { - effective residual cohesion } \\
& \text { E } \quad \text { - Young's Modulus (Section 4.2.3) } \\
& \text { E } \quad \text { - interslice normal force on each slice (Section 4.2.4) } \\
& \text { H } \quad \text { - total head } \\
& \text { i - hydraulic gradient } \\
& \text { Ip } \quad \text { - plasticity index } \\
& \text { k } \quad \text { - hydraulic conductivity } \\
& k_{x} \quad-\text { hydraulic conductivity in horizontal direction }
\end{aligned}
$$




$$
\begin{aligned}
& \text { ky - hydraulic conductivity in vertical direction } \\
& \mathrm{K}_{0} \quad-\text { coefficient of earth pressure at rest } \\
& \text { M - slope of the critical state line in } q-p^{\prime} \text { space } \\
& \text { OCR - overconsolidation ratio } \\
& \text { p - mean total stress } \\
& p^{\prime} \quad \text { - mean effective stress } \\
& \mathrm{p}_{\mathrm{c}}^{\prime} \quad \text { - mean effective preconsolidation pressure } \\
& \text { P } \quad \text { - normal stress at the base of a slice } \\
& \text { q } \quad \text { - deviator stress (Section 3.5.2) } \\
& \text { q } \quad \text { - specific discharge (Section 4.2.2) } \\
& \text { Q - boundary flux } \\
& \text { R-A - net repulsive minus attractive forces between soil particles } \\
& \mathrm{R} \quad-\text { rate of softening in strain softening constitutive model } \\
& \mathrm{S}_{\mathrm{u}} \quad \text { - undrained shear strength } \\
& S_{u} \text { (residual) - residual undrained shear strength } \\
& S_{u} \text { (peak) - peak undrained shear strength } \\
& \text { t - time } \\
& \text { u } \quad \text { - pore water pressure (Section 3.5) } \\
& \text { u - displacement component in } \mathrm{x} \text { - direction (Section 4.2.3) } \\
& \text { v - displacement component in } \mathrm{y} \text { - direction }
\end{aligned}
$$




\section{List of Tables and Figures}

\section{Tables:}

Table 2.1 Strength parameters from Peterson et al. (1957)

Table 2.2 Strength parameters from Rivard and Lu (1978)

Table 3.1 Pressures used for hydraulic conductivity testing

Table 3.2 Preconsolidation pressures from oedometer tests

Table 3.3 Vertical to horizontal hydraulic conductivity ratios for section SS036

Table 3.4 Vertical to horizontal hydraulic conductivity ratios for section SS040

Table 3.5 Triaxial test values of $M$ and $\phi_{c s}^{\prime}$ for dyke material

Table 3.6 Triaxial test values of $M$ and $\phi^{\prime}{ }_{\text {cs }}$ for foundation material

Table 3.7 Direct shear test results for foundation material

Table 3.8 Pore fluid chemistry analysis results

Table 4.1 Stress-deformation modeling parameters

Table 4.2 Slope stability modeling parameters

Table 4.3 Slope stability modeling results

\section{Figures:}

Figure 2.1 Results of slope stability analysis at Seven Sisters by Peterson et al. (1957)

Figure 2.2 Results of slope stability analysis at Seven Sisters by Rivard and Lu (1978)

Figure 2.3 Geology of Manitoba (Davis et al., 1962)

Figure 2.4 Distribution of ions adjacent to clay surface (Mitchell, 1993) 
Figure 2.5 Effect of calcite content on a) Atterberg limits and b) ultimate residual shear angle (Hawkins and McDonald, 1992)

Figure 2.6 Strain softening behavior

Figure 3.1 Borehole information for section SS-036

Figure 3.2 Borehole information for section SS-040

Figure 3.3 Photograph of color change from light brown dyke material to darker brown highly plastic foundation soil

Figure 3.4 CPT test data near section SS-036

Figure 3.5 CPT test data near section SS-040

Figure 3.6 Hydrometer test result from section SS-036 at $3.9 \mathrm{~m}$ depth

Figure 3.7 Hydrometer test result from section SS-036 at $7.8 \mathrm{~m}$ depth

Figure 3.8 Hydrometer test result from section SS-036 at $9.5 \mathrm{~m}$ depth

Figure 3.9 Hydrometer test result from section SS-040 at $4.5 \mathrm{~m}$ depth

Figure 3.10 Hydrometer test result from section SS-040 at $5.1 \mathrm{~m}$ depth

Figure 3.11 Hydrometer test result from section SS-040 at $8.4 \mathrm{~m}$ depth

Figure 3.12 Hydrometer test result from section SS-040 at $9.4 \mathrm{~m}$ depth

Figure 3.13 Estimation of unsaturated hydraulic conductivity curve

Figure 3.14 Oedometer test result from section SS-036 at $2.2 \mathrm{~m}$ depth

Figure 3.15 Oedometer test result from section SS-036 at $4.1 \mathrm{~m}$ depth

Figure 3.16 Oedometer test result from section SS-036 at $6.4 \mathrm{~m}$ depth

Figure 3.17 Oedometer test result from section SS-036 at $8.4 \mathrm{~m}$ depth

Figure 3.18 Oedometer test result from section SS-036 at $10.0 \mathrm{~m}$ depth

Figure 3.19 Oedometer test result from section SS-036 at $12.1 \mathrm{~m}$ depth

Figure 3.20 Oedometer test result from section SS-040 at $2.2 \mathrm{~m}$ depth

Figure 3.21 Oedometer test result from section SS-040 at $4.0 \mathrm{~m}$ depth

Figure 3.22 Oedometer test result from section SS-040 at $6.3 \mathrm{~m}$ depth

Figure 3.23 Oedometer test result from section SS-040 at $8.0 \mathrm{~m}$ depth

Figure 3.24 Oedometer test result from section SS-040 at $10.0 \mathrm{~m}$ depth

Figure 3.25 Oedometer test result from section SS-040 at $11.5 \mathrm{~m}$ depth 
Figure 3.26 $\mathrm{CIU}$ triaxial test results for section SS-036 in dyke material showing deviator stress and change in pore water pressure vs. axial strain

Figure 3.27 CIŨ triaxial test results for section SS-036 in dyke material showing deviator stress vs. mean effective stress

Figure 3.28 $\mathrm{CIU}$ triaxial test results for section SS-036 in foundation material showing deviator stress and change in pore water pressure vs. axial strain

Figure 3.29 $\mathrm{CIU}$ triaxial test results for section SS-036 in foundation material showing deviator stress vs. mean effective stress

Figure 3.30 CIŪ triaxial test results for section SS-040 in dyke material showing deviator stress and change in pore water pressure vs. axial strain

Figure 3.31 CIŪ triaxial test results for section SS-040 in dyke material showing deviator stress vs. mean effective stress

Figure 3.32 $\mathrm{CIU}$ triaxial test results for section SS-040 in foundation material showing deviator stress and change in pore water pressure vs. axial strain

Figure 3.33 CIŪ triaxial test results for section SS-040 in foundation material showing deviator stress vs. mean effective stress

Figure 3.34 Normalized plots of deviator stress vs. mean effective stress for dyke material (at critical state)

Figure 3.35 Normalized plots of deviator stress vs. mean effective stress for foundation material

Figure 3.36 Change in pore water pressure vs. change in mean stress for foundation material at section SS-036

Figure 3.37 Change in pore water pressure vs. change in mean stress for foundation material at section SS-040

Figure 3.38 Direct shear test results for Sample 1 from section SS-036

Figure 3.39 Direct shear test results for Sample 2 from section SS-040

Figure 3.40 Initial direct shear tests on specimens

Figure 3.41 Soil water characteristic curves

Figure 3.42 Calcium concentration vs. elevation 
Figure 3.43 Magnesium concentration vs. elevation

Figure 3.44 Sodium concentration vs. elevation

Figure 3.45 Sulphate concentration vs. elevation

Figure 3.46 Bicarbonate concentration vs. elevation

Figure 3.47 Chlorine concentration vs. elevation

Figure 4.1 Linear elastic constitutive model

Figure 4.2 Elastic perfectly-plastic constitutive model

Figure 4.3 Strain softening constitutive model

Figure 4.4 Forces acting on slide mass and slice within slide mass (from Fredlund and Krahn, 1977)

Figure 4.5 Modeled pore water pressure distribution (in $\mathrm{kPa}$ ) through section SS-036 of dykes

Figure 4.6 Modeled vertical stress distribution (in $\mathrm{kPa}$ ) through section SS-036 of dykes

Figure 4.7 Slope stability results at section SS-036 with stress-deformation analysis and residual strength parameters in upper foundation

Figure 4.8 Slope stability results at section SS-040 with stress-deformation analysis and residual strength parameters in upper foundation 


\section{Chapter 1 - Introduction}

\subsection{History of Seven Sisters Generating Station}

The Seven Sisters Generating Station, Manitoba Hydro's largest producer of electricity on the Winnipeg River in southeastern Manitoba, is located approximately $110 \mathrm{~km}$ northeast of Winnipeg, Manitoba. The construction began in 1929 and was completed in 1931. In its original form, it required earth dykes built to a maximum height of 2 to $3 \mathrm{~m}$. Seven Sisters is a "run-of-river" design, meaning there is no storage of water in the forebay for later use, but it is used immediately. A drop in water level of $20 \mathrm{~m}$ occurs as the water from the forebay enters the turbine generators and is released into the river downstream of the generating station.

In 1951, the very early generating station at Pinawa was retired to provide a more efficient use of the water flows at Seven Sisters Generating Station. Beginning in June of 1947 and ending in June 1949 the dykes on the north and south shore's of the Winnipeg River at Seven Sisters were increased in elevation and length in order to raise the head on the power plant. The dykes were constructed with a clay core covered with a thick layer of rip-rap to act as a shell. The dykes were built to a maximum height of $6.5 \mathrm{~m}$ (Elevation $276.2 \mathrm{~m}$ ) with a crest width of approximately $4.3 \mathrm{~m}$. The dykes have been built for $5.6 \mathrm{~km}$ 
upstream on the Winnipeg River's north shore and $7.2 \mathrm{~km}$ upstream on the south shore.

\subsection{Justification of Research Topic}

During construction, slides and other minor movements occurred along the dykes. The belief at the time was that these initial slides were related to the steep construction of slopes or other unusual conditions. It was thought that the strength of the soil would increase with time due to the reduction of pore water pressures during consolidation. Therefore the movements during construction did not cause much concern.

Since that time, slope instability has occurred at various positions along the length of the dyke on an irregular basis. In a paper by Peterson et al (1957), a description of the previous slides showed similarities, with the first indication being the formation of a crack along the dyke crest. Although initially there was no vertical displacement, with time there was progressive movement causing settlement and the development of a crack up to $0.3 \mathrm{~m}(1 \mathrm{ft})$ wide over a length of 30 to $120 \mathrm{~m}$. Over a period of several weeks, a scarp of approximately 0.3 to 1.8 $\mathrm{m}$. high would form between the dyke centerline and the waterside shoulder. Upheaval on the landside toe was seen in some cases, but was subtle and difficult to observe. None of the slides have been of a serious nature as there 
was no immediate threat of a breach. All of the slides have been stabilized by the construction of toe berms.

The proposed research project undertakes studies to determine the possible causes of the instabilities and answer the question of why some dyke sections became unstable while others have remained stable. Two sections of the dykes were investigated, one that has had previous instability and a second that has remained stable. The outcome of the research will provide insight on possible differences along the dyke that may be related to slope instability.

\subsection{Hypothesis}

Changes in soil chemistry, resulting from leaching of cementation bonds produced by seepage under the dykes, causes changes in brittleness and anisotropy and triggers delayed instabilities of the Seven Sisters dykes.

\subsection{Organization of Thesis}

This thesis is set out in the following manner.

Chapter 1 provides a brief history of the Seven Sisters Generating Station, the justification of the research topic, and the organization of the thesis. 
Chapter 2 gives a discussion of the previous literature that is pertinent to the work done in this paper. The first section looks at previous research done at Seven Sisters. Beginning as far back as 1957, papers discussing the instability of the Seven Sisters dykes have been published. The use of different strength parameters has also been investigated at the Seven Sisters site. This is followed by a brief discussion of the geology at the site. A short background section on physicochemical investigations will also be provided to discuss how changes in pore fluid chemistry can affect the physical properties of soils.

Also in this chapter is a discussion of other possible explanations of the slope instability. This will outline possible causes for the slope instability as found by other researchers. These include such causes as cyclic variations of pore pressures or removal of cementation bonding.

Strain softening behavior was found in the highly plastic foundation of the Seven Sisters dykes. The effect of this stress-strain behavior, which is usually found in overconsolidated or cemented clays, and its presence at other embankment instabilities, will be discussed.

Finally previous modeling of embankments on clay foundations is discussed. This section provides information about some of the shortcomings of current modeling of embankments that are built on soft ground. 
Chapter 3 discusses results from laboratory testing conducted by the author on samples retrieved from Seven Sisters. The testing included soil identification, hydraulic conductivity tests, oedometer tests, isotropically consolidated undrained triaxial tests, direct shear tests, and construction of a soil water characteristic curve. Testing of pore fluid chemistry taken from fluid samples within soil samples is also discussed.

Chapter 4 discusses the numerical modeling done for this project. Modeling included a seepage analysis to investigate the pore water pressure distributions within the dykes and foundation soil, a stress-deformation analysis to incorporate the strain softening behavior of the foundation soil, and a slope stability analysis to compare the stable and unstable sections. Sequential modeling of the two sections of the dykes was done to determine the factor of safety.

The final chapter (Chapter 5) provides a general summary of the results of the modeling and testing and the conclusions that can be made from the results. Recommendations for further testing are also included.

A laboratory testing summary report (Garinger et al., 2001a) and oedometer testing report for hydraulic conductivity determination (Garinger et al., 2001b) have been given to Manitoba Hydro and include some details not presented in this thesis. Work from this thesis has also been presented at the $54^{\text {th }}$ Canadian Geotechnical Conference in Calgary, Alberta (Garinger et al., 
2001c) and submitted for the $55^{\text {th }}$ Canadian Geotechnical Conference in Niagara Falls, Ontario (Garinger et al., 2002). 


\section{Chapter 2 - Literature Review}

\subsection{Previous Seven Sisters Research}

As indicated earlier, slope instabilities have occurred in the dykes at Seven Sisters on an irregular basis since their heightening in 1947. Numerous reports have been written regarding the slope stability of the dykes at the Seven Sisters Generating Station. A report on behalf of the Prairie Farm Rehabilitation Administration (PFRA) by Peterson (1957) indicated that when initially constructed there were concerns of possible instability of the dykes due to the soft highly plastic foundation clay and the lack of good quality borrow material. At that time, the most likely instability at the site was believed to involve either a circular arc through the embankment and foundation or else a lateral spreading of the dyke due to the weak foundation clay. Peterson's report discussed two slides and other minor movements that occurred during and after construction.

A paper with similar information by Peterson et al. (1957) investigated the Seven Sisters dykes using both total stress analysis and effective stress analysis. The parameters used in the models are shown in Table 2.1. As shown in Figure 2.1, using the parameters shown in Table 2.1, the factors of safety for the critical failure surface was found to be 1.31 using the total stress method and 1.40 using the effective stress method and ignoring side forces on the slices. A correlation between the occurrence of slides and precipitation was attempted, but 
no significant outcome was found that would explain the high factors of safety in slopes that had actually become unstable. The conclusions indicated that it could not be established why there were safety factors greater than 1.0 at sections where instability had occurred. The paper outlined other areas that required further investigation, including the possibility of progressive failure, compatibility of the stress-strain characteristics of the foundation and fill material, representativeness of the samples used for strength testing, the relationship between the laboratory rates of strain to field rates, and the applicability of the shear failure criterion used.

In another paper by Peterson et al. (1960), the slope instability at Seven Sisters was discussed in more detail with descriptions of the slides. The soil conditions of the foundation and embankment materials were also discussed. A review of previous works included a paper by Berger (1951) who described failures of unsaturated compacted embankments placed on softer plastic saturated clays, with similar movements to those seen at Seven Sisters. Berger concluded that stability calculations when stress-strain characteristics of the embankment and foundation soils are different could be unreliable. Also cited in the paper by Peterson et al. (1960) is a report by Leonards (1958) who indicated that arching in the embankment could create a potential slip surface due to the distribution of normal and shear stresses. The factor of safety for this form of failure would then be less than that predicted by conventional analyses. The paper also references a paper by Casagrande (1959) who expressed the opinion 
that induced pore pressures in laminations or silt layers in the clay may have been responsible for the movements.

Peterson also noted that the movements at Seven Sisters were considered to involve some type of progressive action. It was presented that arching of the embankment caused by the settlement of the weaker foundation may cause instability. The foundation movements were indicated to perhaps be more of a lateral deformation or a lateral squeezing than a definite circular arc failure plane since field observations had not located failure planes in the foundation.

Rivard and Lu (1978) studied a number of dykes built on soft, fissured clay in Manitoba. A review of six case histories, including Seven Sisters, used suggestions from the paper by Bjerrum (1969). In his paper, Bjerrum explained how fissured clay would soften when subject to strain, which would gradually reduce the cohesion. Therefore he suggested that in fissured clay at shallow depths where there is weathering and groundwater fluctuations it could be assumed that the cohesion intercept would approach zero while the friction angle would remain the same as intact clay. Rivard and Lu indicated that at the Seven Sisters dykes, the normally consolidated strengths should be used in the highly plastic foundation to obtain a reasonable factor of safety. The strength parameters used in this modeling are shown in Table 2. 
As shown in Figure 2.2, the results of the slope stability analysis with a circular arc slip surface gave a factor of safety of 1.71 when using intact (peak) strength and 0.97 using normally consolidated strength. Therefore it was concluded that the normally consolidated strength should be used for embankments on soft highly plastic clay soils containing structural discontinuities.

Liu and Dubois (1996) published a paper that discussed a method for predicting where future instability would most likely occur along the Seven Sisters dykes. Using a back analysis to determine the value of the frictional strength when the factor of safety is 1.0 , the plasticity index could then be found using an $\phi_{\mathrm{nc}}-I_{\mathrm{p}}$ relationship for Lake Agassiz clays. Then using a frequency chart of the distribution of the plasticity index in the foundation, the probability of the foundation soil having an $I_{p}$ at least as high as that determined from the $\phi_{n c}-I_{p}$ relationship could be determined. Using the method to back analyze locations of past instability showed that the probability of instability varied substantially and the order of instability could not be predicted.

Betke (2001) investigated the stability of the Seven Sisters dykes using different soil parameters based on suggestions from past journal papers. From his analyses, a factor of safety of 1.00 could be obtained using normally consolidated strengths with a small effective cohesion as outlined by Burland et al. (1996). Also, a sensitivity analysis for the effect of softening (reduction in cohesion) and pore water pressures by adjusting the phreatic surface was 
examined. The results of the sensitivity analysis showed that the effect of the cohesion was more significant than that of the phreatic surface in reducing the factor of safety.

In summary, early research of the dykes at Seven Sisters had difficulty in identifying causes of the slope instabilities and recognized some areas of concern. Research by Rivard and Lu (1978) was extremely important in recognizing that normally consolidated strengths were required in the foundation soil, but did not indicate reasons why certain sections experienced instability before others. More recent work by Liu and Dubois (1996) and Betke (2001) has been done to identify sections where future instability will occur and show the significance of softening and pore pressure changes on the stability of the dykes. It is probably fair to say that these studies raised further questions that have been addressed by the author's study.

\subsection{Geological Background of Lake Agassiz Deposits}

The bedrock in the eastern part of Manitoba is made up of Precambrian rock of the Archean eon as shown in Figure 2.3. Erosion in the area removed most of the Paleozoic rock of eastern and central Manitoba during the preJurassic period (Teller and Clayton, 1983). The Precambrian rock of eastern Manitoba belongs to the Superior Province. It has an easterly structural grain and is dominated by granitic rock and granite gneiss. Further to the west the 
bedrock changes to Ordovician rock of dolomite and limestone around the city of Winnipeg, with Mesozoic shale occurring to the west of the Red River Valley.

Much literature has been written on the subject of the history of Lake Agassiz (Mayer-Oakes, 1967, Teller, 1976, Teller and Clayton, 1983). Between 13500-14000 years ago when the first lake developed until after 8700 years before present, lacustrine deposition occurred three times due to repeated retreat and readvance of the ice (Teller, 1976). The foundation soil at the Seven Sisters site is a lakebed and flood plain deposited by glacial Lake Agassiz.

The Seven Sisters area is considered the South-Eastern Lake Terrace area of the Lake Agassiz deposits and lies between the lacustrine plain of the Red River Valley and the Precambrian Shield. Based on the soil map from Smith and Ehrlich (1967), the soil series of the foundation soil at Seven Sisters is the Framnes series. This soil consists of gleyed dark grey soils on a thin mantle of clay over strongly calcareous silty, lacustrine sediments. It is mainly found along the Whitemouth and Lee rivers as well as the Winnipeg River, which is where Seven Sisters is located.

\subsection{Physicochemical Investigation}

With the heightening of the dykes at the Seven Sisters Generating Station, the changing groundwater conditions possibly impacted the foundation soil by 
leaching cementation bonds in the original clay and changing the pore fluid chemistry.

On clay mineral surfaces, particularly when the clay is plastic, net negative charges can develop due to broken crystal bonds or isomorphous substitution (Mitchell, 1993). In order to satisfy the negative charge, cations and anions form a double diffuse layer around the clay mineral as shown in Figure 2.4. The double diffuse layer consists of a tightly packed layer of cations near the clay surface (Stern layer) and the Gouy layer where the concentration of cations is greater than anions. Away from the clay surface the concentrations of cations decrease and anion concentrations increase until electrical neutrality is reached in the bulk solution.

When clay particles are closely spaced, cations from overlapping double layers repel each other. The magnitude of this repulsive force is a function of the electrolyte concentration, cation valence, dielectric constant, and temperature. Also occurring between clay particles are attractive forces due to van der Waal's forces. The attractive forces are not dependant on cation concentration or valence. The magnitude of the net long-range electrostatic repulsive minus attractive stress (denoted by R-A) can be dominant in controlling volume change and shear strength behavior of clay soils. It has been suggested by Lambe (1960), Bailey (1965), Balasubramonian (1972), Barbour and Fredlund (1989), 
and Graham et al. (1992) that the influence of R-A on the effective stress can be defined as shown in Equation 2.1.

$$
\sigma^{\prime}=\sigma^{*}+(\mathrm{R}-\mathrm{A})
$$

In this equation $\sigma^{\prime}$ is the true effective stress and $\sigma^{*}$ is the interparticle contact stress. If $\sigma^{\prime}$ is constant and the R-A term increases due to a change in pore fluid chemistry, a decrease in the $\sigma^{*}$ term must occur.

The effect of permeation of soil with $\mathrm{NaCl}$ solution on the net long-range electrostatic repulsive stress, R-A, was researched by Barbour and Yang (1993). The authors also looked at the influence of clay-brine interactions on the properties and behavior of typical soils in western Canada. They indicated that $\mathrm{NaCl}$ brine permeation significantly affected several soil properties, including a decrease in soil plasticity due to the presence of salt. Increased shear strengths were observed after brine permeation due to decreases in the net long-range electrostatic repulsive stress.

Boone and Lutenegger (1997) looked at cementing agents based on investigations by other sources. They indicated that carbonates were found to be the main cementing agents in soils around the world. This cementation could increase the undisturbed (intact) strength, but when the soil is remolded, it is prone to collapse and rearrangement. This can lead to a rapid decrease in strength. Also, the paper indicates that carbonate leaching from seepage may be an important mechanism in reducing shear strengths and creating slope 
instability. It was concluded that since many cohesive soils throughout Canada are glacially derived from sedimentary bedrock, carbonate cementation might be relatively common.

Related to Boone and Lutenegger's studies was research done by Hawkins and McDonald (1992). The purpose of their research was to observe changes in soil properties with the removal of calcium, otherwise called decalcification. During decalcification it was found that the calcareous component of the soil removed by decalcification consisted predominantly of medium and coarse silt grade particles. This was found to increase the Atterberg limits linearly and reduce the residual shear angle non-linearly from $15^{\circ}$ to $6^{\circ}$ as shown in Figure 2.5. The study indicated that the relationship between the calcite content and geotechnical properties is important as the calcite content can change as a result of dissolution.

\subsection{Possible Triggers for Slope Instability}

As discussed earlier, several ideas for the causes of the instability at Seven Sisters have been brought forth in the papers written about the early slides that occurred. Other possible explanations will now be discussed regarding the instabilities based on more recent research at other sites. 
One possible explanation for the on-going instability following construction of the Seven Sisters dykes could be related to a reduction of strength to residual values caused by cyclic pore pressure variation. This phenomenon has been discussed by Lacerda (1989) in another case history, in which changing pore pressures with seasons can cause 'fatigue' within the soil as effective stresses fluctuate. The changes can result in an accumulation of strain and the breakage of bonds that account for structural cohesion. The paper also outlined a future testing program that could investigate the number of cycles and accumulated volumetric and axial strains required for failure.

Another possible explanation for instability could be based on excess pore pressures developing due to a breakdown of clay structure along weak seams. Leonards (1982) discussed this as a possible cause of instability due to excess pore pressures propagating from zones of high shear strain along the planar slip surface and inducing a rapid progressive failure although no surficial evidence would indicate that it is occurring. An implication of this is that measurements of pore water pressure in areas adjacent to the actual slide may not be representative of the pore pressures in the sliding zone. The same paper also indicated that naturally sedimented clays possess critical strain levels at which the clay structure breaks down and generates positive excess pore water pressures and a progressive undrained failure can occur rapidly even though drained conditions were previously present for a long period of time. 


\subsection{Strain Softening Behavior}

Strain softening is a behavior of soil in which upon straining, the soil reaches a peak strength value that is followed by a reduction of shearing resistance with additional straining beyond the yielding point. Eventually a residual strength is reached in which there is no further reduction in strength. A schematic illustration of strain softening behavior is shown in Figure 2.6. This behavior is usually seen in overconsolidated or cemented soils. The mechanism of progressive failure has been found to be especially active in materials showing pronounced strain softening characteristics.

Skempton (1964) discussed the stability of clay slopes with emphasis on overconsolidated clays and the mechanism of progressive failure. It was noted that the strength at a point would decrease once the clay had passed the peak strength. This will generally transfer additional stress to clays at neighboring points and exceed the peak strength at those points. This would then initiate progressive failure and eventually the strength along the entire slip surface length would reduce to a limiting residual strength. The paper indicated that progressive failure could occur when fissures and joints were observed since these features could initiate instability. Eventually the limiting residual strength would then be reached as the progressive failure continued. 
Bjerrum (1967) discussed progressive failure in slopes of overconsolidated plastic clay and indicated that the rate at which a continuous sliding surface will develop can vary from one clay to another. In stiff clays, the rate can be so small that the delay of a slide may be of the order of centuries. He concluded that all available evidence proved 'beyond a doubt' that slope failures in overconsolidated plastic clays are preceded by the development of a continuous sliding surface by a mechanism of progressive failure, whereby the shear strength is progressively reduced from the peak to residual value.

Lefebvre and La Rochelle (1974) presented a paper that investigated two landslide sites in sensitive Champlain clay deposits. Strain softening of the clay was observed, with high peak strengths caused by cementation bonds being followed by a rapid decrease in strength to residual strength. The authors used samples from the sensitive Champlain clay deposits to illustrate brittle behavior of the soil and confirmed cementation bonds in the clay structure based on the triaxial test results. Stability analyses were then undertaken to determine the factors of safety using peak strength parameters and residual strength parameters. The results of the stability analyses showed that based on four different failure locations, the average shear strength mobilized at failure was close to the residual strength. From isotropically consolidated drained triaxial tests, residual strengths were reached at relatively low strains of about 10 to $18 \%$ axial strain due to the cementation bonds being strain sensitive and brittle. It was also concluded that the use of the residual strength could be explained by the 
progressive failure mechanism, which as noted earlier, is common in brittle materials.

Research by La Rochelle et al. (1974) provided a report of a test embankment constructed on Champlain clay deposits that was built to failure. The embankment was instrumented with piezometers, settlement plates with vertical pipes, and wooden stakes to measure the position of the failure surface. It was shown that determination of the factor of safety was most reasonably found with a critical slip surface similar to that observed in numerical modeling that used 'residual undrained strength' parameters from unconsolidated undrained triaxial tests.

Leroueil et al. (1979) performed studies to investigate the effect of destructuration caused by consolidation on limit state and other mechanical characteristics. The tests on initially intact Champlain sea clays concluded that intact clays possess a structure as the result of a combination of factors that include depositional environment, consolidation, aging, thixotropic hardening, and possibly cementation and leaching. Properties such as preconsolidation pressure and shear strength were found to be directly representative of the structure. It was found that when consolidated under stresses greater than the initial limit state, the structure of the clay is modified, and further the mechanical properties are strongly modified even after unloading. It was suggested that all natural clays are subjected to the same factors listed above. 


\subsection{Modeling of Embankments on Soft Clays}

This section provides a short overview of some of the more unusual features of modeling embankments on soft clays. More details of the numerical and modeling procedures will be formed in Chapter 4 .

Several research papers have been written on some of the particular difficulties that are associated with modeling embankments built on soft clays. Dounias et al. (1988) presented a description of a finite element model that used strain softening of the soil to analyze two progressive failures of embankments. The results indicated that in one case the softening began near the upstream core extension and moved towards the toe, while in the other it began near the toe and expanded to the core. The different mechanisms of failure were believed to be due to different embankment geometries. Comparing models with strain softening to those without strain softening showed a reduction in the factor of safety of $12 \%$ associated with strain softening. The authors discussed some numerical difficulties associated with strain softening functions and the size of the elements.

A paper by Chai and Bergado (1993) discussed some of the important considerations when modeling embankments on soft ground. One consideration needs to be the construction process, such that the sequence of loading is 
correct and coordinates of the embankment material nodes are updated to account for deformations. The second important consideration is the simulation of consolidation processes, and in particular the changes in permeability that accompany consolidation. An example analysis using the finite element method produced results that were compared with measured field values of pore pressures, settlements, and lateral displacements. The results showed that using a constant hydraulic conductivity for the soil throughout the consolidation gave results different from measured values. Much better results were obtained using a hydraulic conductivity variation based on changes before and after soil yielding, and a model using modified Cam clay

\subsection{Literature Review Summary}

Based on the review of literature, the effect of leaching of cementation bonds through changes in groundwater conditions has been identified as a possible trigger for slope instability at the Seven Sisters dykes. The need for laboratory soil tests is shown since previous testing was done at a time when sampling and laboratory testing procedures were not as well developed as at present and the influence of leaching in the soil may not have been significant. The availability of modern computer software allows for modeling of the sections of the dykes that incorporates new laboratory test results and the strain softening behavior of the foundation soil that were not investigated in previous research. 


\subsection{Objectives of Research}

1) Compare two sections of the dykes, one that has had previous instability and another that has remained stable, by performing laboratory tests including soil identification, oedometer testing, hydraulic conductivity testing, isotropically consolidated undrained triaxial testing, and direct shear testing.

2) Compare pore fluid chemistry of two sections beneath the dykes and a third section away from the dykes to identify any significant differences that would indicate leaching of cementation bonds.

3) Perform modeling using current computer software to determine the factor of safety of the dykes based on parameters obtained from laboratory testing. 
Table 2.1. Strength parameters from Peterson et al. (1957)

\begin{tabular}{|c|c|c|c|c|}
\hline \multirow{2}{*}{} & \multicolumn{2}{|c|}{ Total Stress Analysis } & \multicolumn{2}{c|}{ Effective Stress Analysis } \\
\cline { 2 - 5 } & $\mathbf{c}_{\mathbf{u}}(\mathbf{k P a})$ & $\phi_{\mathbf{u}}$ & $\mathbf{c}^{\prime}(\mathbf{k P a})$ & $\phi^{\prime}$ \\
\hline Dyke & 24.8 & 13 & 13.8 & 24 \\
\hline Foundation & 20.7 & 0 & 10.3 & 19 \\
\hline
\end{tabular}

Table 2.2. Strength parameters from Rivard and Lu (1978)

\begin{tabular}{|c|c|c|c|c|}
\hline & Rip-Rap & Dyke & \multicolumn{2}{|c|}{ Foundation } \\
\cline { 2 - 5 } & & & $\begin{array}{c}\text { Intact } \\
\text { Strength }\end{array}$ & $\begin{array}{c}\text { Normally Consolidated } \\
\text { Strength }\end{array}$ \\
\hline $\mathbf{c}^{\prime}$ & 0 & 13.8 & 13.8 & 0 \\
\hline$\phi^{\prime}$ & 35 & 24 & 14.5 & 16 \\
\hline
\end{tabular}




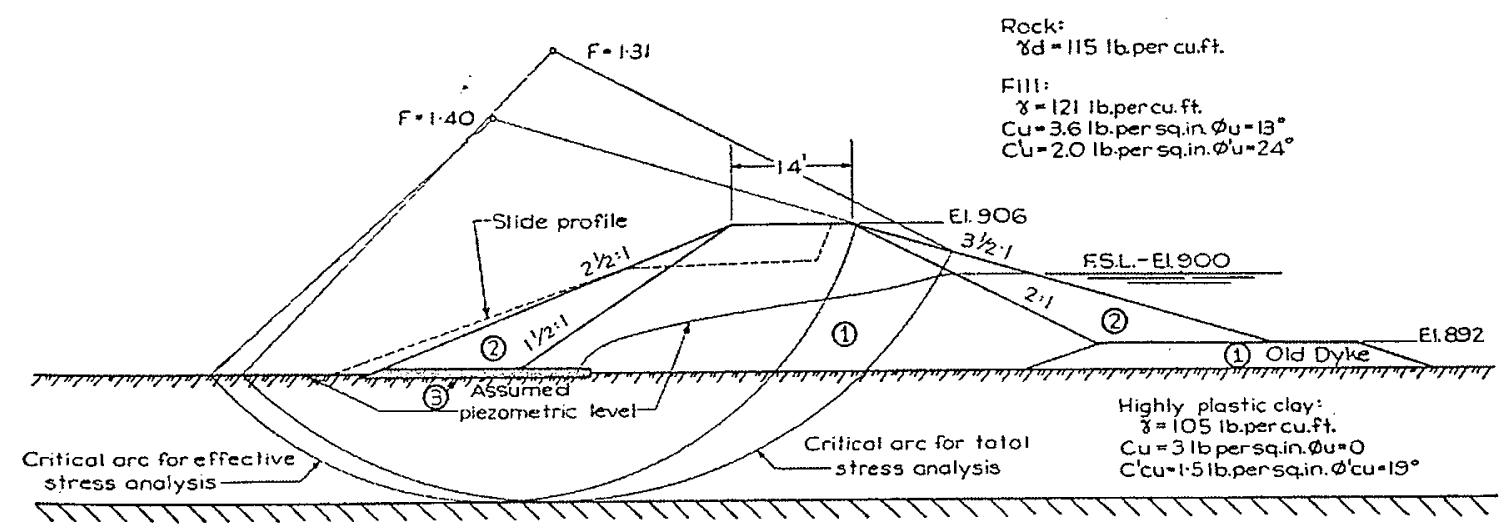

Figure 2.1. Results of slope stability analysis at Seven Sisters by Peterson et al. (1957)

\begin{tabular}{|c|c|c|}
\hline \multirow[b]{2}{*}{$\begin{array}{l}\text { FOUNDATION } \\
\text { SHEAR STAENGTH }\end{array}$} & \multicolumn{2}{|c|}{ FACTOR OF SAFETY } \\
\hline & $\begin{array}{l}\text { EISHOP'S } \\
\text { CIACULAR } \\
\text { ARC }\end{array}$ & $\begin{array}{l}\text { JANBU'S } \\
\text { SLIDING } \\
\text { BLOCK }\end{array}$ \\
\hline $\begin{array}{c}\text { INTACT STRENGTH } \\
c^{\prime}=13.6 \mathrm{kPa} \quad \Phi^{\prime}=14.5^{\circ}\end{array}$ & 1.71 & 1.72 \\
\hline $\begin{array}{l}\text { NORMALLY CONSOLIDATED } \\
\text { STRENGTH } \\
c^{\circ}=0 \quad \phi_{n}^{\prime}=16^{\circ}\end{array}$ & 0.97 & 1.04 \\
\hline
\end{tabular}

LEGEND

(1) Hedium to highly plastic clay $-\gamma=19.0 \mathrm{kH} / \mathrm{m}^{3} ; c^{\circ}=13.0 \mathrm{kP}$;

(2) Rock $-\gamma=18.1 \mathrm{kN} / \mathrm{m}^{3} ; c^{\circ}=0 ; \phi^{\prime}-35^{\circ}$.

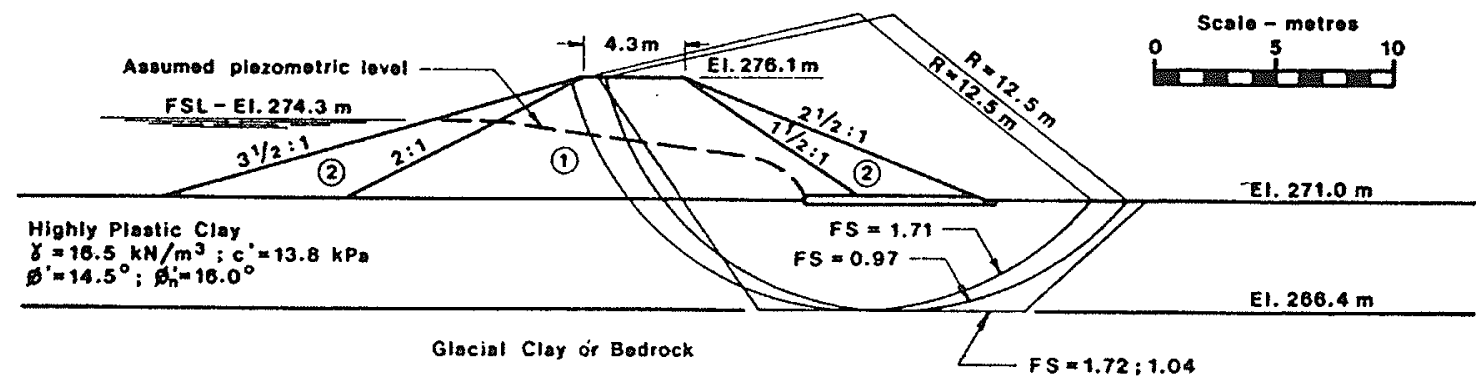

Figure 2.2. Results of slope stability analysis at Seven Sisters by Rivard and Lu (1978) 


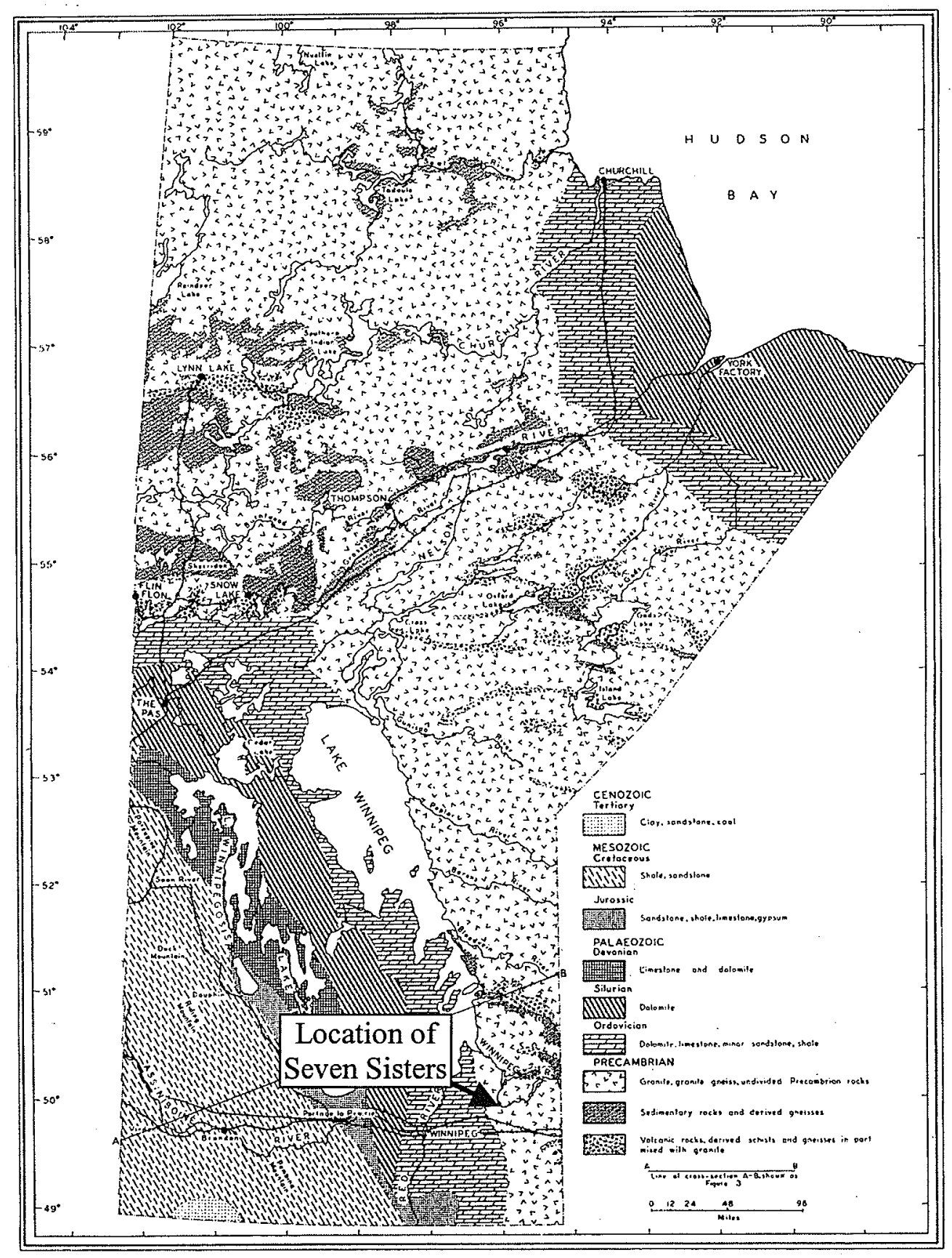

Figure 2.3. Geology of Manitoba (Davis et al., 1962) 

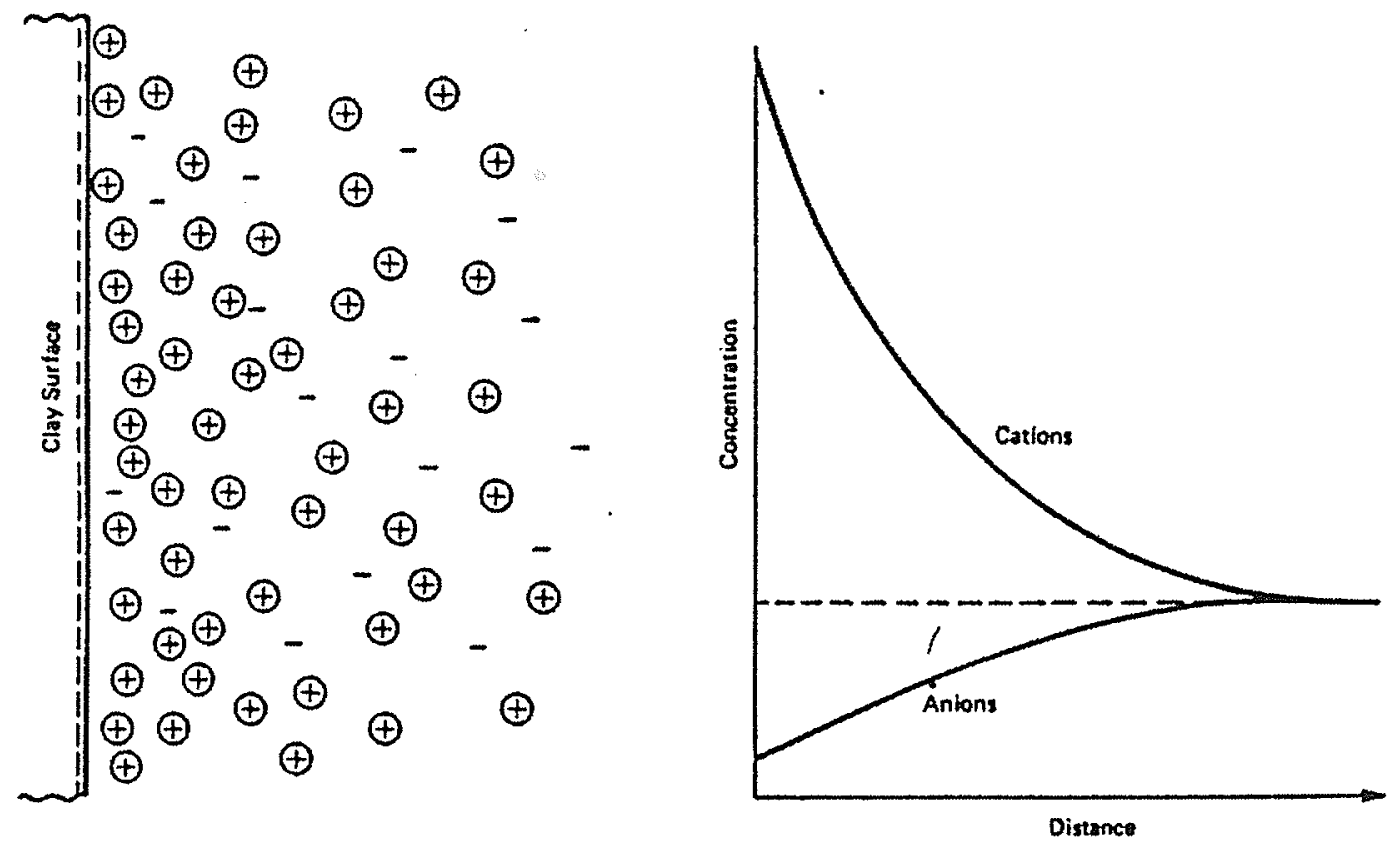

Figure 2.4. Distribution of ions adjacent to clay surface (Mitchell, 1993) 

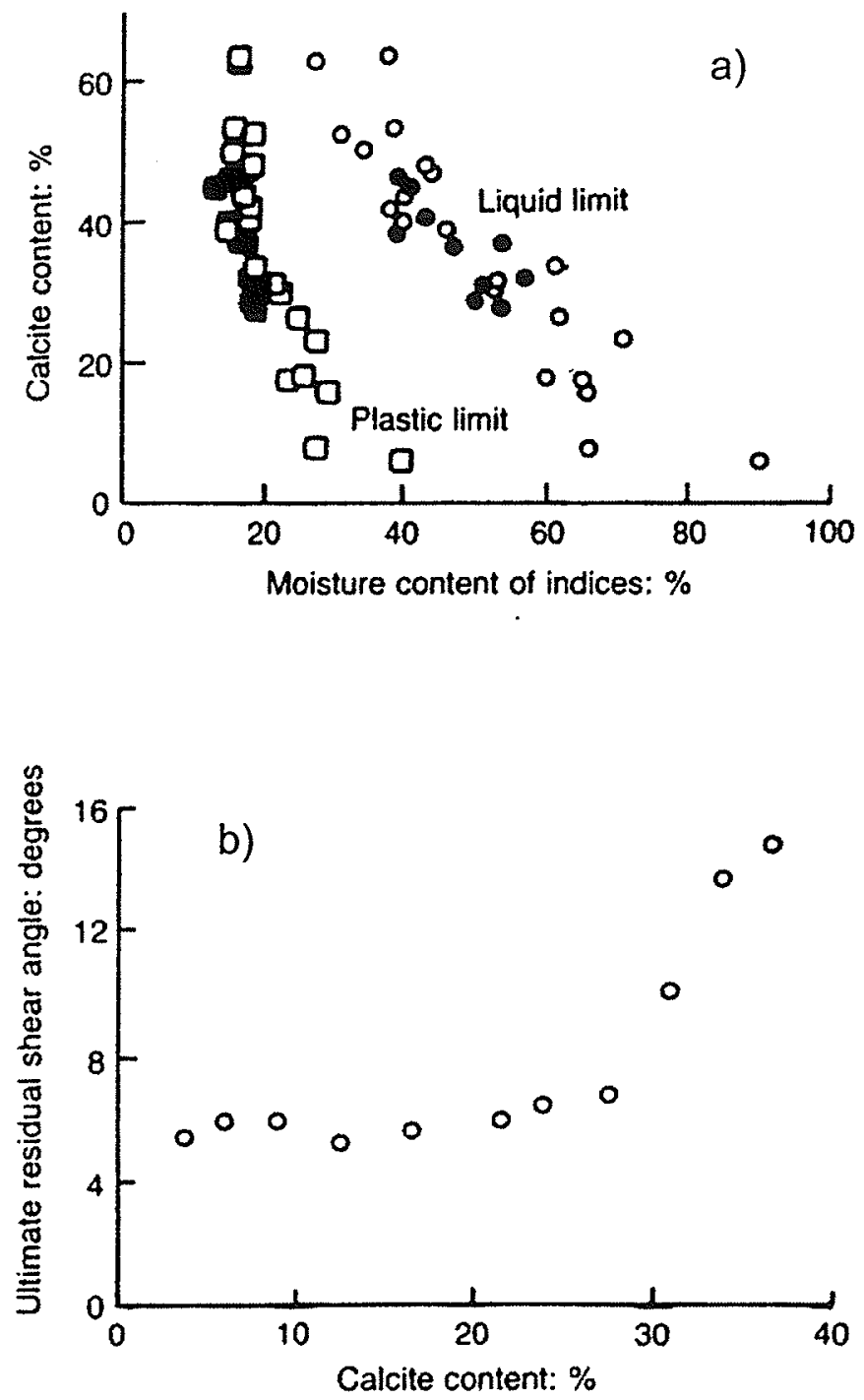

Figure 2.5. Effect of calcite content on a) Atterberg limits and b) ultimate residual shear angle (Hawkins and McDonald, 1992) 


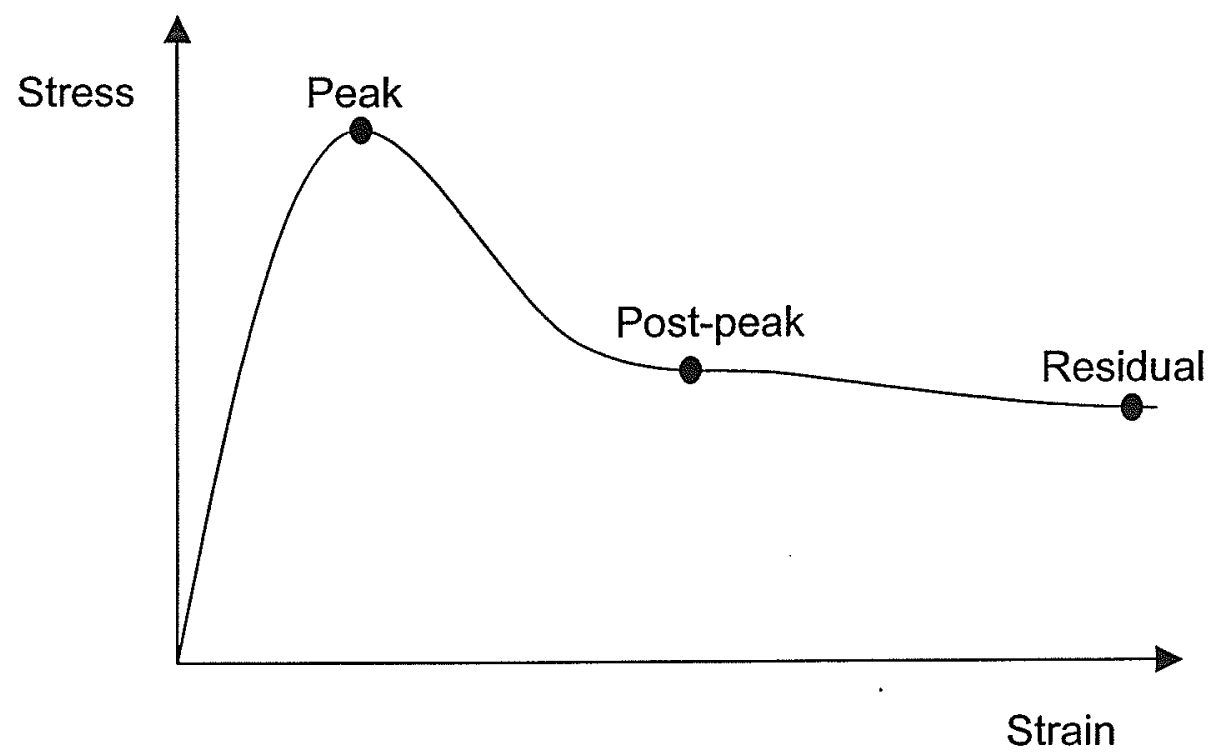

Figure 2.6. Strain softening behavior 


\section{Chapter 3 - Laboratory Testing}

\subsection{Sample Information}

Testing was performed on samples retrieved from boreholes on the crest of the dykes at the Manitoba Hydro Seven Sisters generating station. Samples were obtained by continuous sampling from two boreholes using $76 \mathrm{~mm}$ ( 3 in) diameter Shelby tubes on the landside crest of the south dyke. The first borehole, SS-036, was located at station 10+28.95, and the second borehole SS-040 was at station $10+92.7$. Borehole SS-036 was drilled at a previously unstable section, while borehole SS-040 was drilled at a section where no slope instability had been observed. Bedrock was reached at $13.11 \mathrm{~m}$. for borehole SS-036 and at $12.75 \mathrm{~m}$ for borehole SS-040. Soil testing included saturated hydraulic conductivity tests, oedometer tests, isotropically consolidated undrained $(\mathrm{ClU})$ triaxial tests, direct shear tests, and soil water characteristic curve construction. Material properties were also determined by hydrometer and Atterberg limit tests.

\subsection{Soil Identification}

\subsubsection{Atterberg Limits}

Atterberg limit tests were performed on samples from both boreholes according to ASTM D4318 (ASTM, 2000a). The results are plotted in Figures 3.1 and 3.2. It can be seen that the fill material was fairly uniform between the 
surface and approximately eight meters below the top of the dyke. The liquid limits in the dyke material of section SS-036 were found to range from 46 to $70 \%$, while plastic limits ranged from 17 to $24 \%$. Water contents typically ranged from 22 to $40 \%$. At section SS-040, liquid limits typically ranged from 50 to $60 \%$, while plastic limits ranged from 16 to $27 \%$. Water contents ranged from 22 to $29 \%$.

For the highly plastic foundation soil, at section SS-036 the liquid limits ranged from 99 to $119 \%$, while plastic limits ranged from 34 to $44 \%$. Water contents ranged from 42 to $56 \%$. At section SS-040, liquid limits ranged from 80 to $112 \%$, while plastic limits ranged from 20 to $36 \%$. Water contents ranged from 39 to $50 \%$.

At section SS-036, below a depth of eight meters, the water content and plasticity index increased significantly. This indicates the change from the dyke material to the highly plastic foundation, although at different sections of the dyke the depth of fill varies due to stripping of overlying material during construction. The water content and plasticity index were observed to decrease slightly in borehole SS-036 below twelve meters. This indicated that the thickness of the high plastic foundation is approximately four meters below the dyke.

At section SS-040 the plasticity index and water content increased between 7.5 and $8 \mathrm{~m}$ below the crest. Below ten meters the water content and plasticity index decreased more significantly than that observed at section SS- 
036. This indicated that the thickness of the high plastic foundation is approximately 2.0 to 2.5 meters beneath the dyke.

Plots of variations in unit weight, undrained shear strength, and preconsolidation pressure with depth are also shown in Figures 3.1 and 3.2. From the samples taken at section SS-036, a change from dyke material to foundation material was clearly observed as the color changed from light brown to dark brown, as shown in Figure 3.3. Atterberg limits done on the sample further verified this change in material at a depth of approximately $8.2 \mathrm{~m}$ below the crest of the dyke (Elevation of $268 \mathrm{~m}$ ). For section SS-040, the change was not as well defined as that from section SS-036. The Atterberg limit test results corresponded well with data from tests performed by P.F.R.A. in 1957 (Peterson, 1957).

The material changes at approximately $8 \mathrm{~m}$ depth agree with previous results of cone penetration tests done by Manitoba Hydro shown in Figures 3.4 and 3.5. Figure 3.4 shows results at section $10+25$, near section SS-036, on the landside of the south dyke. As seen on the plot of measured friction on the CPT, there is some variability within the dyke, followed by a stronger crust of the foundation at approximately $8 \mathrm{~m}$. Underlying the crust, the friction is greatly reduced to approximately $50 \mathrm{kPa}$, which stays relatively constant until the end of the test at approximately $12 \mathrm{~m}$ depth. Figure 3.5 shows the same results at section $10+85$, near section SS-040, on the landside of the south dyke. The 
measured friction from the CPT again varies in the dyke material, but is significantly greater than that of the previous section. Again a stronger crust of the foundation can be seen at approximately $8 \mathrm{~m}$ depth, which is underlain by material of less friction at approximately $75 \mathrm{kPa}$. Below approximately $10 \mathrm{~m}$ there is a greater variability in the results caused by a change in material, which was also observed in Atterberg limit test results.

\subsubsection{Hydrometer Testing}

Hydrometer testing was performed on samples from the dyke and foundation of both boreholes to see how they compared to each other. The procedures for the hydrometer analysis followed ASTM D 422 (ASTM, 2000b).

Test results for borehole SS-036 are shown in Figures 3.6 to 3.8. In the dyke at a depth of approximately $3.9 \mathrm{~m}$, the clay fraction was found to be about $58 \%$. At a depth of approximately $7.8 \mathrm{~m}$, just above the foundation, the clay fraction was about $52 \%$. In the foundation at a depth of approximately $9.5 \mathrm{~m}$, the material was nearly $100 \%$ clay size.

The results from borehole SS-040 are shown in Figures 3.9 to 3.12. In the dyke material at a depth of approximately $4.5 \mathrm{~m}$, the clay fraction was found to be about $46 \%$. Below this at a depth of approximately $5.1 \mathrm{~m}$, the clay fraction was similar at about $45 \%$. In the foundation at a depth of approximately $8.4 \mathrm{~m}$, the clay fraction was about $96 \%$. At lower depths the clay fraction was observed to 
decrease. Testing on material from approximately $9.4 \mathrm{~m}$ showed the clay content was about $72 \%$. Lower in the till material at a depth of about $11.7 \mathrm{~m}$, the clay content was only around $37 \%$.

Based on these results it was seen that the material in the foundation of the dykes is significantly different from the fill, as the former was mostly clay, while the latter was a silty clay. Also, visual observation showed the there was significantly more silt in the foundation of section SS-040 as compared to SS-036, which was confirmed by the comparison of hydrometer tests.

\subsection{Flexible Wall Hydraulic Conductivity Testing}

\subsubsection{Procedure}

Saturated hydraulic conductivity testing was also performed on samples consisting of fill material and in the upper and lower foundation of borehole SS036 as well as the upper foundation of borehole SS-040 according to ASTM D 5084 (ASTM, 2000c). Specimens were approximately $76.2 \mathrm{~mm}$ (3 in) in diameter and $90 \mathrm{~mm}$ in length. Consolidation of specimens was allowed for approximately seven days until no changes in burette water levels were observed. Following this, permeation using distilled water was commenced in which a hydraulic gradient of $28 \mathrm{kPa}$ ( $4 \mathrm{psi}$ ) was applied between the top and bottom of the specimen, causing water to flow up through the specimen. The quantity of inflow 
and outflow was recorded for about one week until the rate of flow through the specimen was approximately constant.

Samples were chosen to represent the different materials in the dykes from borehole SS-036. Sample 1 was from the fill material at a depth of approximately $5.2 \mathrm{~m}$, Samples 2 and 3 were from the upper foundation at a depth of about 9.0 and $9.2 \mathrm{~m}$, and Sample 4 was from the lower foundation at a depth of about $11.1 \mathrm{~m}$. Sample 5 was tested from the upper foundation of borehole SS-040 from a depth of approximately $8.3 \mathrm{~m}$ below the crest. The pressures used for each sample during consolidation and permeation are shown in Table 3.1. These pressures were determined based on effective overburden pressures and pore pressures that were estimated to be acting on the sample at a given depth. The limited in-house pressure also controlled what could be used for the tests.

\subsubsection{Saturated Hydraulic Conductivity Results}

Results of the testing corrected to that at $20^{\circ} \mathrm{C}$ showed that there was no significant difference in hydraulic conductivity in the different soil layers. Sample 1 gave a hydraulic conductivity of approximately $4.6 \times 10^{-11} \mathrm{~m} / \mathrm{s}$. Samples 2 and 3 gave an average value of about $1.6 \times 10^{-11} \mathrm{~m} / \mathrm{s}$ while for Sample 4 the hydraulic conductivity was found to be approximately $2.9 \times 10^{-11} \mathrm{~m} / \mathrm{s}$. Results of Sample 5 
taken from borehole SS-040 gave a hydraulic conductivity of approximately $2.2 \mathrm{x}$ $10^{-11} \mathrm{~m} / \mathrm{s}$.

\subsubsection{Unsaturated Hydraulic Conductivity}

As the hydraulic conductivity depends on the water content of a soil and the water content depends on the suction (or negative pore water pressure) in the soil, it is recognized that the hydraulic conductivity depends on the suction. This results from the fact that in unsaturated areas, air in the soil can prevent the flow of water and therefore reduce the hydraulic conductivity. The upper part of the embankment at Seven Sisters is believed to be unsaturated, as the phreatic surface drops from the height of the forebay down to the sand drains at a lower elevation on the land-side of the dykes. Using the unsaturated hydraulic conductivity curve can therefore be very helpful in aiding the accuracy of seepage modeling in regions of unsaturated flow. It was found that there are two main approaches for determining the unsaturated hydraulic conductivity curve, one based on empirical equations and the second on statistical models (Fredlund et al, 1994).

Based on results from soil - water characteristic curve determination (shown later in Section 3.7.1), hydrometers tests (Section 3.2.2), and saturated hydraulic conductivity testing (Section 3.3.2), an estimate of the unsaturated hydraulic conductivity curve could be made using a statistical model. This was

done through SoilVision Systems Ltd. using a knowledge-based system with a 
database of over 5000 soils. Figure 3.13 shows the results from this estimation based on the Fredlund and Xing pedo-transfer function drying method (Fredlund et al, 1994). Of the various methods to estimate the unsaturated hydraulic conductivity curve, this technique has proved to be the most reliable based on comparisons of estimated and measured curves on over 600 soils using the database by SoilVision Systems Ltd.

\subsection{Oedometer Testing}

\subsubsection{Procedure}

Oedometer tests were performed on several samples within the dyke and foundation. In each borehole, tests were performed on specimens at approximately every two meters. Testing was performed according to ASTM D 2435 (ASTM, 2000d) with slight modification. Differences from the ASTM were that the initial load placed on each sample was based on approximately $60 \%$ of the overburden pressure in order to prevent swelling of the soil. Also, the loading was incremented at a ratio of 1.8 up to an approximate stress of $2000 \mathrm{kPa}$ on the specimens. This provided more points than using the common load increment ratio of 2.0 and the high pressure ensured that the pressure was much greater than the preconsolidation pressure and produced a clear normally consolidated line. All specimens were obtained and tested in a cutting ring with a $63.5 \mathrm{~mm}$ (2.5-inch) diameter and $19 \mathrm{~mm}$ height. The height of the specimen in the ring was reduced by $3 \mathrm{~mm}$ in case of swelling during the addition of water. To 
prevent swelling, distilled water was added two minutes after the initial load had been applied. Each load increment was applied to the soil specimen for approximately 24 hours

\subsubsection{Oedometer Testing Results}

Results of testing are shown in Figures 3.14 to 3.25 as plots of void ratio vs. normal stress. The preconsolidation pressures and compression indexes obtained from testing results for each sample are shown in Table 3.2. For each sample the preconsolidation pressure was obtained using the Casagrande method and the compression index was determined from the slope of the linear portion of the e-log $\sigma_{\mathrm{n}}$ plot.

Graphs of preconsolidation pressure vs. depth for each section are shown in Figures 3.1 and 3.2. The general trend is that of increasing preconsolidation pressures with depth in the fill until about $10 \mathrm{~m}$. At $10 \mathrm{~m}$ depth in the highly plastic foundation clay, relatively higher values in preconsolidation pressure were observed, followed by decreased values at depths below $10 \mathrm{~m}$ corresponding to the normal reduction in preconsolidation pressure in the formerly weathered crust. 


\subsubsection{Oedometer Hydraulic Conductivity Testing}

To make comparisons between the vertical and horizontal hydraulic conductivity of samples from the upper foundation, further oedometer tests were performed (according to ASTM D2435) on specimens obtained from sections SS036 and SS-040. The report by Armstrong (2001) used samples taken from the same depths as those discussed above, but the specimens were tested horizontally. The same loading pressures were also used such that comparisons of horizontal to vertical hydraulic conductivity could be made.

Results of the tests are summarized in Tables 3.3 and 3.4 , where $k_{y}$ is the vertical and $k_{x}$ the horizontal hydraulic conductivity. The results indicate that for section SS-036 the ratio of $k_{y} / k_{x}$ is near or less that 0.4 while for section SS-040 the same ratio is near or greater than 1.1 .

It was noted that the oedometer test is not normally used for hydraulic conductivity determination and the resulting absolute values of horizontal and vertical hydraulic conductivity may not well represent the in-situ condition. However, it is believed that the ratio $k_{y} / k_{x}$ may be useful. Yuen et al. (1998) showed that the hydraulic conductivity measured by oedometer tests typically decreases by $1-2$ orders of magnitude over the commonly used range of pressures. At low pressures, $k$ may be one order of magnitude lower than equivalent results from a triaxial hydraulic conductivity test. 


\subsection{CIŪ Triaxial Testing}

\subsubsection{Procedure}

Isotropically consolidated undrained (CIŪ) triaxial tests were also performed on samples from both the dyke and foundation of each borehole. The tests were conducted according to ASTM D 4767 (ASTM, 2000e). Specimens were trimmed to a diameter of approximately $50.8 \mathrm{~mm}(2 \mathrm{in})$ and $100 \mathrm{~mm}$ length. They were then placed in the triaxial testing device and sealed with two membranes and two O-rings on the top and bottom of the specimen. Filter paper was placed on the top and bottom of the specimen as well as along the periphery to speed up the drainage of water in the specimen during the saturation and consolidation processes. Porous stones were placed beneath the bottom filter paper and above the top filter paper. Following this, the cell pressure and back pressure were applied to the specimen. The specimens were then allowed to consolidate, usually taking approximately 24 hours, until water levels in the back pressure burette remained constant. This was followed by a B-test in which the all-round pressure is increased under undrained conditions. The change in pore pressure, $\Delta \mathrm{u}$, resulting from the change in cell pressure, $\Delta \sigma_{3}$, was then used to determine the value of $\mathrm{B}$ from the following equation:

$$
B=\frac{\Delta u}{\Delta \sigma_{3}}
$$

For a fully saturated medium-dense soil, $B$ is equal to 1.0 . For this research, a B value of approximately 0.98 was considered acceptable for assuming saturation. Shearing of the specimen was carried out at a slow rate 
(approximately $0.012 \mathrm{~mm} / \mathrm{min}$ ) over 24 hours to produce approximate equalization of pore pressures throughout the specimen at failure.

For borehole SS-036, four specimens were taken from the dyke in two neighboring tubes. The effective stresses applied to the specimens were 100 , 150,200 , and $400 \mathrm{kPa}$. Five specimens were also taken from the foundation and tested with applied effective stresses of $100,200,400,450,550 \mathrm{kPa}$. These represent a normal range of pressures in geotechnical practice. Application of higher effective stress was not possible due to the limitations of available pressure.

For borehole SS-040, the effective stress applied to specimens from within the dyke were $100,200,400$, and $550 \mathrm{kPa}$. For the specimens tested from the foundation, the effective stresses used were $200,400,450$, and $500 \mathrm{kPa}$.

\subsubsection{ClŪ Triaxial Test Results}

The results of the testing are shown in Figures 3.26 to 3.33 . Figures 3.26 and 3.27 show results from the fill material of borehole SS-036. Figure 3.26 shows the deviator stress, $\mathrm{q}$, and change in pore pressure vs. axial strain during shearing of the specimen. Figure 3.27 shows the deviator stress vs. mean effective stress, $p^{\prime}$. Similar graphs are shown for the foundation of SS-036 as well as the fill and foundation of SS-040. 
Normalized plots of q vs. p' are shown in Figures 3.34 (dyke material) and 3.35 (foundation material). These were done so that samples from different depths could be compared and for determining the critical state friction angle.

Figure 3.34(a) shows the critical state (post-peak) points of the dyke material normalized by preconsolidation pressure. For the specimens tested with a confining pressure less than the preconsolidation pressure measured by the oedometer test, the preconsolidation pressure was determined based on the following equations. The at-rest earth pressure was determined using the correlation in equation 3.2 for overconsolidated soils proposed by Mayne and Kulhawy (1982).

$$
K_{0}=\left(1-\sin \varphi^{\prime}\right)(O C R)^{\sin \varphi^{\prime}}
$$

In this equation OCR is the overconsolidation ratio and $\phi^{\prime}$ is the critical state effective friction angle. Equations 3.3 and 3.4 can then be used to determine the horizontal preconsolidation pressure, $\sigma_{\mathrm{hc}}^{\prime}$, and preconsolidation pressure, $\mathrm{p}_{\mathrm{c}}^{\prime}$.

$$
\begin{gathered}
\sigma_{h c}^{\prime}=K_{0} \sigma_{v c}^{\prime} \\
\mathrm{p}_{\mathrm{c}}^{\prime}=\frac{\sigma_{\mathrm{vc}}^{\prime}+2 \sigma_{\mathrm{hc}}^{\prime}}{3}
\end{gathered}
$$

For specimens tested with a confining pressure greater than the preconsolidation pressure measured by the oedometer test, the points were normalized by the confining pressure in the triaxial test. Figure $3.34(\mathrm{~b})$ shows the same critical state points all normalized by the consolidation pressures used 
in the triaxial tests. The resulting values of $\mathrm{M}$ and $\phi_{c s}^{\prime}$ are shown in Table 3.5. It is interesting to note that in the dyke, the unstable section at SS-036 has slightly lower $\phi^{\prime}\left(23.3^{\circ}\right)$ than the stable section SS-040 $\left(24.9^{\circ}\right)$.

Figure 3.35 shows the plots normalized by the same approach as before for the foundation material. Values of peak and critical state points are plotted on these graphs. The values of $\mathrm{M}$ and $\phi_{c s}^{\prime}$ are shown in Table 3 .

- Based on lines connecting approximate critical state points on deviator stress vs mean effective stress plots, $\phi_{c s}^{\prime}$ was found to be approximately $13^{\circ}$ in the foundation of section SS-036 and $14^{\circ}$ at section SS-040. These are very low values of $\phi_{c s}^{\prime}$ that correspond to rather poorly defined 'post-peak plateaus' in the $q$ vs. p' diagrams shown in Figures 3.28 and 3.32.

Following the 'post-peak plateaus' some tests showed a further reduction in deviator stress with additional axial strain. At the unstable section, SS-036, minimum values of deviator stress were found at the end of tests performed at effective stresses of $100,200,400$, and $450 \mathrm{kPa}$ as shown in Figure 3.28. Connecting these points in the $q$ vs. $p^{\prime}$ plot and assuming no cohesion, the friction angle was found to be $10.3^{\circ}$. At the stable section, SS-040, using end points from tests performed at effective stresses of 400 and $550 \mathrm{kPa}$ and no cohesion, the friction angle was found to be $10.7^{\circ}$. 
Cohesion values were also determined from the $q$ vs. $p^{\prime}$ plots based on the following equation.

$$
c_{o c}^{\prime}=\frac{c_{p q}^{\prime}\left(3-\sin \varphi^{\prime}\right)}{6 \cos \varphi^{\prime}}
$$

Based on Equation 3.5, the over consolidated (peak) effective cohesion in the dyke was found to be $33 \mathrm{kPa}$ for borehole SS-036 and $19 \mathrm{kPa}$ for borehole SS040. In the foundation, the peak effective cohesion was found to be $33 \mathrm{kPa}$ in both boreholes SS-036 and SS-040.

Figures 3.36 and 3.37 show plots of change in pore pressure vs. change in mean total stress, $p$, for the foundation materials in boreholes SS-036 and SS040. The average slopes of the linear sections of these graphs are $m=\Delta u / \Delta p=2.40$ for SS-036 and 1.94 for the stable section SS-040. A line has been drawn on the graphs showing a slope of unity, representing isotropic elastic material. Both sets of results show the materials to be anisotropic, with the foundation soil of borehole SS-036 being more anisotropic than SS-040. These results also show that for the same value of deviator stress, SS-036 generates a higher excess pore pressure than SS-040.

\subsection{Direct Shear Testing}

\subsubsection{Procedure}

Direct shear testing was also completed on circular, undisturbed specimens obtained from the upper foundation of boreholes SS-036 and SS-040. 
The tests were conducted according to ASTM D 3080 (ASTM, 2000f). The diameter of all specimens was approximately $70.8 \mathrm{~mm}$ with heights of approximately $28 \mathrm{~mm}$. Specimens were allowed to consolidate under each loading until there was no further vertical movement, followed by horizontal shearing. The shearing consisted of pushing the shear box forward during the day and reversing it at night at a slow rate of displacement until a residual strength was reached. The shearing rate during all forward cycles was the same and slightly faster than the constant shearing rate used for the reverse cycle.

All specimens were initially loaded with a normal stress of $35 \mathrm{kPa}$. Further stress increments of 75 and $150 \mathrm{kPa}$ were then used for each specimen to obtain three points that could be used to determine the residual strength.

For some shearing cycles, a clear residual strength was not seen from the data. Upon taking the shear box apart, it was observed that these specimens did not have a smooth horizontal surface. Therefore the specimens were manually remolded to a smooth horizontal surface in the shear box and reconsolidated and sheared to improve the results for residual strength.

Sample 1 was taken from borehole SS-036 at a depth of $9.13-9.73 \mathrm{~m}$ and Sample 2 was taken from borehole SS-040 at a depth of $9.03-9.65 \mathrm{~m}$. 


\subsubsection{Direct Shear Testing Results}

Summary graphs of shear stress vs. normal stress are shown in Figures 3.38 and 3.39. The residual strength parameters determined from the tests are shown in Table 3.7. These results are similar to those determined from Manitoba Hydro tests done on foundation material specimens, which gave $\mathrm{c}_{r}{ }^{\prime}=2 \mathrm{kPa}$ and $\phi_{r}^{\prime}=8.5^{\circ}$. These residual strengths are slightly lower than the end of test strengths determined from triaxial testing in Section 3.5.

To observe and compare their initial intact strengths, conventional direct shear tests were done on samples at constant shearing rates and normal stresses as shown in Figure 3.40. These tests indicate that at higher elevations near the surface, the material is more brittle and the strength decreases quite rapidly. Approximately one meter below this the samples were less brittle and did not have as much of a reduction in strength. It can also be seen that the peak strengths of the samples from SS-040 are greater than those of SS-036, although the final residual strengths are similar. 


\subsection{Soil Water Characteristic Curve Construction}

\subsubsection{Procedure}

Due to the possible unsaturated conditions in the upper portions of the dykes, a soil water characteristic curve was constructed to relate water content to suction. The benefit of this curve is that it can be incorporated into seepage modeling to provide a relationship between the volume of water stored in the soil pores and pore water pressure. Also as discussed in Section 3.3.3 it is used to obtain an estimation of the unsaturated hydraulic conductivity curve.

Construction of the soil water characteristic curve for the dyke material was done using fourteen specimens obtained from section SS-036. Two specimens were then placed into each of the seven desiccators of different suction levels. The lower suction levels of $0.1,0.5,1$, and $5 \mathrm{MPa}$ were created using solutions of potassium chloride $(\mathrm{KCl})$. Higher suction levels of 10,50 , and $100 \mathrm{MPa}$ were created with solutions of sulphuric acid $\left(\mathrm{H}_{2} \mathrm{SO}_{4}\right)$.

The specimens used for testing were trimmed to approximately $50 \mathrm{~mm}$ in diameter and $100 \mathrm{~mm}$ in height. Before being placed into the desiccators, specimens were weighed and measured. After thirty days the specimens were removed and again weighed and measured to determine weight and volume changes. 
Due to the variability of material in the fourteen samples of the previously described test, a second soil water characteristic curve was constructed using only a single specimen taken from the dyke at section SS-040. The specimen was then moved from desiccator to desiccator so that the resulting curve would not be subject to soil variability. The suctions used in each dessicator were the same as those used for the original test and the specimen remained in each desiccator for thirty days.

\subsubsection{Soil Water Characteristic Curve Results}

The results from the first test described above resulted in the soil water characteristic curve shown in Figure 3.41. As can be seen the results provide a range of values for the soil water characteristic curve due to the variability of the specimens used in the testing.

The result of the second soil water characteristic curve is also shown in Figure 3.41 with the results from the previous test. This curve has much less variability compared to the previous test. 


\subsection{Pore Fluid Chemistry Analysis}

\subsubsection{Procedure}

In collaboration with the Department of Soil Sciences at the University of Manitoba, analyses were done on pore fluid extracted from saturated soil samples. Of particular interest were cations including $\mathrm{Na}^{+}, \mathrm{Ca}^{2+}, \mathrm{Mg}^{2+}$, and $\mathrm{Fe}$. Also measured were $\mathrm{Cl}, \mathrm{SO}_{4}$, carbonates/bicarbonates, electrical conductivity, $\mathrm{pH}$, and alkalinity.

The pore fluid samples tested were obtained from the highly plastic foundation soil at three different sections. The first location at section SS-036 had experienced previous instability and the second section at SS-040 had remained stable. A third section, called SS-042, was located along an access road southeast of the generating station. The samples obtained from this section represented background samples to compare with samples taken from below the dyke.

At each location four samples were taken for analysis, the first being approximately 0.5 to $1.0 \mathrm{~m}$ below the top of the foundation layer. Three other samples were taken from depths between 1.0 to $2.5 \mathrm{~m}$ below the top of the foundation layer. 


\subsubsection{Pore Fluid Chemistry Analysis Results}

The results of the pore fluid testing are shown in Table 3.8. Graphs of the cation and anion concentrations with elevation at each section are shown in Figures 3.42 to 3.47 . As shown in Figure 3.42 , the calcium concentration at each elevation is significantly higher at the background section (SS-042) as compared to the sections below the dykes (SS-036 and SS-040). Comparing the two sections below the dykes, at higher elevations there is not much difference in the concentration, but at lower elevations the stable section, SS-040, has greater concentrations than the unstable section, SS-036.

In Figure 3.43 it can be seen that the concentration of magnesium is significantly greater at the background section as compared to the other sections. Again at higher elevations, the concentrations are similar, but at lower elevations the stable section has slightly greater concentrations of magnesium.

The concentration of sodium at each section is shown in Figure 3.44. As shown the concentrations at the background and unstable sections are similar. The sodium concentration at the stable section is slightly less than the other sections. 
In Figure 3.45 , the sulphate concentration is significantly greater in the background section than the sections below the dyke. Comparing the stable and unstable sections indicate that the concentrations are very similar except at the elevation of $266.5 \mathrm{~m}$.

In Figure 3.46 is the graph of the concentration of bicarbonate $\left(\mathrm{HCO}_{3}\right)$ with elevation. As shown the concentration of the background section is less than that of the other two sections. Comparing the two sections beneath the dykes shows concentrations lower in the stable section than in the unstable sections at higher elevations. At lower elevations the concentrations are similar.

Figure 3.47 shows the concentration of chlorine with elevation at the three sections. Again the concentration of the background section is less than the sections below the dyke. At higher elevations the concentration of the chlorine is slightly less in the stable section than the unstable section. At lower elevations the concentration at the stable section is slightly greater than or equal to that of the unstable section. When comparing the three sections it must be noted that although there are differences, the actual concentrations of chlorine are very small and therefore may not be significant.

Concentrations of iron are not shown in Table 3.9, as the values ranged from only 0.1 to $0.5 \mathrm{mg} / \mathrm{L}$ and did not indicate any relationships between sections or elevations. 
The results of the pore fluid testing appear to suggest dissolution of gypsum $\left(\mathrm{CaSO}_{4}\right)$ within the foundation of the dykes at Seven Sisters. Gypsum minerals have a relatively high solubility. Due to the loss of dissolved ions the thickness of the double diffuse layer will increase. Also the reduction of calcium results in an increase in the $\mathrm{Na} / \mathrm{Ca}$ ratio. This represents a relative decrease in valence, which also increases double diffuse layer thickness. The increased double diffuse layer thickness therefore causes an increase in interparticle repulsion and a tendency to increase water contents and decrease strengths. These features are shown in the physical test results in Figures 3.1, 3.2, 3.4, and 3.5.

It is also believed that the removal of gypsum by leaching can create the more brittle behavior that can be seen in the triaxial test results in Figures 3.28 and 3.32. This is due to the reduction in cementation at the contacts between particles as a result of increased leaching. Upon straining of the soil, the quasistable edge to face flocculated structure is then destroyed, causing the observed strain softening behavior.

The results of the Atterberg limits also show that in the unstable section, liquid and plastic limits are greater compared to the stable section. This agrees with the observation discussed in the literature review by Hawkins and McDonald (1992) during decalcification. 
As shown by the results of the pore fluid testing, the concentrations of most cations and anions are significantly different between the background section and those beneath the dyke. This indicates that the flow of water beneath the dykes affects the chemistry of the soil. Although at this site no testing has been done to investigate quantitatively the effect of these changes in chemistry on soil properties, it is known that changes in pore fluid chemistry does change the thickness of the double diffuse layer and therefore affects compressibility, strength, and hydraulic conductivity of soil (Mitchell, 1993; Barbour and Yang, 1993). 
Table 3.1. Pressures used for hydraulic conductivity testing (in $\mathrm{kPa}$ )

\begin{tabular}{|c|c|c|c|c|c|c|}
\hline Sample & \multicolumn{3}{|c|}{ Consolidation } & \multicolumn{3}{c|}{ Permeation } \\
\hline & $\begin{array}{c}\text { Cell } \\
\text { Pressure }\end{array}$ & $\begin{array}{c}\text { Bottom } \\
\text { Back } \\
\text { Pressure }\end{array}$ & $\begin{array}{c}\text { Top } \\
\text { Back } \\
\text { Pressure }\end{array}$ & $\begin{array}{c}\text { Cell } \\
\text { Pressure }\end{array}$ & $\begin{array}{c}\text { Bottom } \\
\text { Back } \\
\text { Pressure }\end{array}$ & $\begin{array}{c}\text { Top } \\
\text { Back } \\
\text { Pressure }\end{array}$ \\
\hline $\mathbf{1}$ & 240 & 165 & 165 & 240 & 180 & 152 \\
$\mathbf{2}$ & 240 & 140 & 140 & 240 & 152 & 124 \\
$\mathbf{3}$ & 240 & 140 & 140 & 240 & 152 & 124 \\
$\mathbf{4}$ & 240 & 115 & 115 & 240 & 128 & 100 \\
$\mathbf{5}$ & 240 & 145 & 145 & 240 & 158 & 131 \\
\hline
\end{tabular}

Table 3.2. Preconsolidation pressures from oedometer tests

\begin{tabular}{|c|c|c|c|c|}
\hline Sample & Borehole & Depth (m) & $\begin{array}{l}\text { Preconsolidation } \\
\text { Pressure (kPa) }\end{array}$ & $\begin{array}{l}\text { Compression } \\
\text { Index }\left(C_{c}\right)\end{array}$ \\
\hline 1 & $S S-036$ & 2.2 & 65 & 0.164 \\
\hline 2 & $S S-036$ & 4.1 & 200 & 0.323 \\
\hline 3 & SS - 036 & 6.4 & 225 & 0.194 \\
\hline 4 & $S S-036$ & 8.4 & 300 & 0.349 \\
\hline 5 & SS - 036 & 10.0 & 550 & 0.621 \\
\hline 6 & $S S-036$ & 12.1 & 380 & 0.334 \\
\hline 7 & SS - 040 & 2.2 & 175 & 0.203 \\
\hline 8 & SS -040 & 4.0 & 200 & 0.213 \\
\hline 9 & $S S-040$ & 6.3 & 230 & 0.173 \\
\hline 10 & SS - 040 & 8.0 & 400 & 0.371 \\
\hline 11 & SS - 040 & 10.0 & 600 & 0.557 \\
\hline 12 & SS - 040 & 11.5 & 300 & 0.161 \\
\hline
\end{tabular}


Table 3.3. Vertical to horizontal hydraulic conductivity ratios for section SS-036

\begin{tabular}{|c|c|c|c|}
\hline & $\begin{array}{c}\text { Sample 5 } \\
\mathbf{S S}-\mathbf{0 3 6} \\
\mathbf{9 . 7 4 - 1 0 . 3 4} \mathrm{m} \\
(\mathbf{S 2})\end{array}$ & $\begin{array}{c}\text { Sample 13 } \\
\mathbf{S S}-\mathbf{0 3 6} \\
\mathbf{9 . 7 4 - 1 0 . 3 4} \mathbf{~ m} \\
(\mathbf{S} 2)\end{array}$ & \\
\hline $\begin{array}{c}\text { Pressure } \\
(\mathrm{kPa})\end{array}$ & $\mathbf{k}_{\mathrm{y}}(\mathrm{E}-11 \mathrm{~m} / \mathbf{s})$ & $\mathbf{k}_{\mathrm{x}}(\mathrm{E}-11 \mathrm{~m} / \mathbf{s})$ & $\mathbf{k}_{\mathrm{y}} / \mathbf{k}_{\mathrm{x}}$ \\
\hline 71 & 2.1 & 3.0 & 0.70 \\
\hline 126 & 2.5 & 9.2 & 0.27 \\
\hline 227 & 1.5 & 3.3 & 0.45 \\
\hline 407 & 1.3 & 4.7 & 0.28 \\
\hline 729 & 0.6 & 1.2 & 0.50 \\
\hline 1311 & 0.3 & 1.5 & 0.20 \\
\hline 2080 & 0.2 & 0.3 & 0.67 \\
\hline
\end{tabular}

Table 3.4. Vertical to horizontal hydraulic conductivity ratios for section SS-040

\begin{tabular}{|c|c|c|c|}
\hline & $\begin{array}{c}\text { Sample 11 } \\
\mathbf{S S}-\mathbf{0 4 0} \\
9.68-10.29 \mathrm{~m} \\
(\mathbf{S 2})\end{array}$ & $\begin{array}{c}\text { Sample 14 } \\
\mathbf{S S}-\mathbf{0 4 0} \\
\mathbf{9 . 6 8 - 1 0 . 2 9} \\
(\mathbf{S} 2)\end{array}$ & \\
\hline $\begin{array}{c}\text { Pressure } \\
(\mathrm{kPa})\end{array}$ & $\mathbf{k}_{\mathrm{y}}(\mathrm{E}-11 \mathrm{~m} / \mathbf{s})$ & $\mathbf{k}_{\mathbf{x}}(\mathrm{E}-11 \mathrm{~m} / \mathbf{s})$ & $\mathbf{k}_{\mathbf{y}} / \mathbf{k}_{\mathbf{x}}$ \\
\hline 60 & 21.0 & 16.0 & 1.31 \\
\hline 106 & 3.7 & 0.8 & 4.62 \\
\hline 194 & 5.1 & 5.6 & 0.91 \\
\hline 352 & 4.5 & 4.1 & 1.10 \\
\hline 650 & 2.2 & 2.8 & 0.79 \\
\hline 1175 & 1.3 & 1.4 & 0.93 \\
\hline 2139 & 1.0 & 0.7 & 1.43 \\
\hline
\end{tabular}


Table 3.5. Triaxial test values of $\mathrm{M}$ and $\phi_{C S}^{\prime}$ for dyke material

\begin{tabular}{|c|c|c|c|c|}
\hline Normalized By & \multicolumn{2}{|c|}{ M } & \multicolumn{2}{c|}{$\boldsymbol{\phi}_{\text {cs }}$} \\
\cline { 2 - 5 } & $\mathbf{S S - 0 3 6}$ & SS-040 & SS-036 & SS-040 \\
\hline $\begin{array}{c}\text { Preconsolidation } \\
\text { Pressure }\end{array}$ & 0.91 & 0.98 & 23.3 & 24.9 \\
\hline $\begin{array}{c}\text { Consolidation } \\
\text { Pressure }\end{array}$ & 0.91 & 0.99 & 23.3 & 25.1 \\
\hline
\end{tabular}

Table 3.6. Triaxial test values of $M$ and $\phi_{c s}^{\prime}$ for foundation material

\begin{tabular}{|c|c|c|c|c|}
\hline Normalized By & \multicolumn{2}{|c|}{ M } & \multicolumn{2}{c|}{$\boldsymbol{\phi}_{\text {cs }}^{\prime}$} \\
\cline { 2 - 5 } & $\mathbf{S S - 0 3 6}$ & $\mathbf{S S - 0 4 0}$ & $\mathbf{S S - 0 3 6}$ & $\mathbf{S S - 0 4 0}$ \\
\hline $\begin{array}{c}\text { Preconsolidation } \\
\text { Pressure }\end{array}$ & 0.47 & 0.47 & 12.5 & 12.5 \\
\hline $\begin{array}{c}\text { Consolidation } \\
\text { Pressure }\end{array}$ & 0.47 & 0.47 & 12.5 & 12.5 \\
\hline
\end{tabular}

Table 3.7. Direct shear test results for foundation material

\begin{tabular}{|c|c|c|c|}
\hline & Borehole & $\mathbf{c}_{r}{ }^{\prime}(\mathbf{k P a})$ & $\phi_{r}{ }^{\prime}$ \\
\hline Sample 1 & SS-036 & 2.5 & 8.2 \\
\hline Sample 2 & SS-040 & 2.9 & 7.5 \\
\hline
\end{tabular}


Table 3.8. Pore fluid chemistry analysis results

\begin{tabular}{|c|c|c|c|c|c|c|c|c|c|c|c|}
\hline No. & Section & $\begin{array}{l}\text { Elevation } \\
(\mathrm{m})\end{array}$ & $\begin{array}{c}\mathrm{EC} \\
(\mu \mathrm{S} / \mathrm{cm})\end{array}$ & $\mathrm{pH}$ & $\begin{array}{c}\text { Alkalinity } \\
\text { (mg/L CaCO3) }\end{array}$ & $\begin{array}{l}\mathrm{HCO}_{3}^{-} \\
(\mathrm{mg} / \mathrm{L})\end{array}$ & $\begin{array}{l}\mathrm{Ca}^{2+} \\
(\mathrm{mg} / \mathrm{L})\end{array}$ & $\begin{array}{c}\mathrm{Mg}^{2+} \\
(\mathrm{mg} / \mathrm{L})\end{array}$ & $\begin{array}{c}\mathrm{Na}^{+} \\
(\mathrm{mg} / \mathrm{L})\end{array}$ & $\begin{array}{l}\mathrm{SO}_{4}{ }^{2-} \\
(\mathrm{mg} / \mathrm{L})\end{array}$ & $\begin{array}{c}\mathrm{Cl}^{-} \\
(\mathrm{mg} / \mathrm{L})\end{array}$ \\
\hline 1 & SS-036 & 267.7 & 772 & 8.12 & 213.5 & 130 & 30 & 71 & 62 & 243 & 6.4 \\
\hline 2 & SS-036 & 266.7 & 1370 & 8.20 & 191.5 & 117 & 112 & 114 & 104 & 720 & 11.2 \\
\hline 3 & SS-036 & 266.4 & 1340 & 8.15 & 170 & 104 & 113 & 108 & 102 & 708 & 10.3 \\
\hline 4 & SS-036 & 266 & 1650 & 7.94 & 145 & 88 & 172 & 131 & 116 & 972 & 10.0 \\
\hline 5 & SS-040 & 267.8 & 546 & 8.20 & 185 & 113 & 28 & 58 & 26 & 153 & 3.0 \\
\hline 6 & SS-040 & 267 & 1190 & 8.09 & 155 & 95 & 97 & 115 & 58 & 609 & 6.3 \\
\hline 7 & SS-040 & 266.5 & 3520 & 8.06 & 185 & 113 & 164 & 159 & 148 & 2016 & 14.3 \\
\hline 8 & SS-040 & 266 & 1810 & 8.11 & 150 & 92 & 220 & 159 & 74 & 1122 & 10.5 \\
\hline$\overline{9}$ & SS-042 & 267.8 & 1460 & 8.00 & 140 & 85 & $\overline{125}$ & 160 & 64 & 870 & 1.4 \\
\hline 10 & SS-042 & 266.8 & 3950 & 7.78 & 90 & 55 & 554 & 505 & 108 & 3360 & 3.0 \\
\hline 11 & SS-042 & 266.6 & 4160 & 7.72 & 105 & 64 & 680 & 533 & 116 & 3750 & 6.0 \\
\hline 12 & SS-042 & 266.2 & 4150 & 8.61 & 100 & 61 & 680 & 505 & 116 & 3660 & 6.2 \\
\hline
\end{tabular}




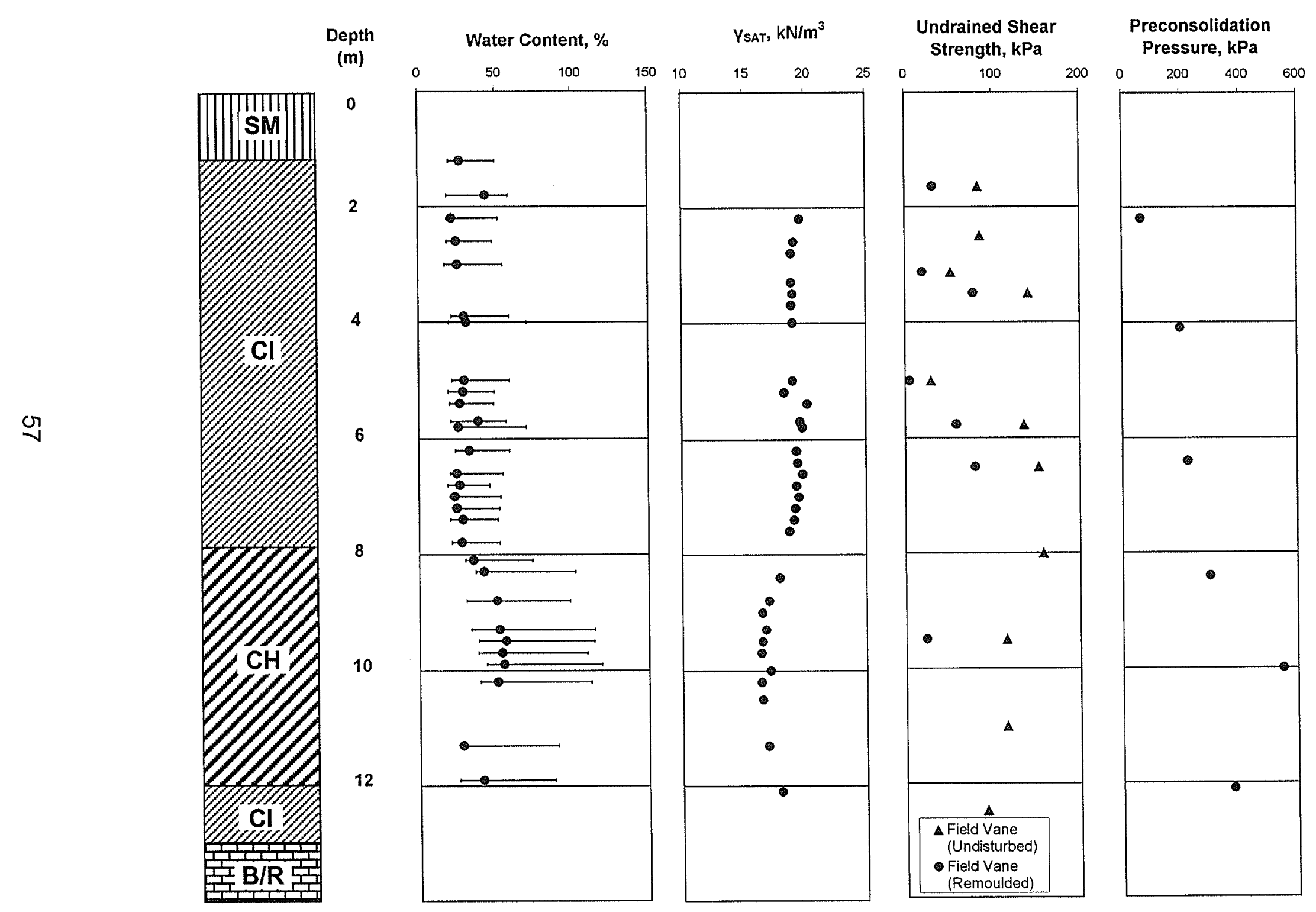

Figure 3.1. Borehole information for section SS-036 

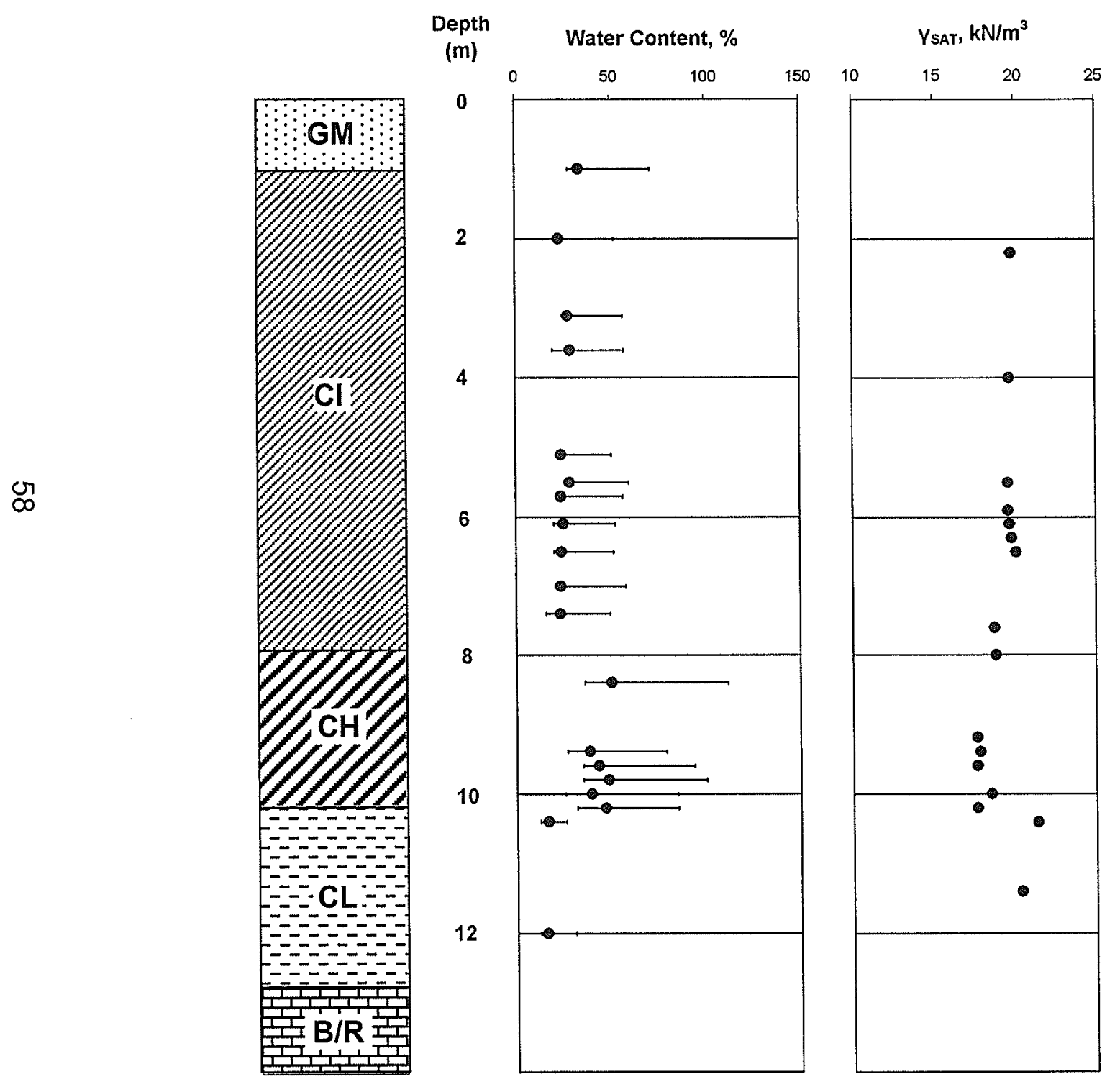

Undrained Shear

Strength, $\mathrm{kPa}$

Preconsolidation

Pressure, kPa

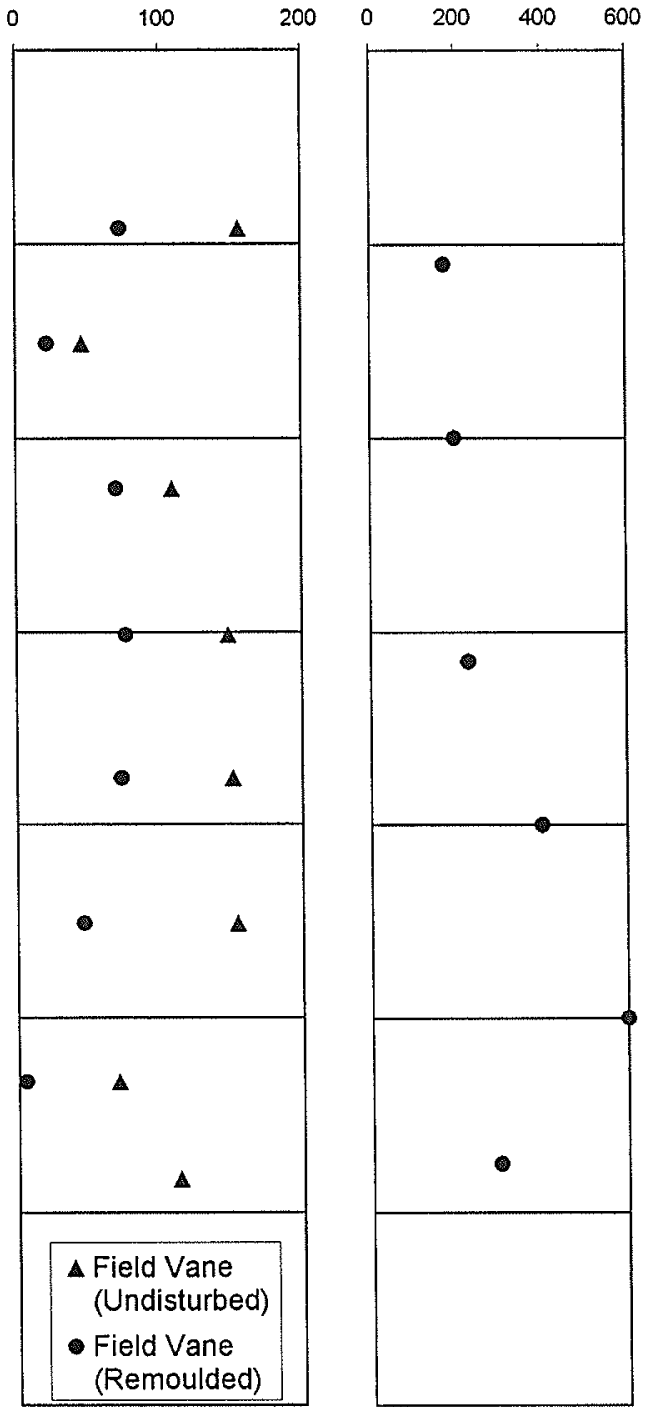

Figure 3.2. Borehole information for section SS-040 


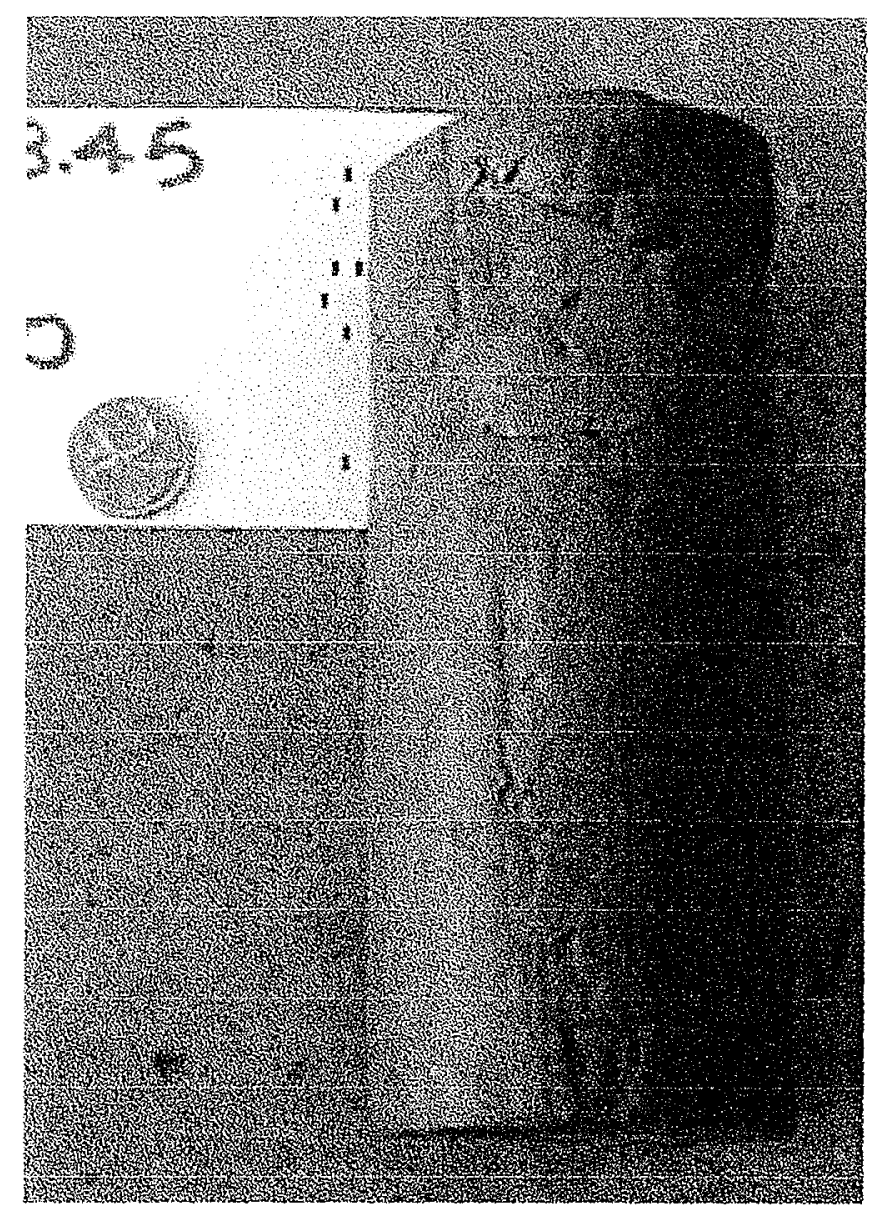

Figure 3.3. Photograph of color change from light brown dyke material to darker brown highly plastic foundation soil 


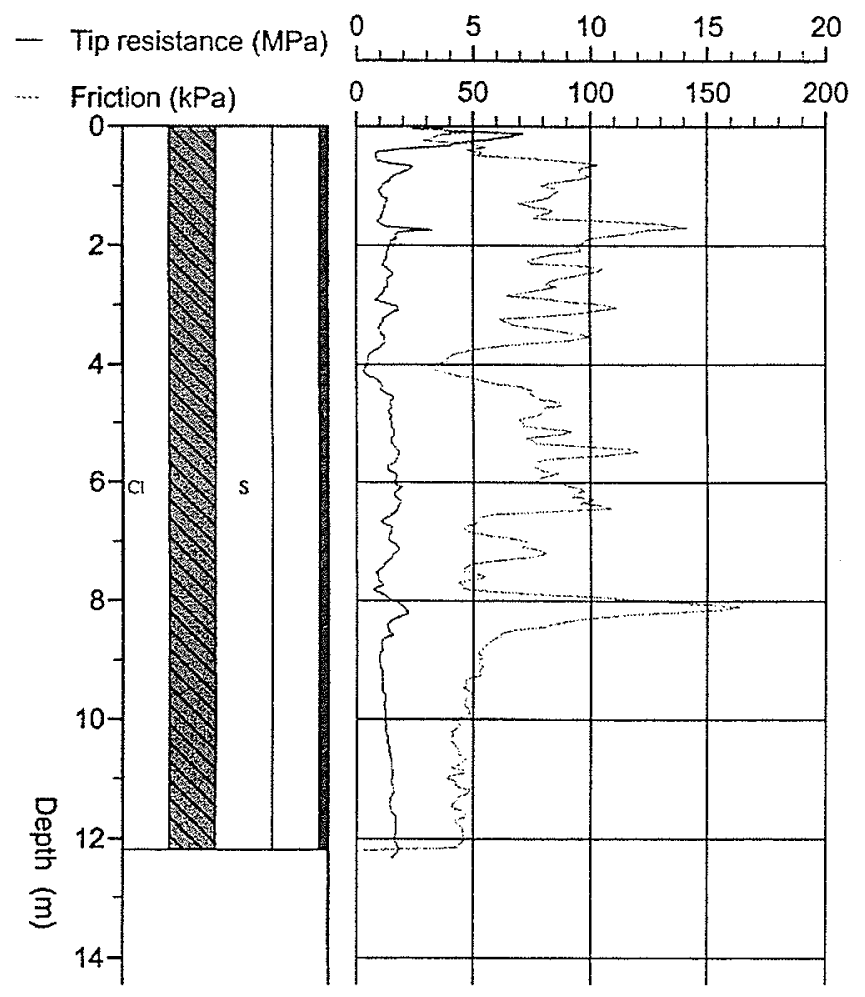

Figure 3.4. CPT test data near section SS-036

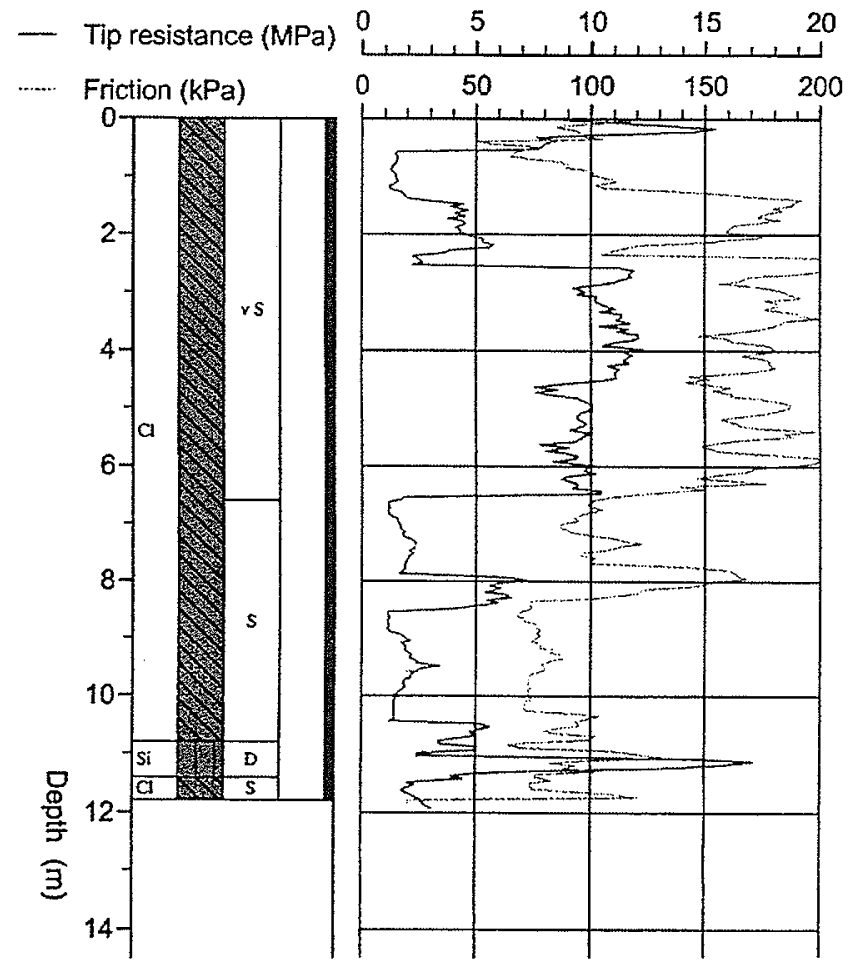

Figure 3.5. CPT test data near section SS-040 


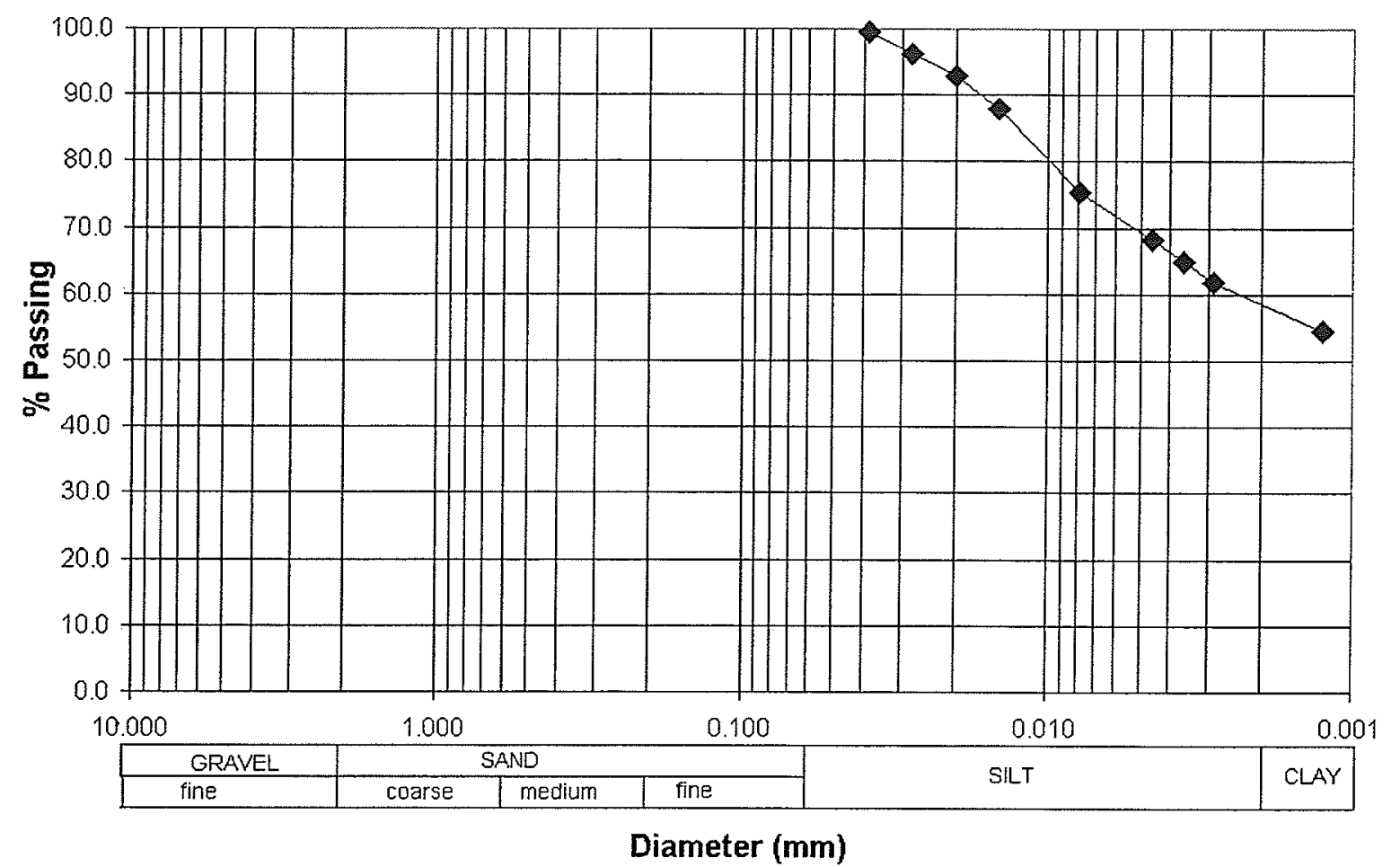

Figure 3.6. Hydrometer test result from section SS-036 at $3.9 \mathrm{~m}$ depth

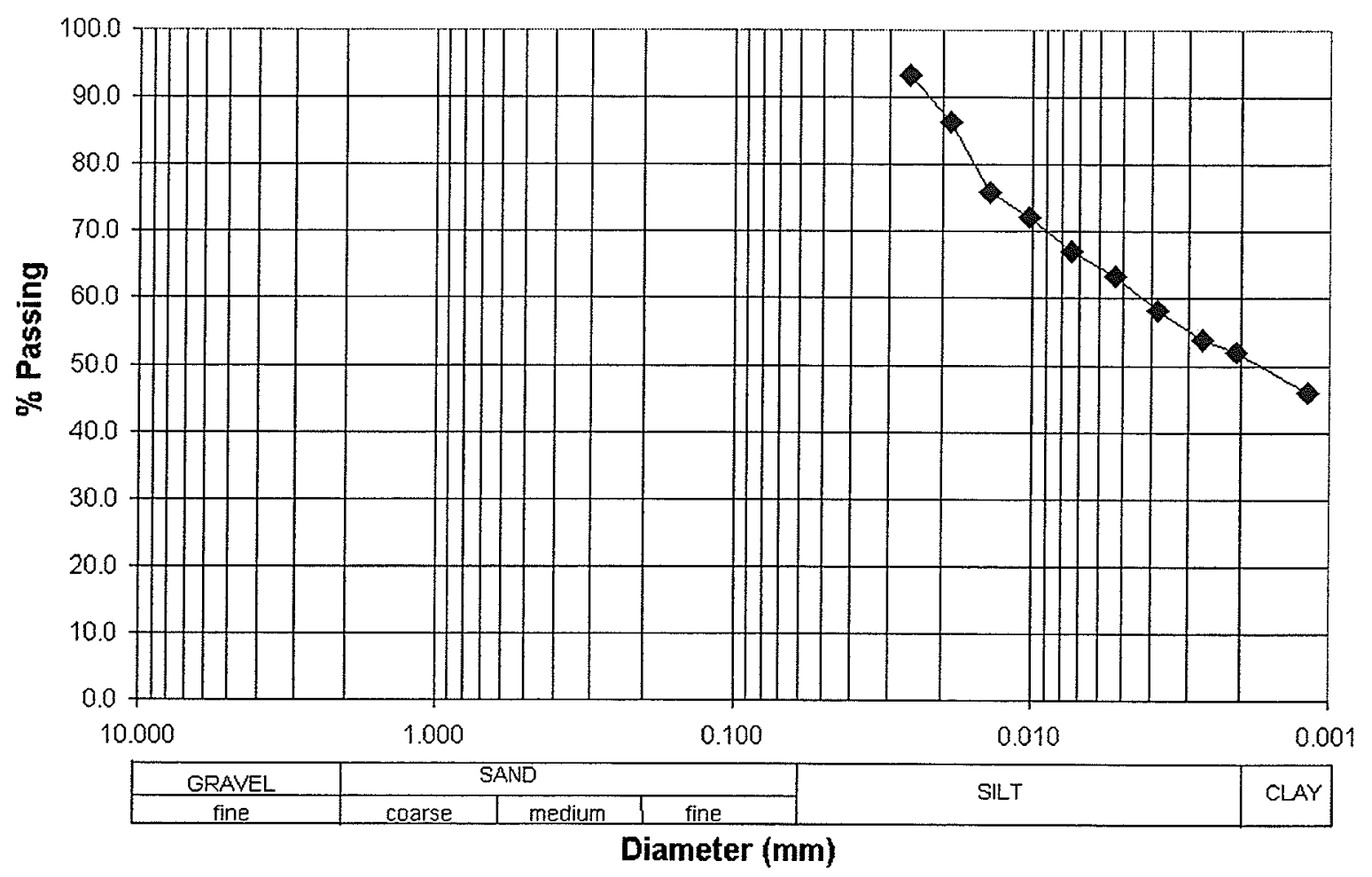

Figure 3.7. Hydrometer test result from section SS-036 at $7.8 \mathrm{~m}$ depth 


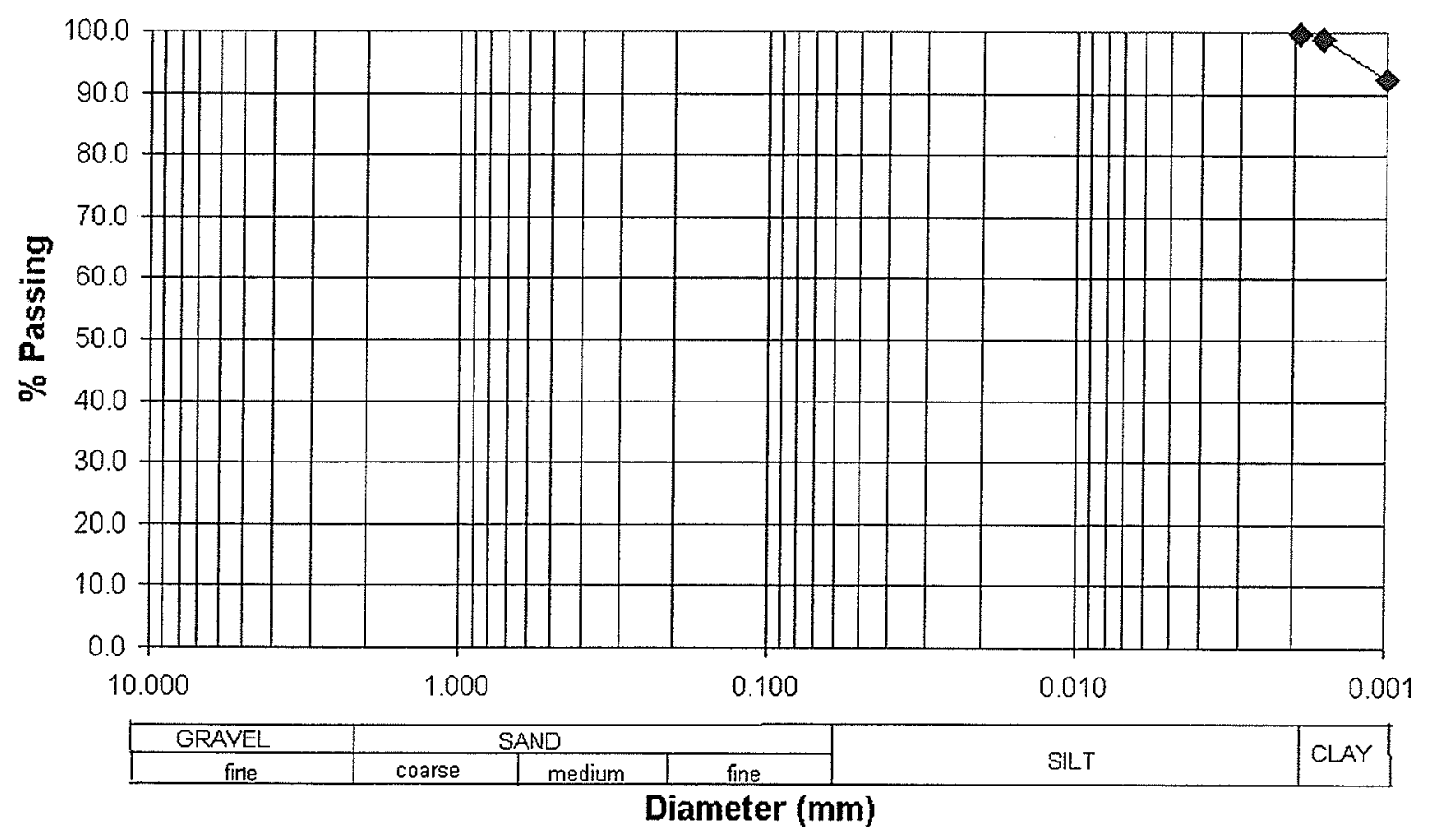

Figure 3.8. Hydrometer test result from section SS-036 at $9.5 \mathrm{~m}$ depth

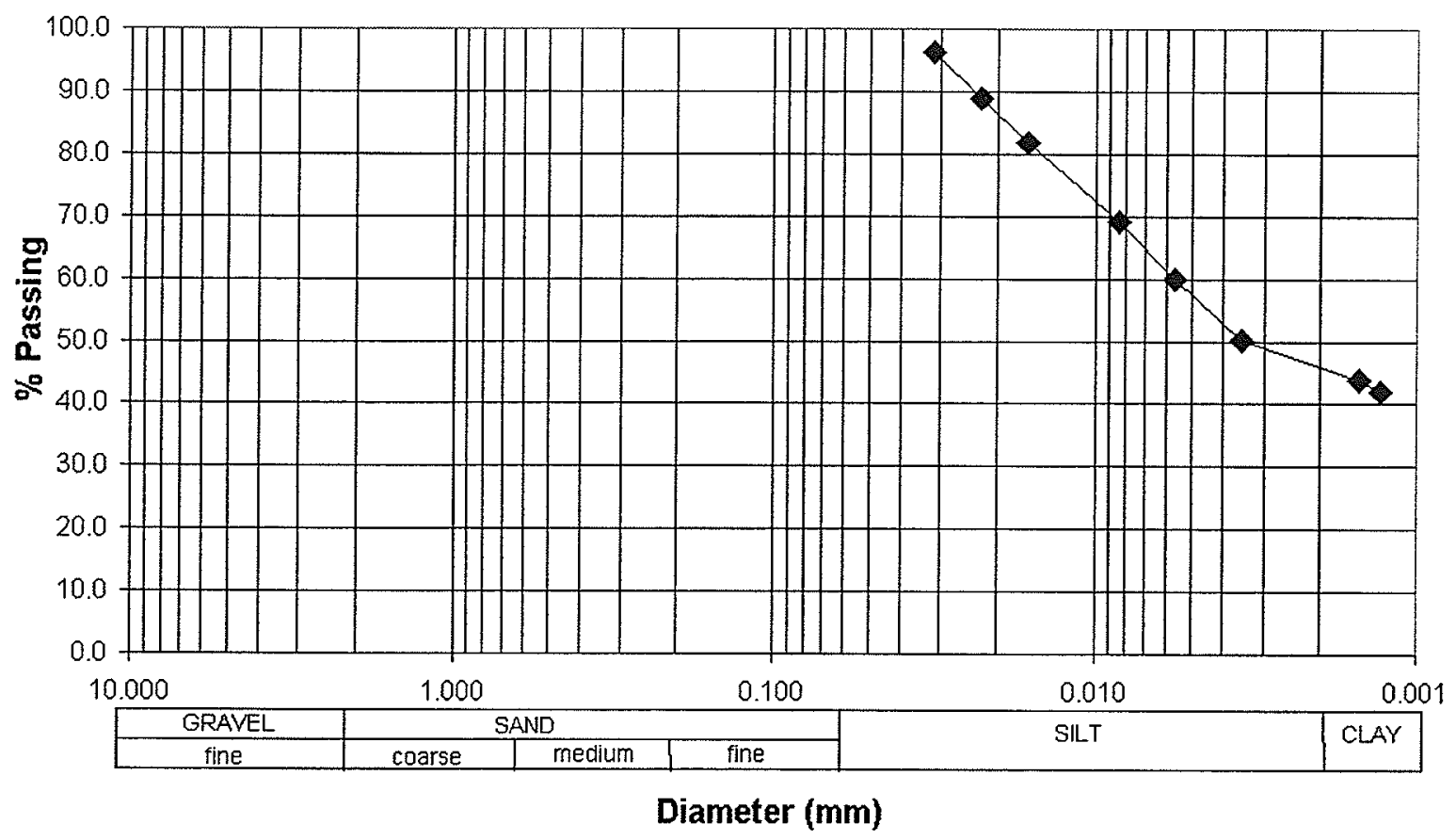

Figure 3.9. Hydrometer test result from section SS-040 at $4.5 \mathrm{~m}$ depth 


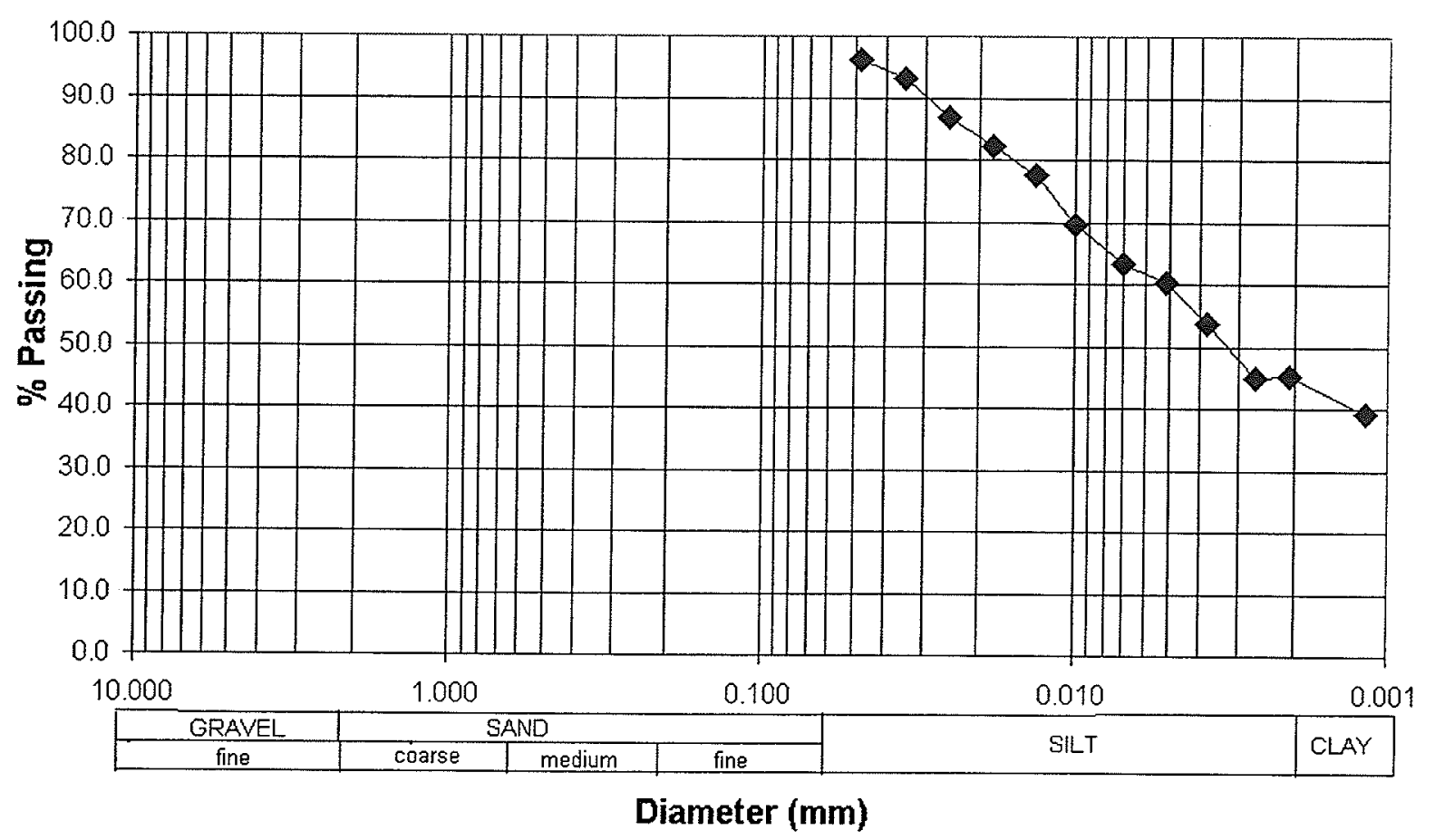

Figure 3.10. Hydrometer test result from section SS-040 at $5.1 \mathrm{~m}$ depth

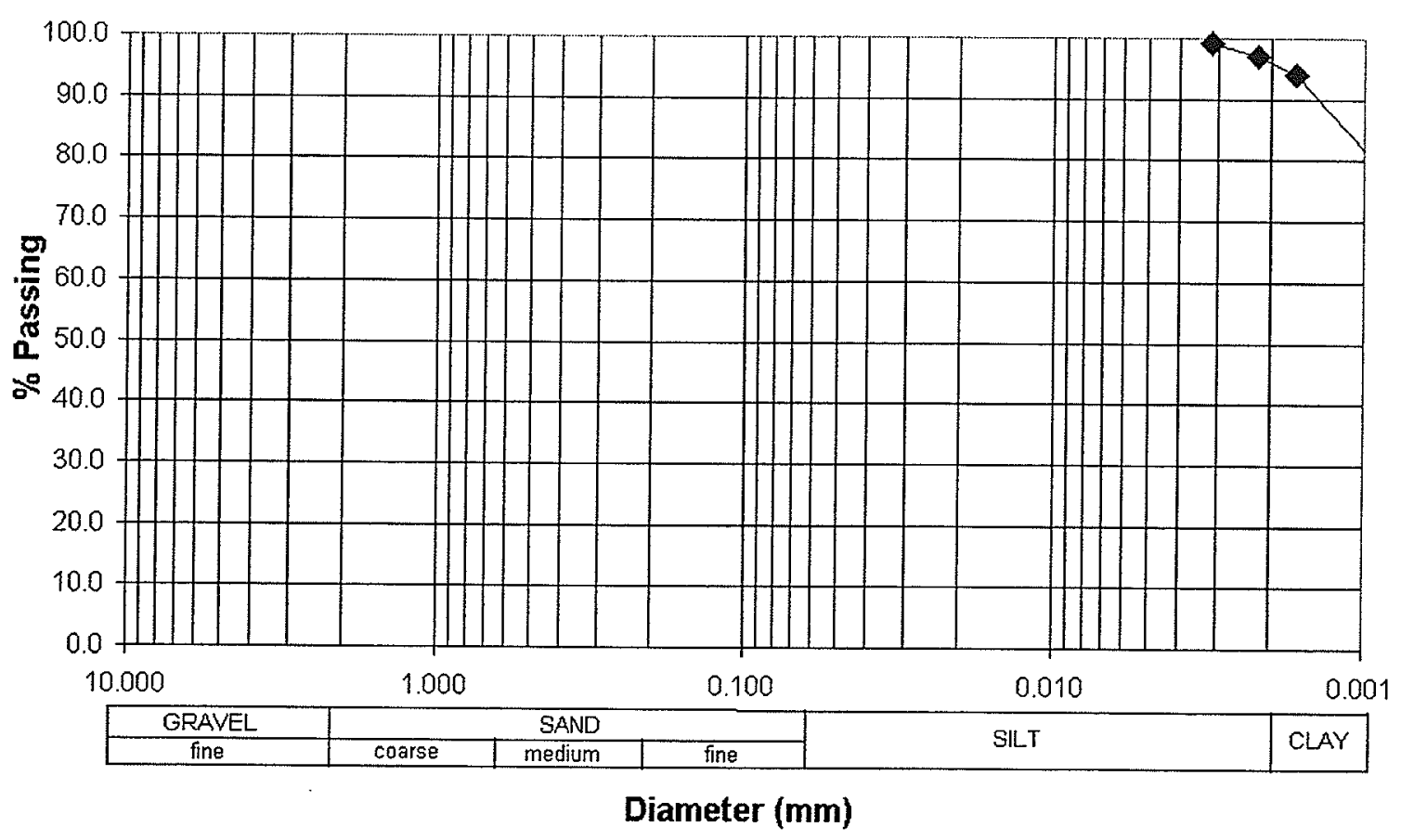

Figure 3.11. Hydrometer test result from section SS-040 at $8.4 \mathrm{~m}$ depth 


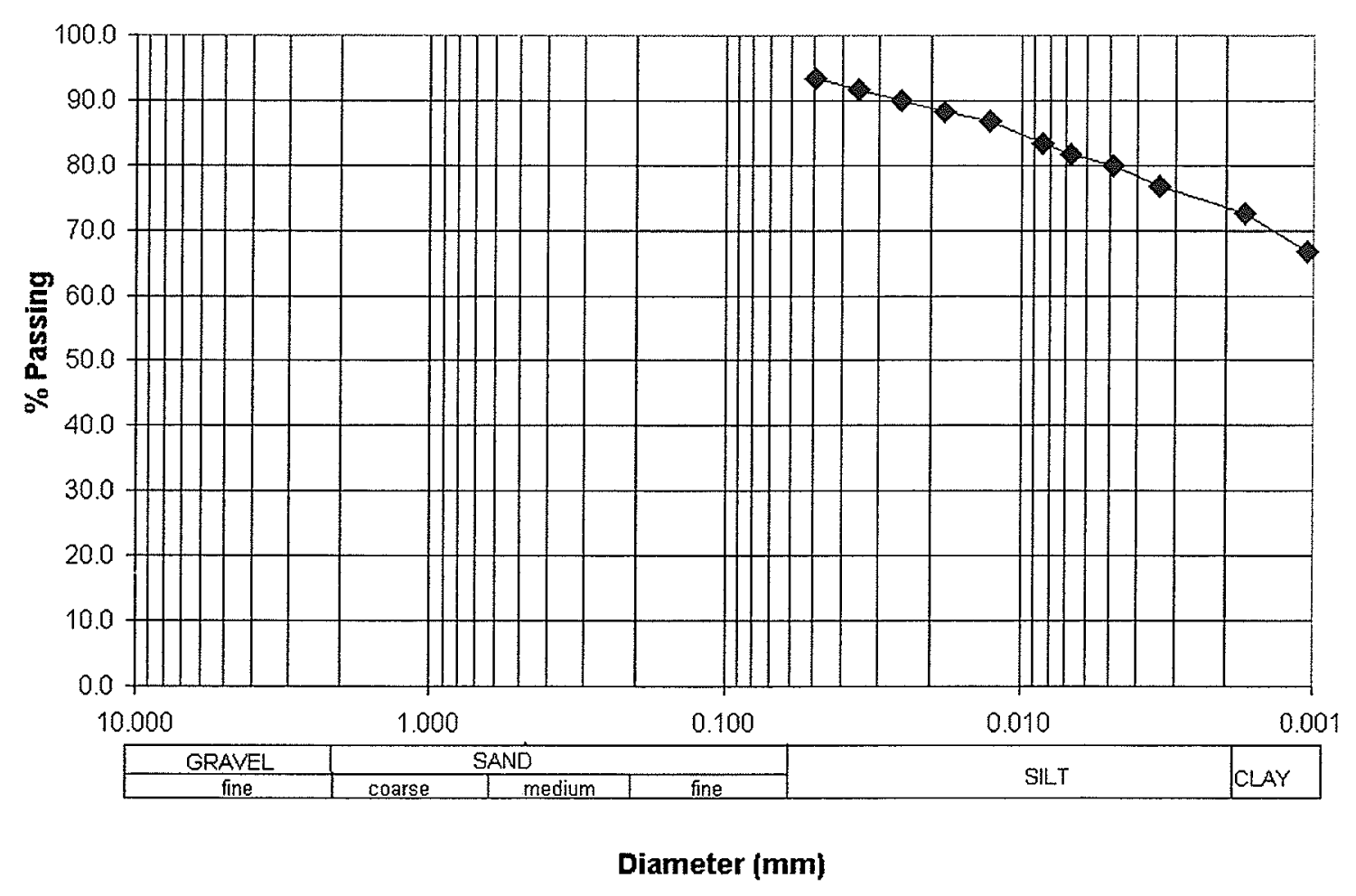

Figure 3.12. Hydrometer test result from section SS-040 at $9.4 \mathrm{~m}$ depth

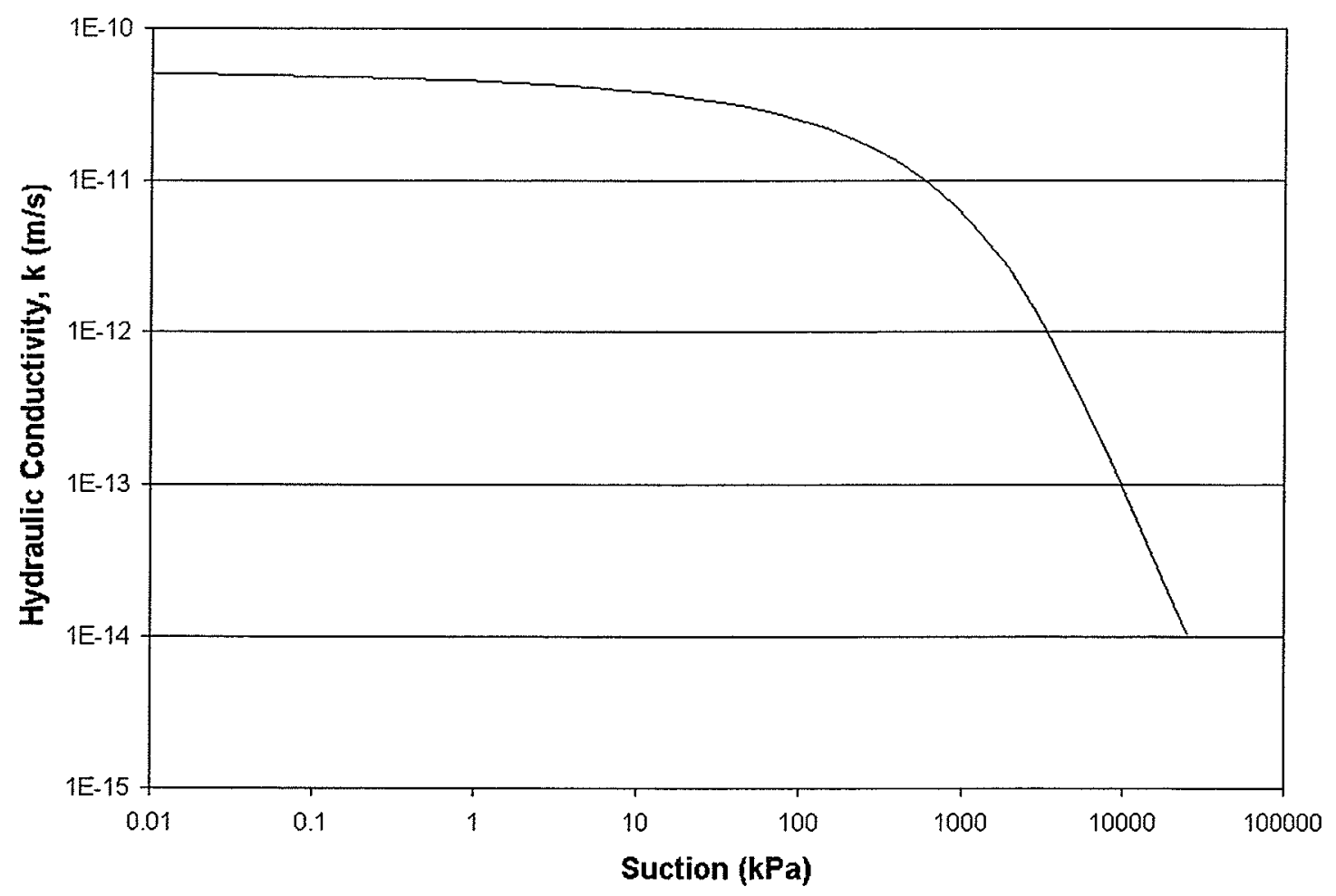

Figure 3.13. Estimation of unsaturated hydraulic conductivity curve 


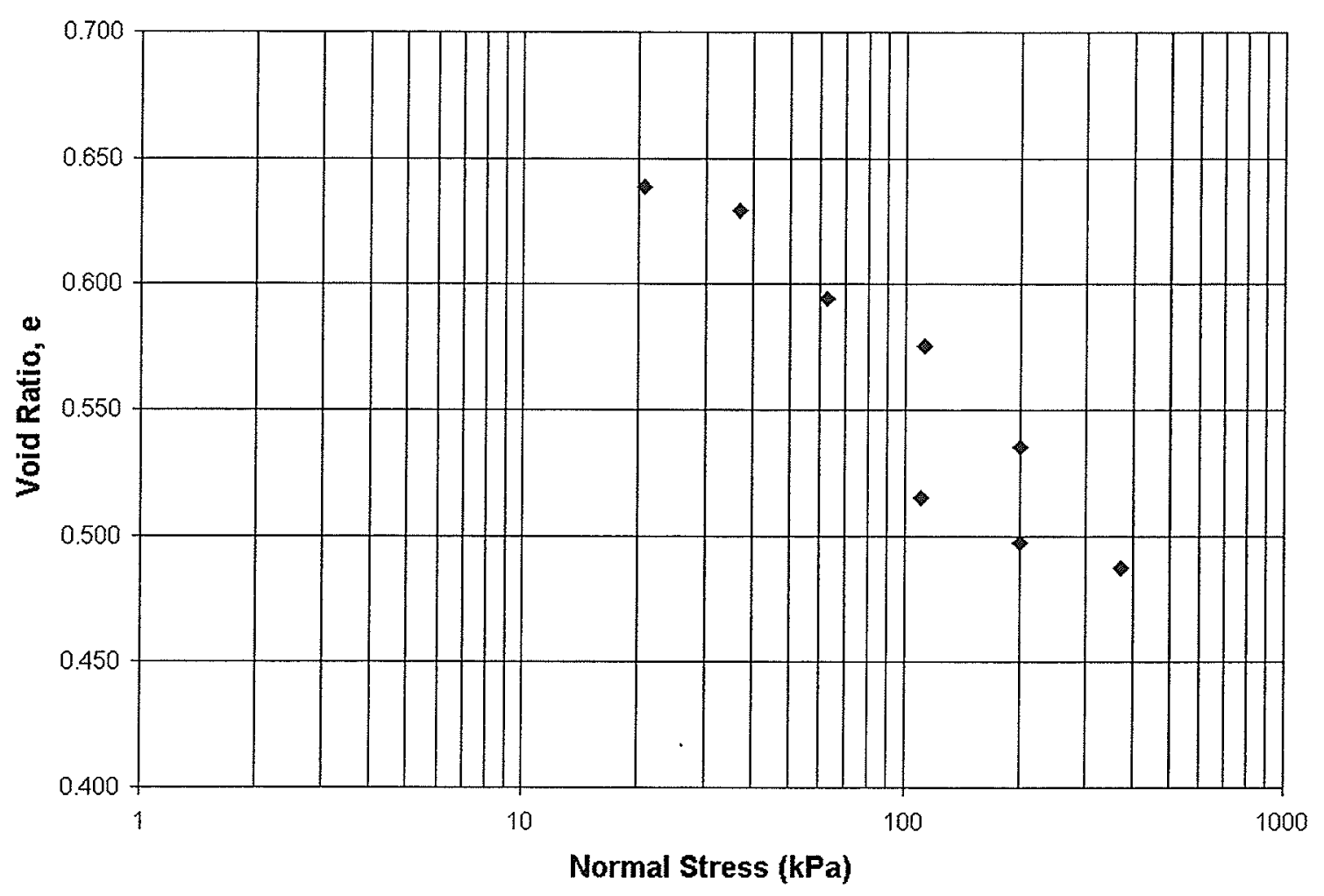

Figure 3.14. Oedometer test result from section SS-036 at $2.2 \mathrm{~m}$ depth

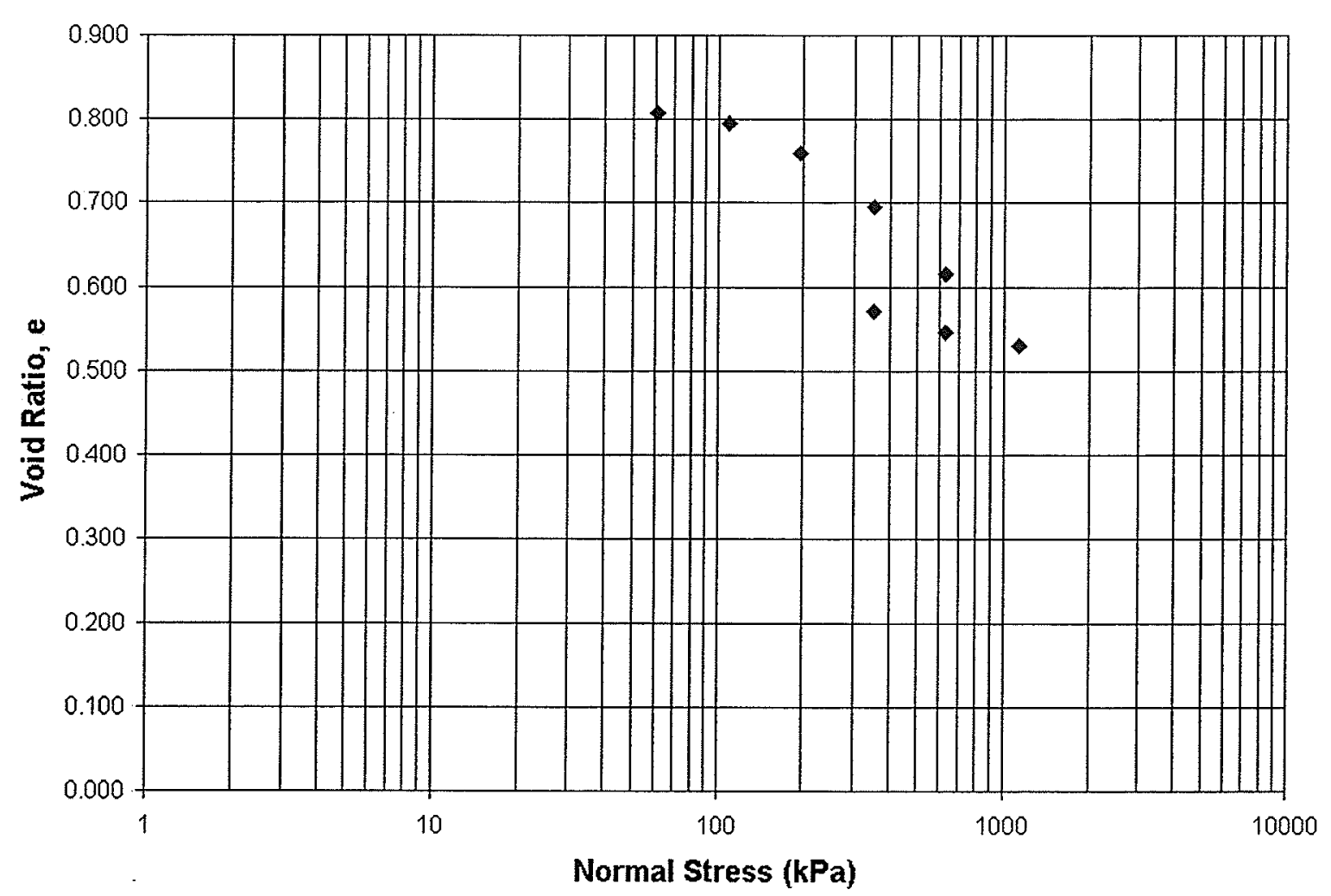

Figure 3.15. Oedometer test result from section SS-036 at $4.1 \mathrm{~m}$ depth 


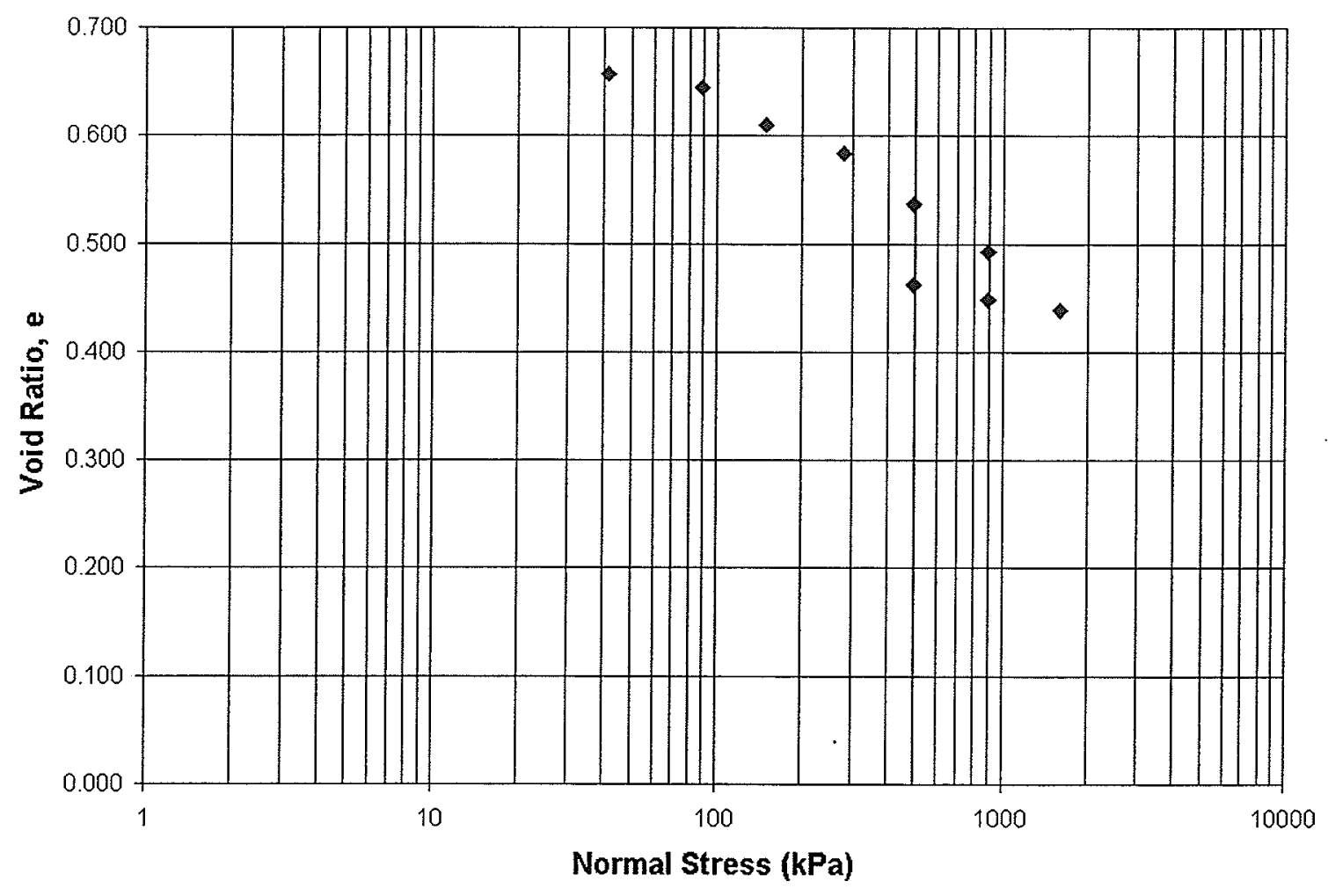

Figure 3.16. Oedometer test result from section SS-036 at $6.4 \mathrm{~m}$ depth

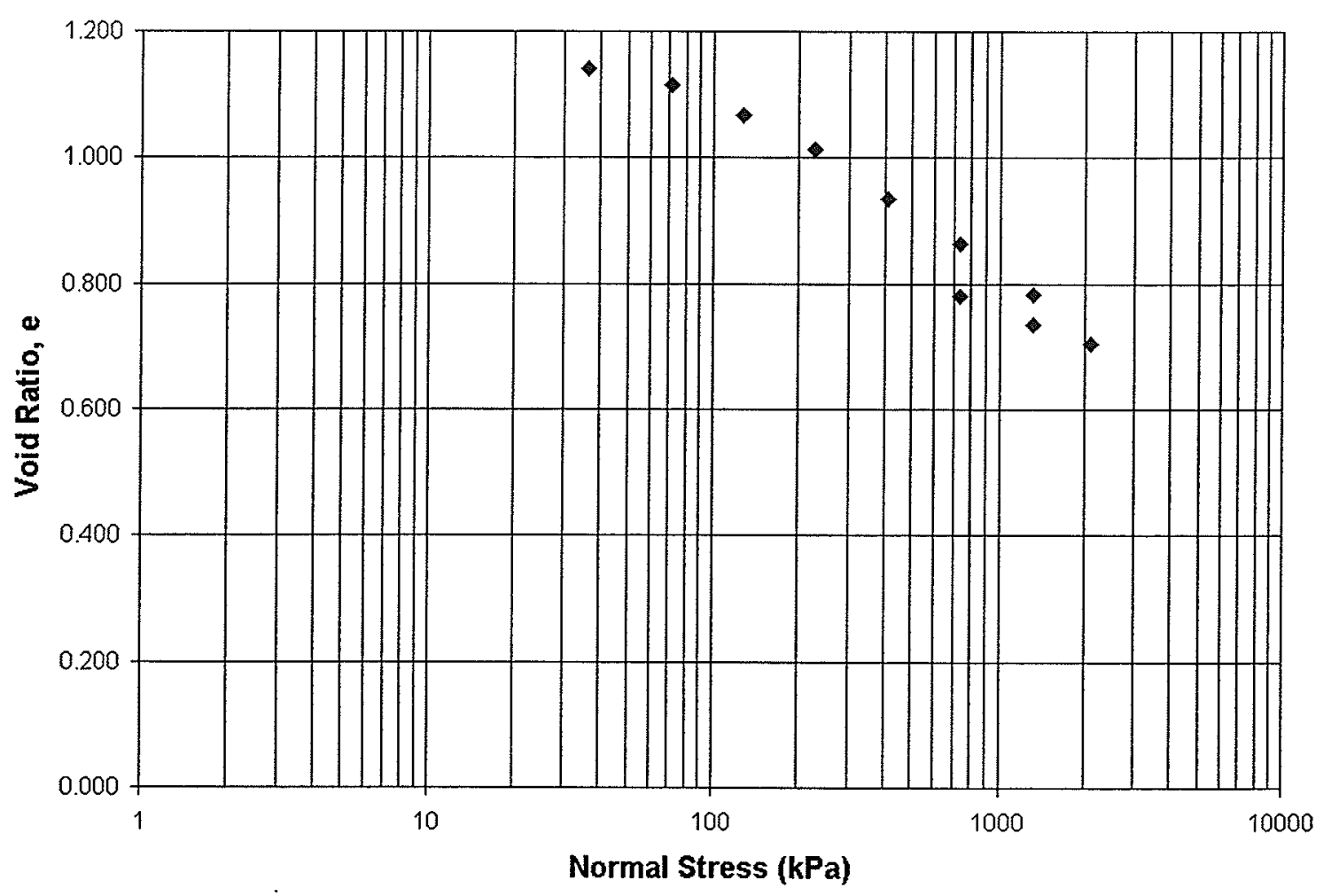

Figure 3.17. Oedometer test result from section SS-036 at $8.4 \mathrm{~m}$ depth 


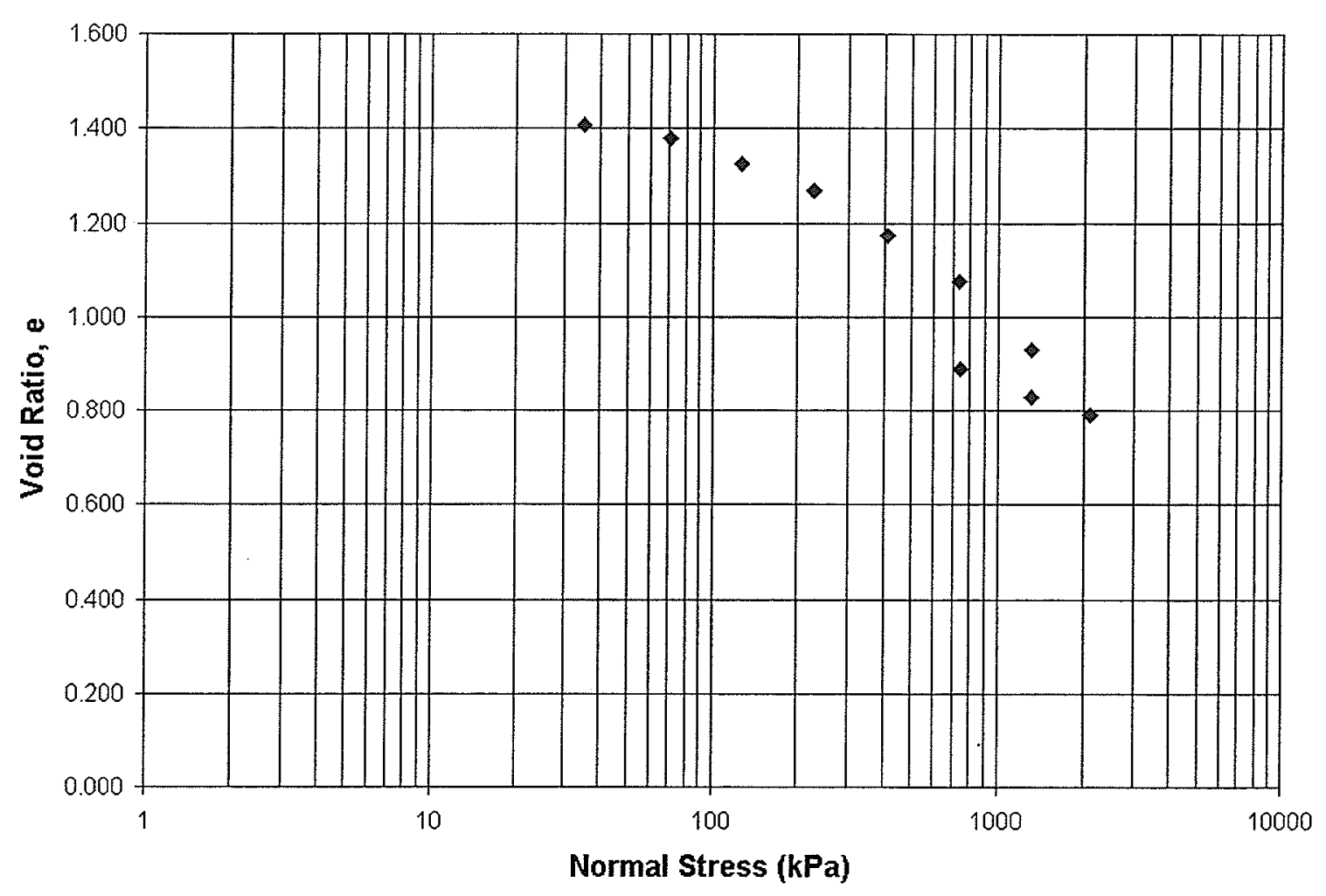

Figure 3.18. Oedometer test result from section SS-036 at $10.0 \mathrm{~m}$ depth

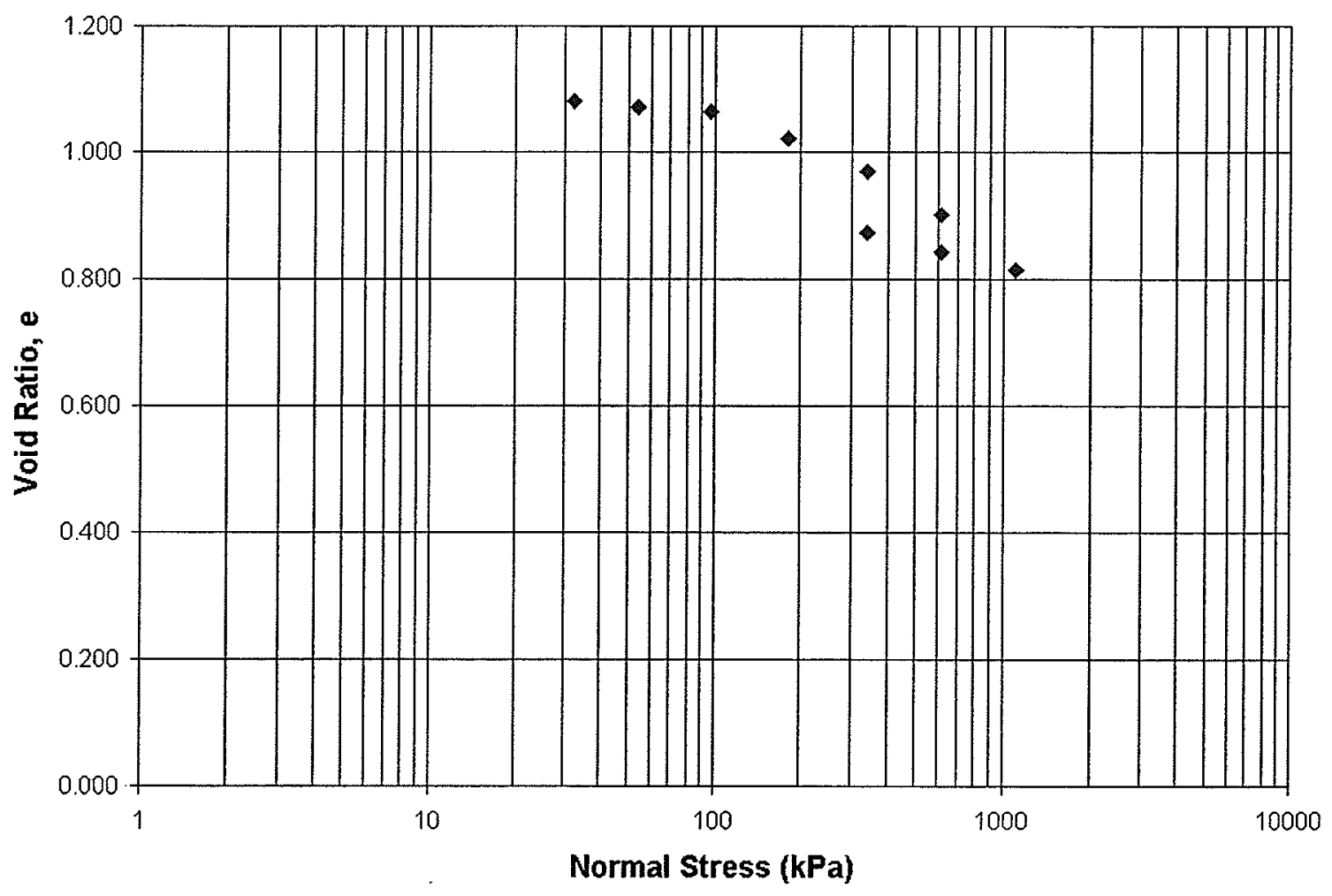

Figure 3.19. Oedometer test result from section SS-036 at $12.1 \mathrm{~m}$ depth 


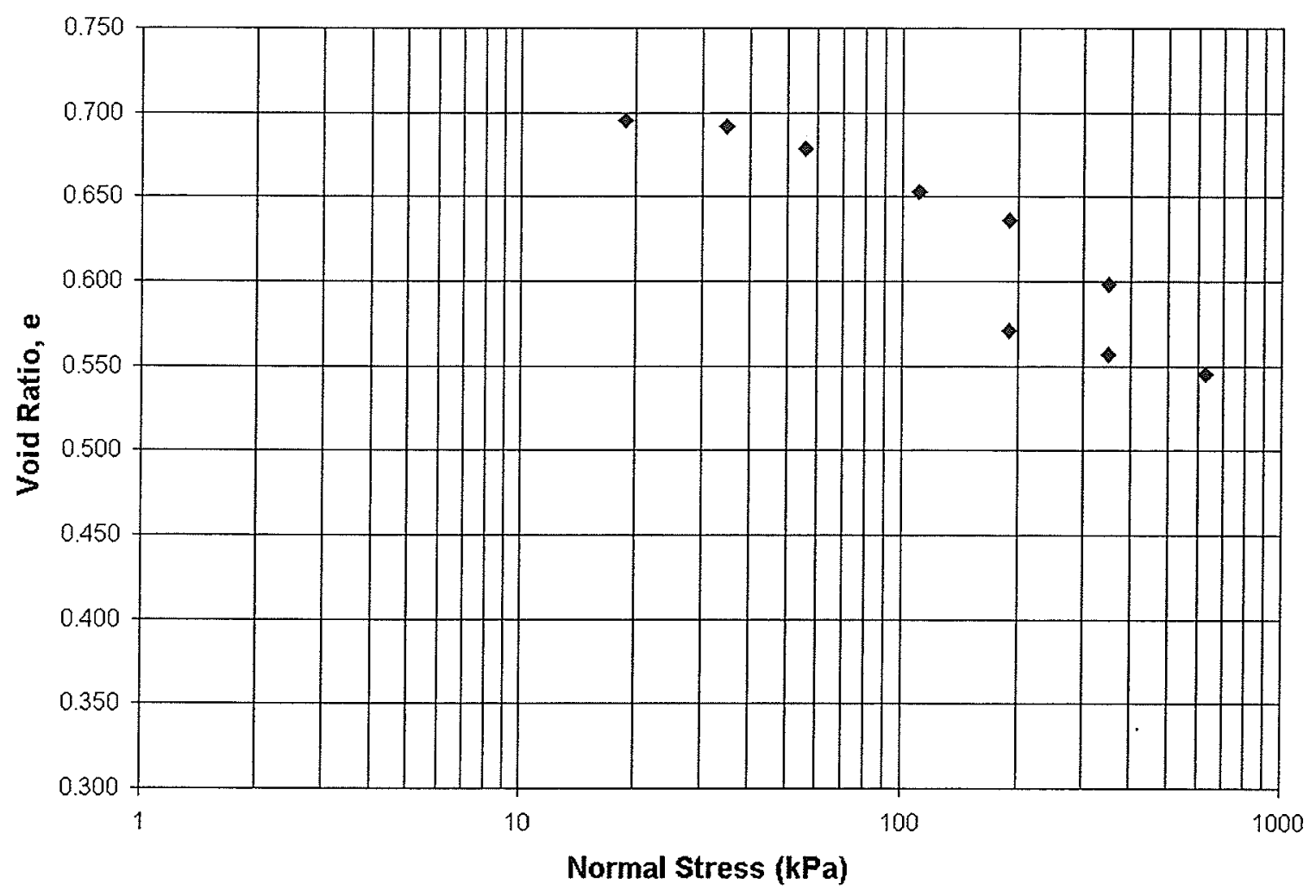

Figure 3.20. Oedometer test result from section SS-040 at $2.2 \mathrm{~m}$ depth

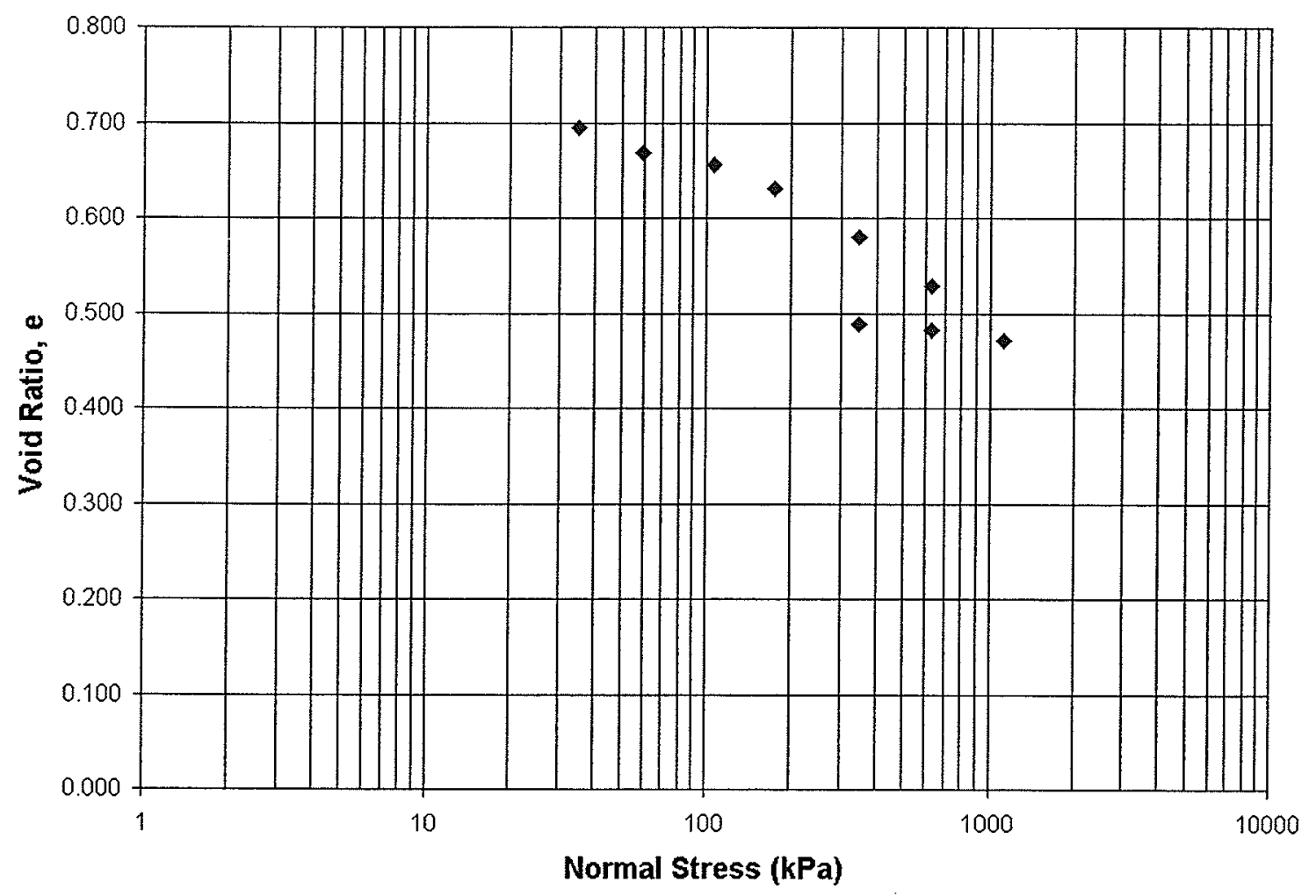

Figure 3.21. Oedometer test result from section SS-040 at $4.0 \mathrm{~m}$ depth 


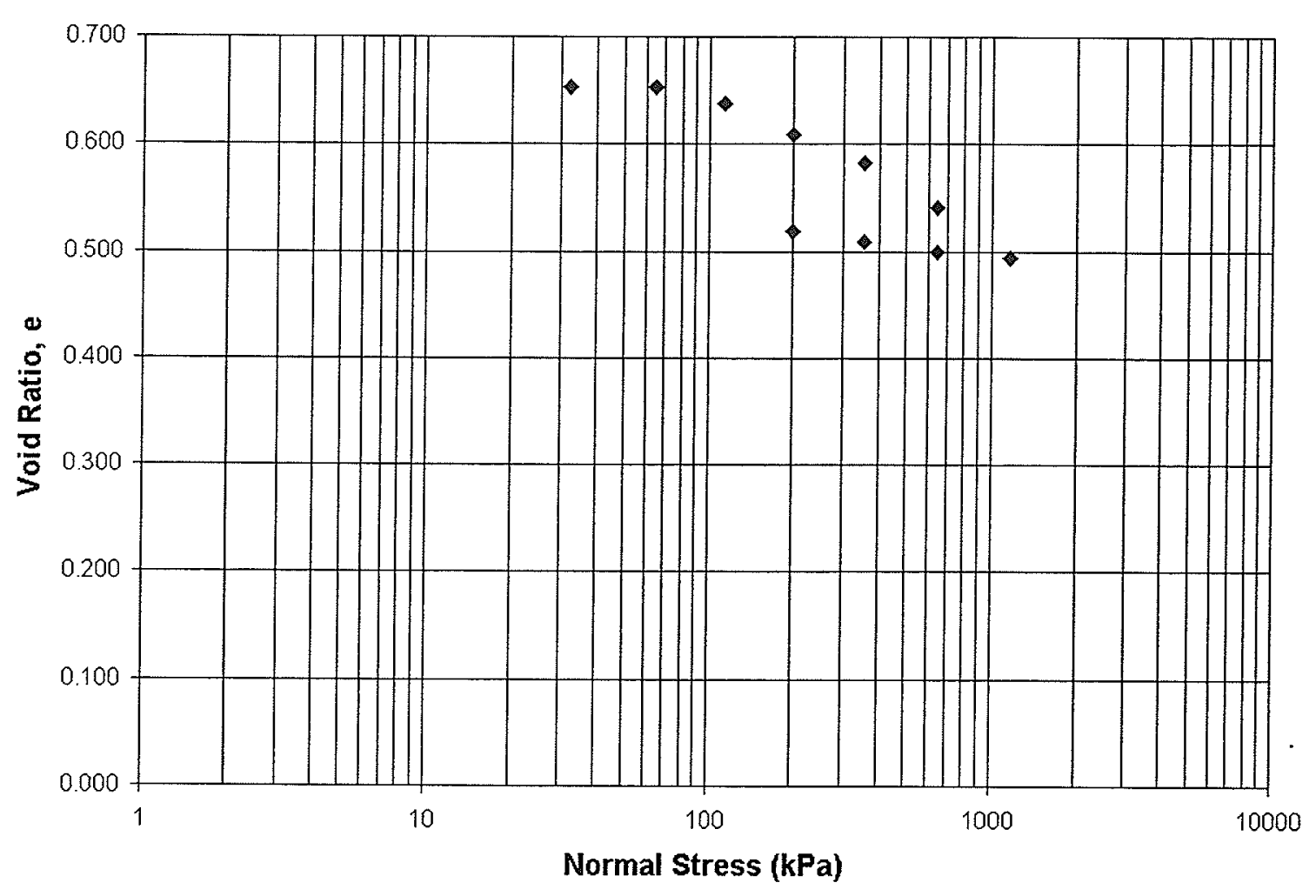

Figure 3.22. Oedometer test result from section SS-040 at $6.3 \mathrm{~m}$ depth

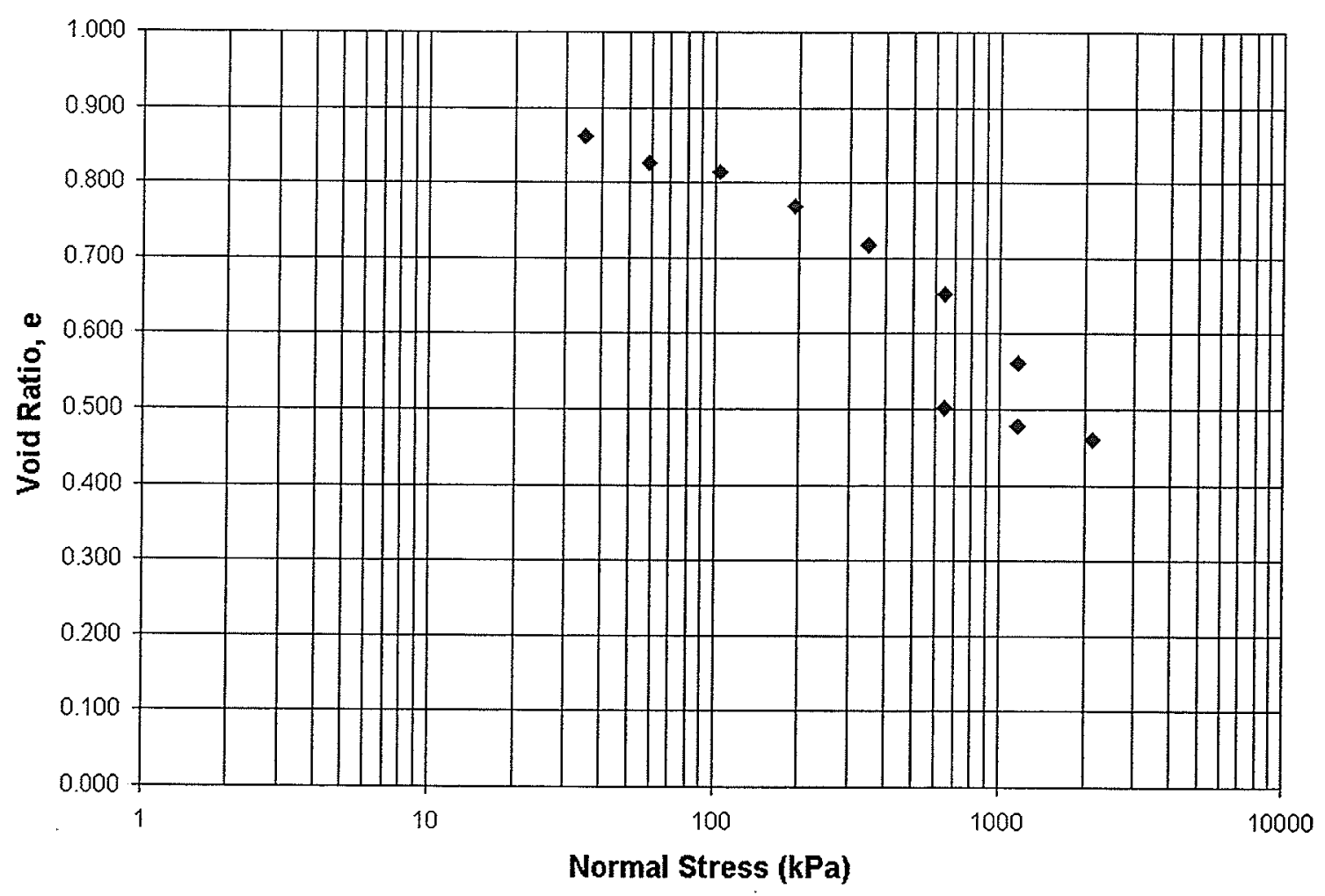

Figure 3.23. Oedometer test result from section SS-040 at $8.0 \mathrm{~m}$ depth 


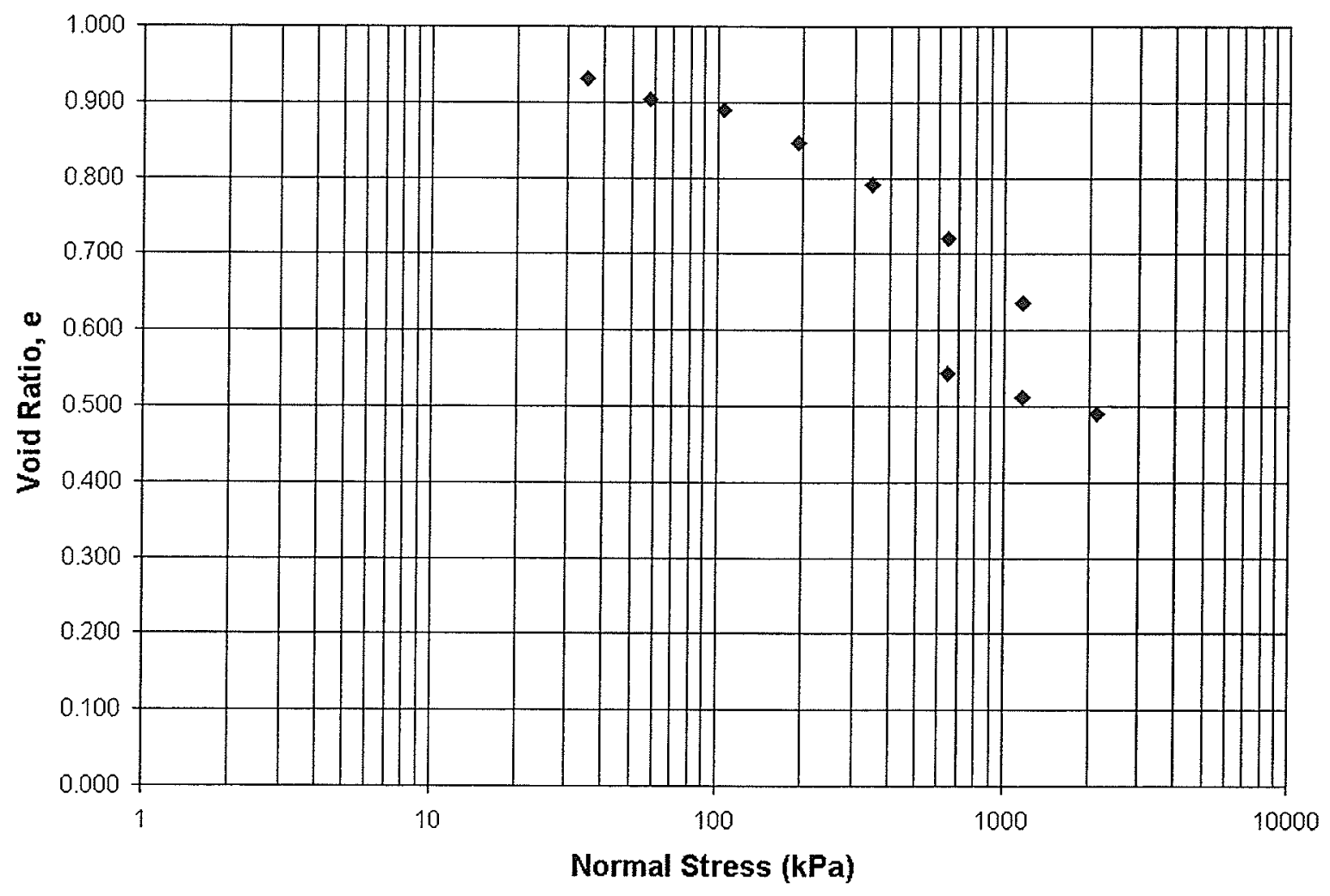

Figure 3.24. Oedometer test result from section SS-040 at $10.0 \mathrm{~m}$ depth

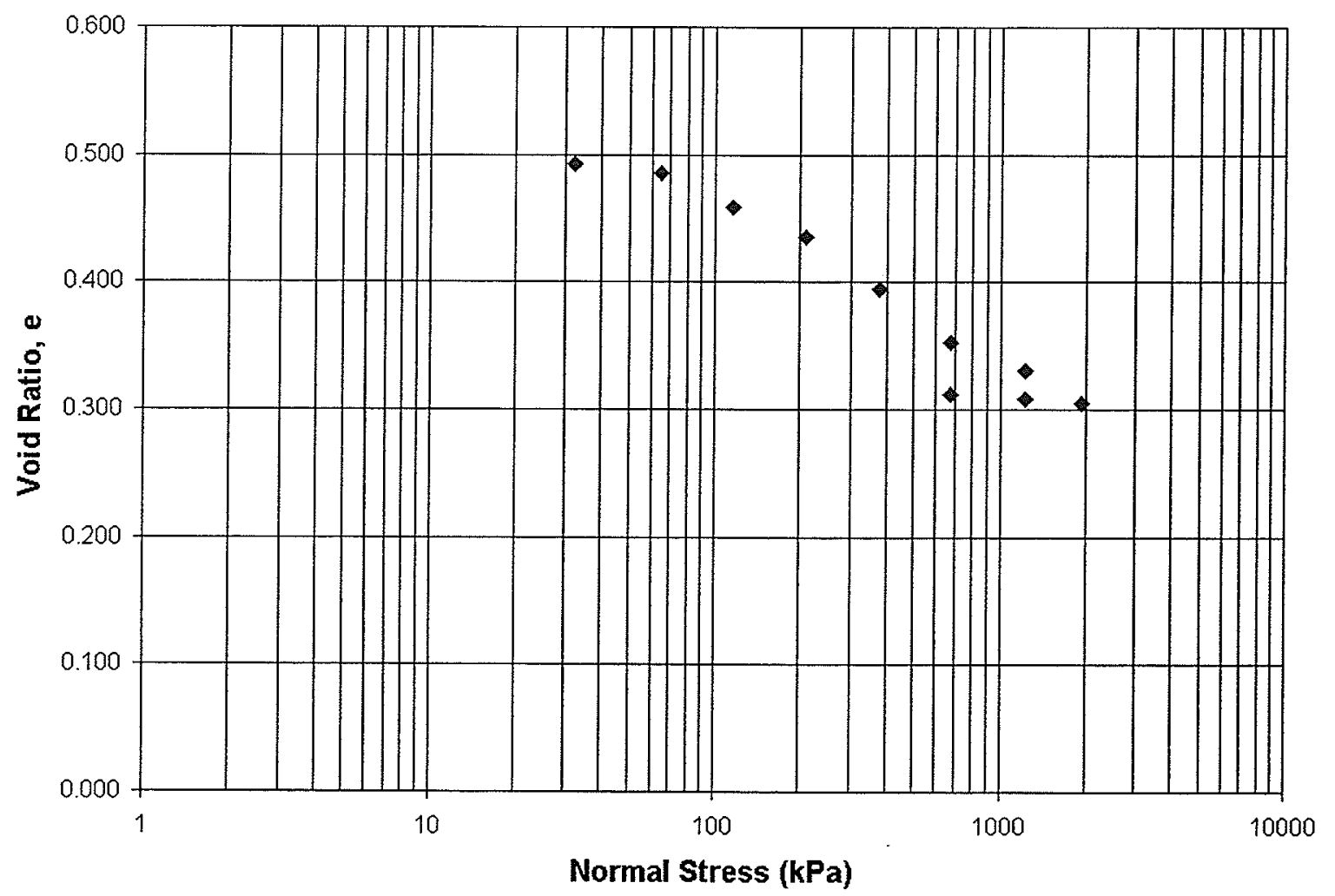

Figure 3.25. Oedometer test result from section SS-040 at $11.5 \mathrm{~m}$ depth 

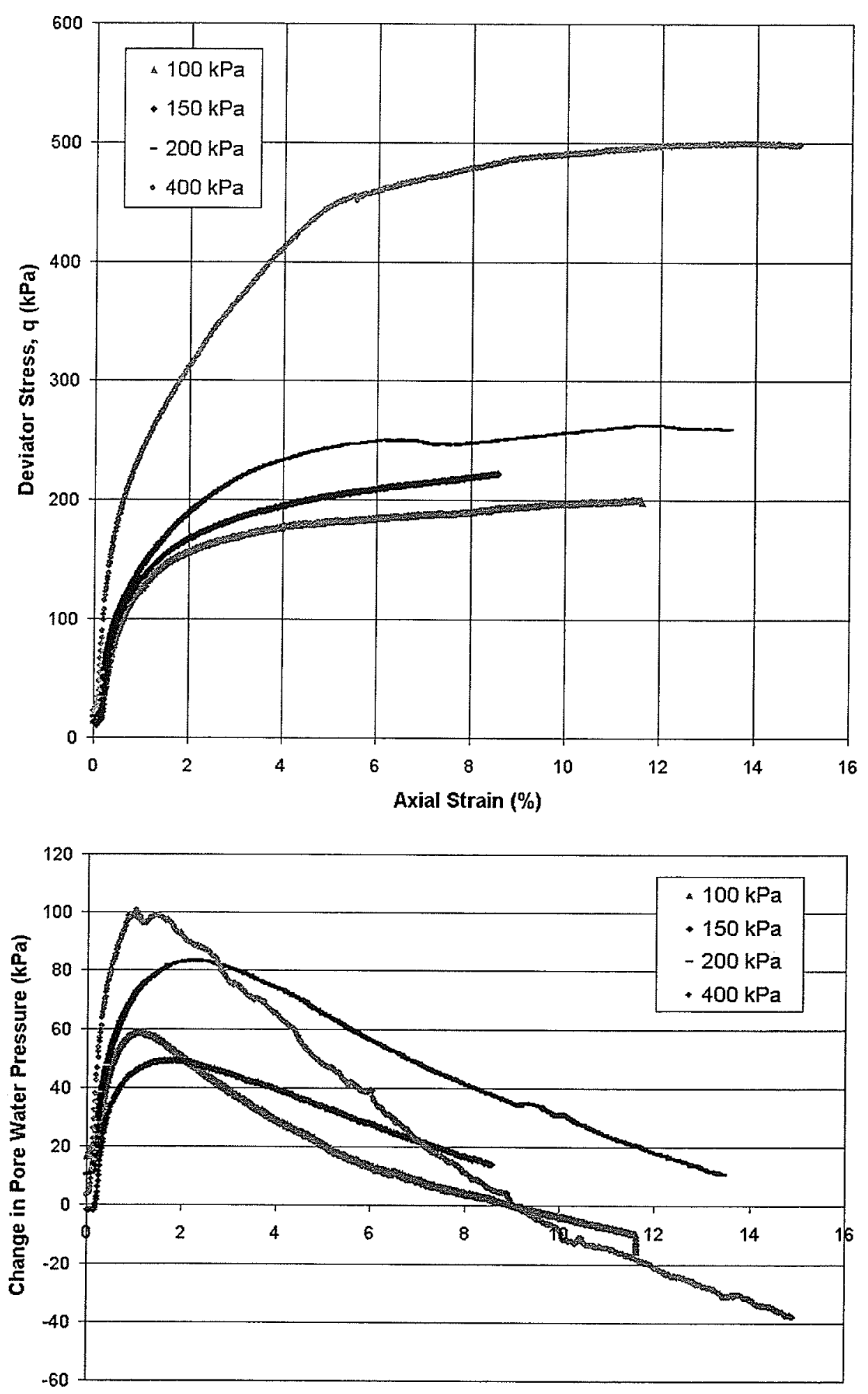

Axial Strain (\%)

Figure 3.26. CIŪ triaxial test results for section SS-036 in dyke material showing deviator stress and change in pore water pressure vs. axial strain 
N

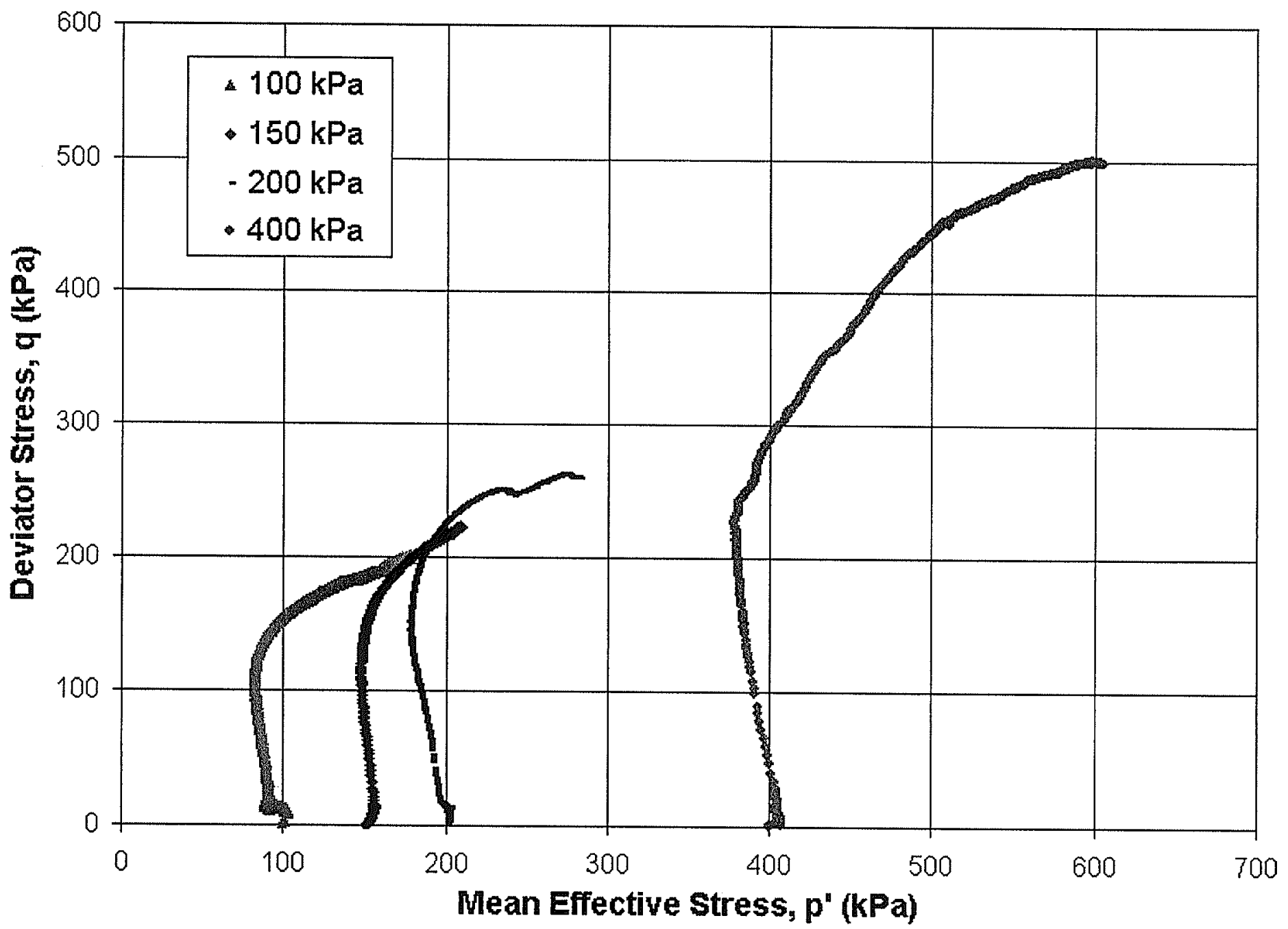

Figure 3.27. CIŪ triaxial test results for section SS-036 in dyke material showing deviator stress vs. mean effective stress 

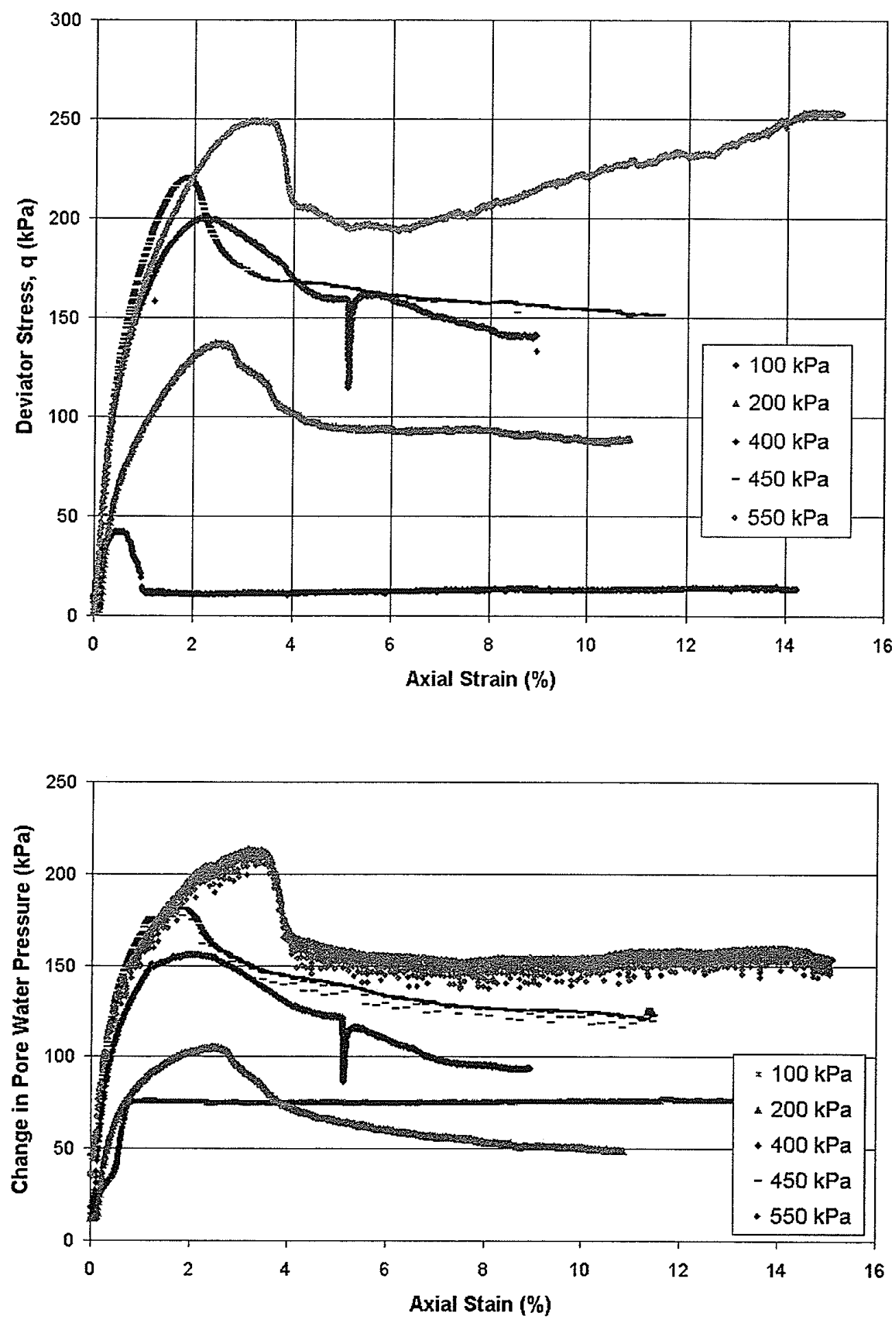

Figure 3.28. CIŪ triaxial test results for section SS-036 in foundation material showing deviator stress and change in pore water pressure vs. axial strain 


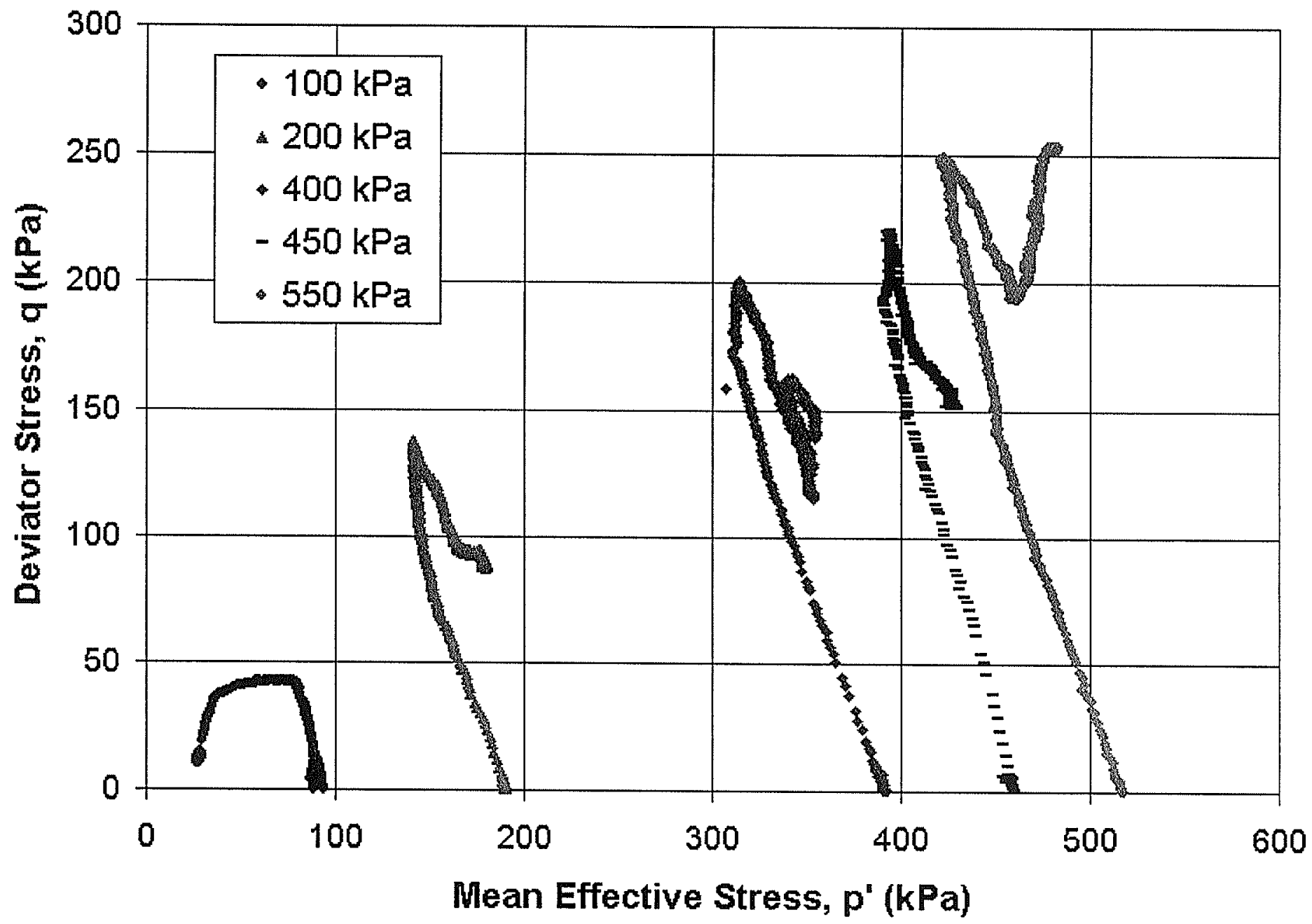

Figure 3.29. CIŪ triaxial test results for section SS-036 in foundation material showing deviator stress vs. mean effective stress 

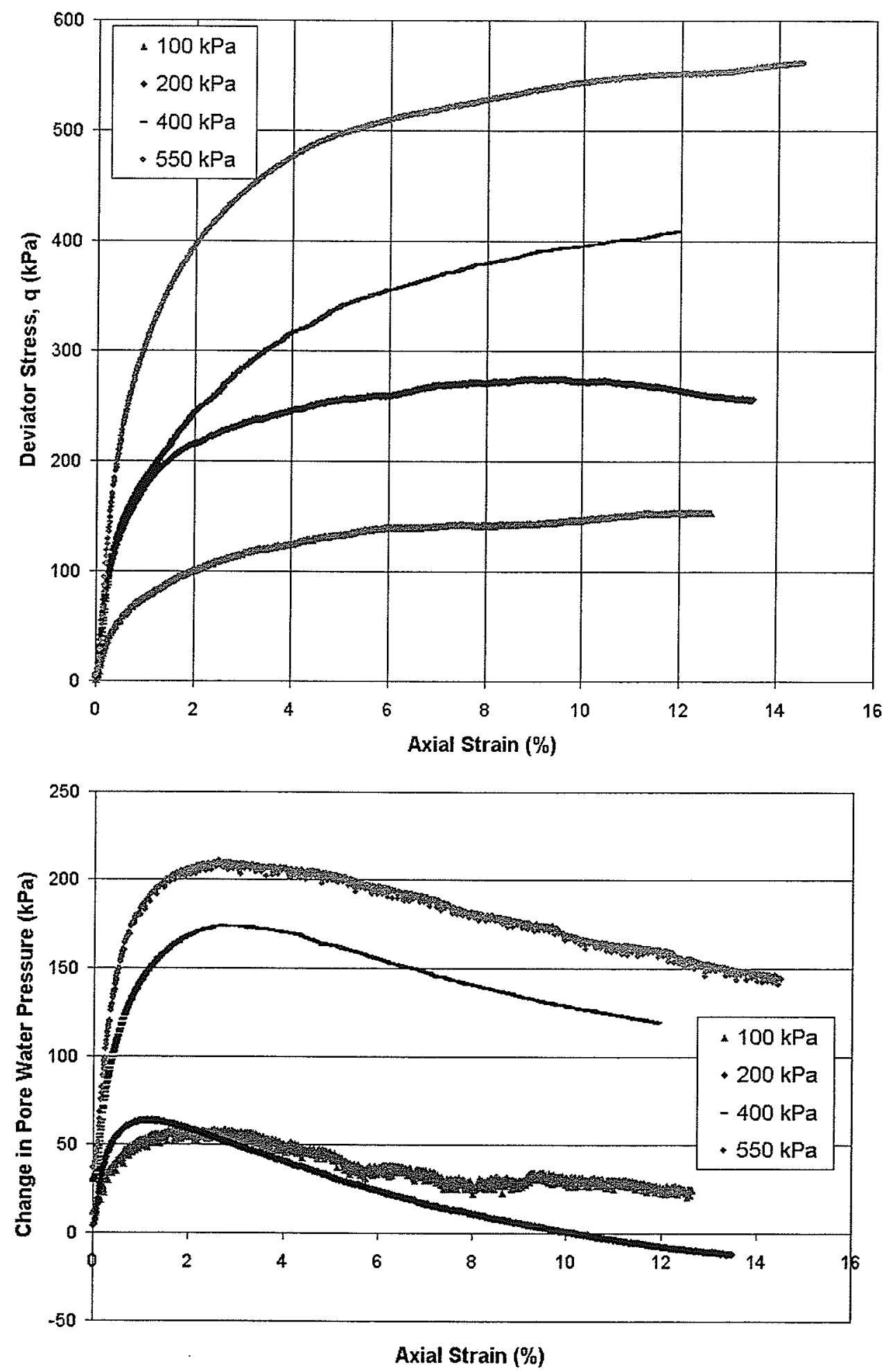

Figure 3.30. CIŪ triaxial test results for section SS-040 in dyke material showing deviator stress and change in pore water pressure vs. axial strain 


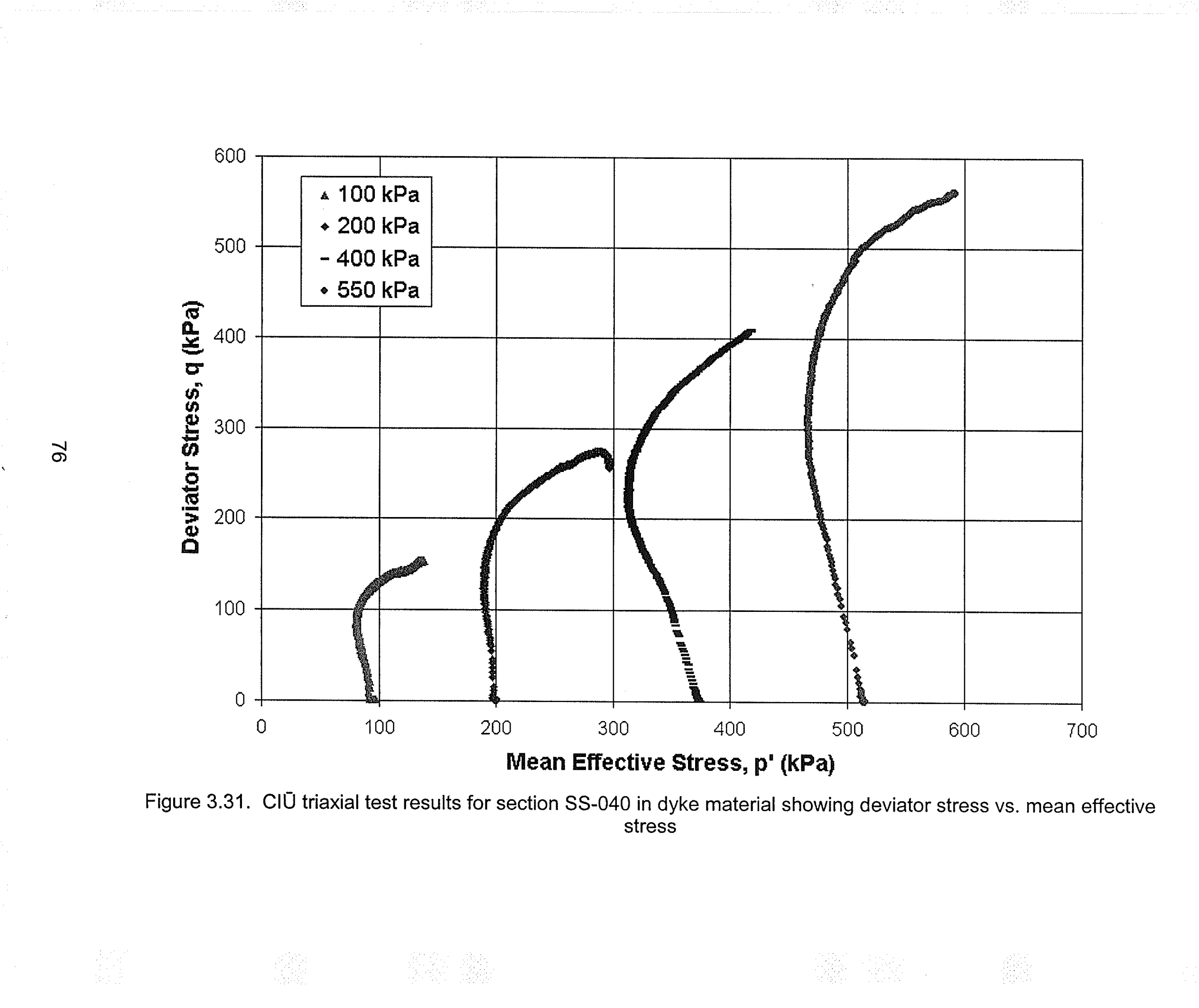



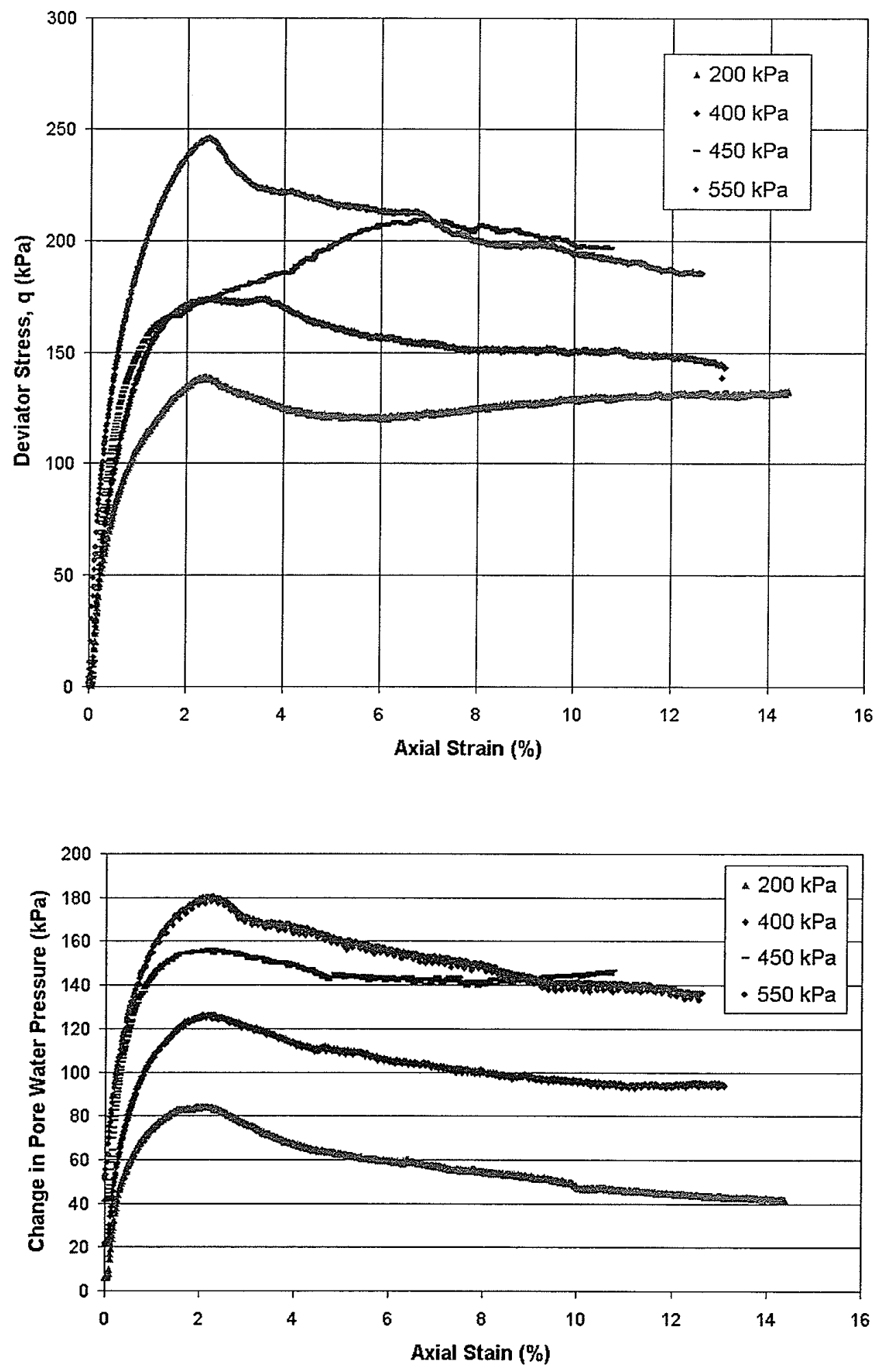

Figure 3.32. CIU triaxial test results for section SS-040 in foundation material showing deviator stress and change in pore water pressure vs. axial strain 


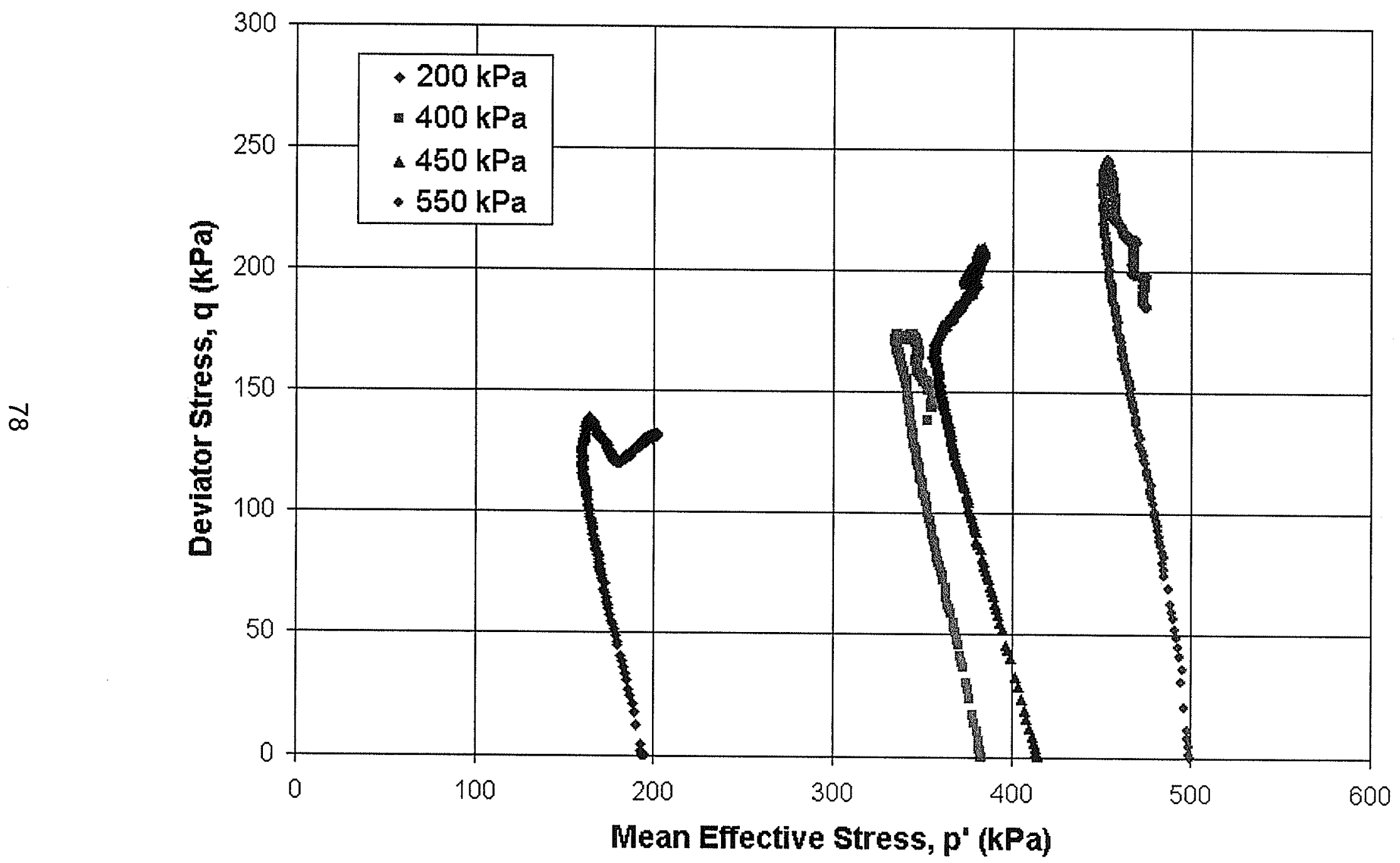

Figure 3.33. CIU triaxial test results for section SS-040 in foundation material showing deviator stress vs. mean effective stress 
a) Normalized by Preconsolidation Pressure

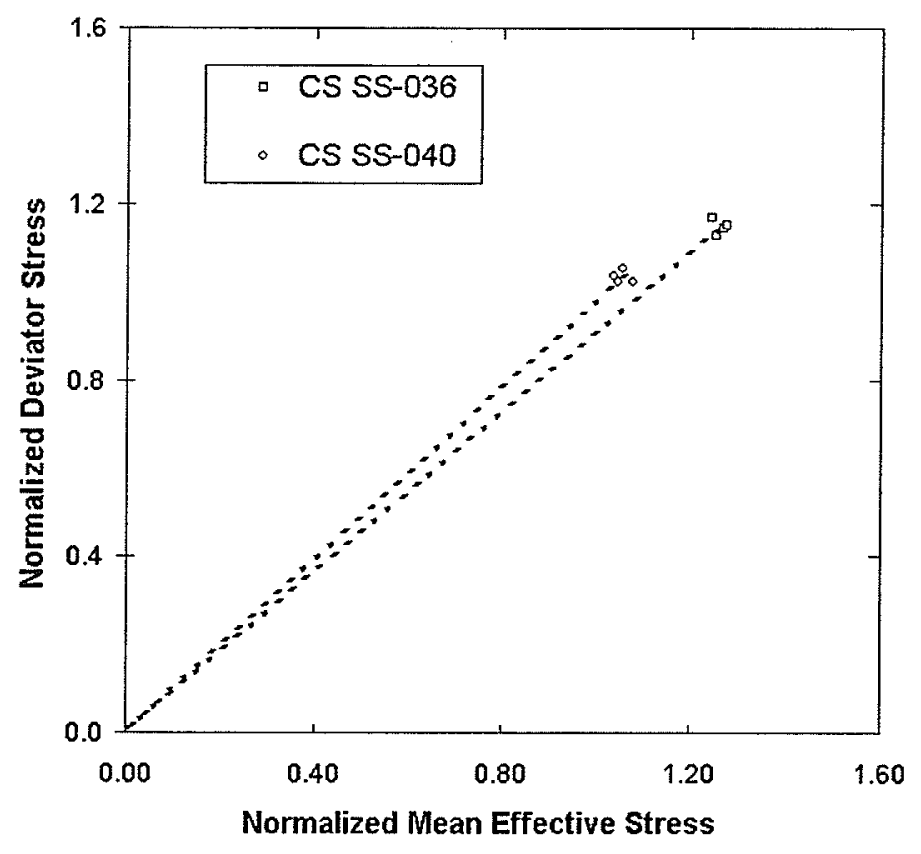

b) Normalized by Consolidation Pressure

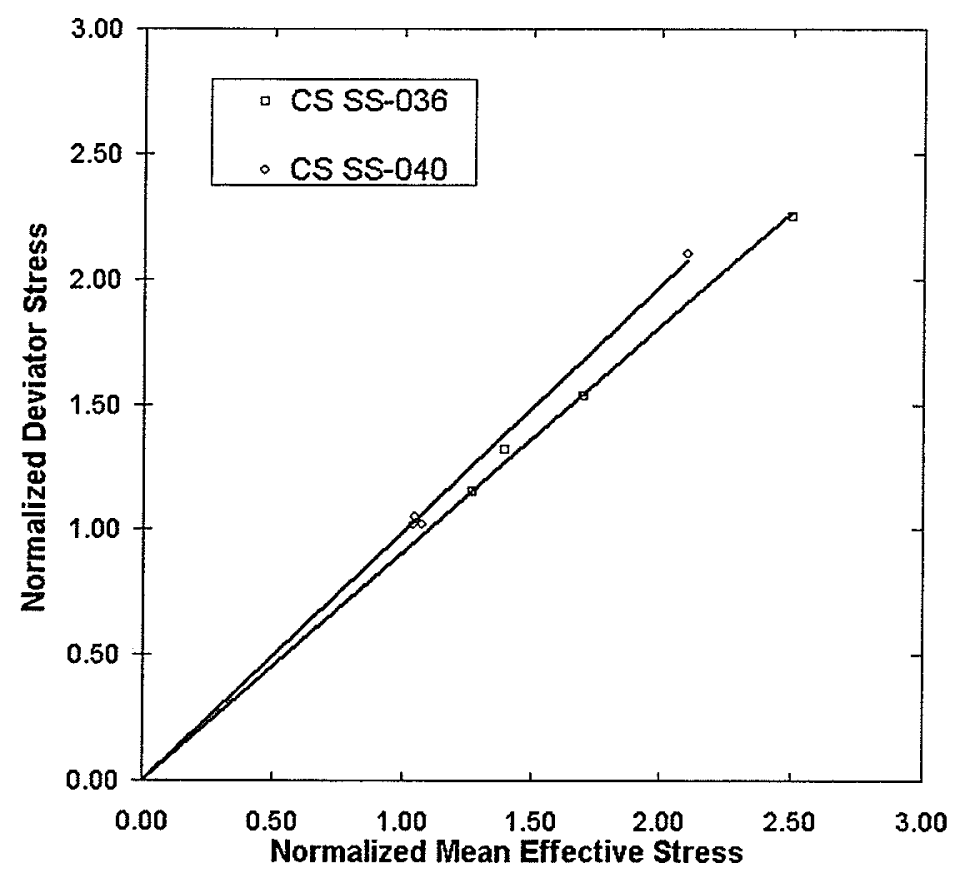

Figure 3.34. Normalized plots of deviator stress vs. mean effective stress for dyke material (at critical state) 
a) Normalized by Preconsolidation Pressure

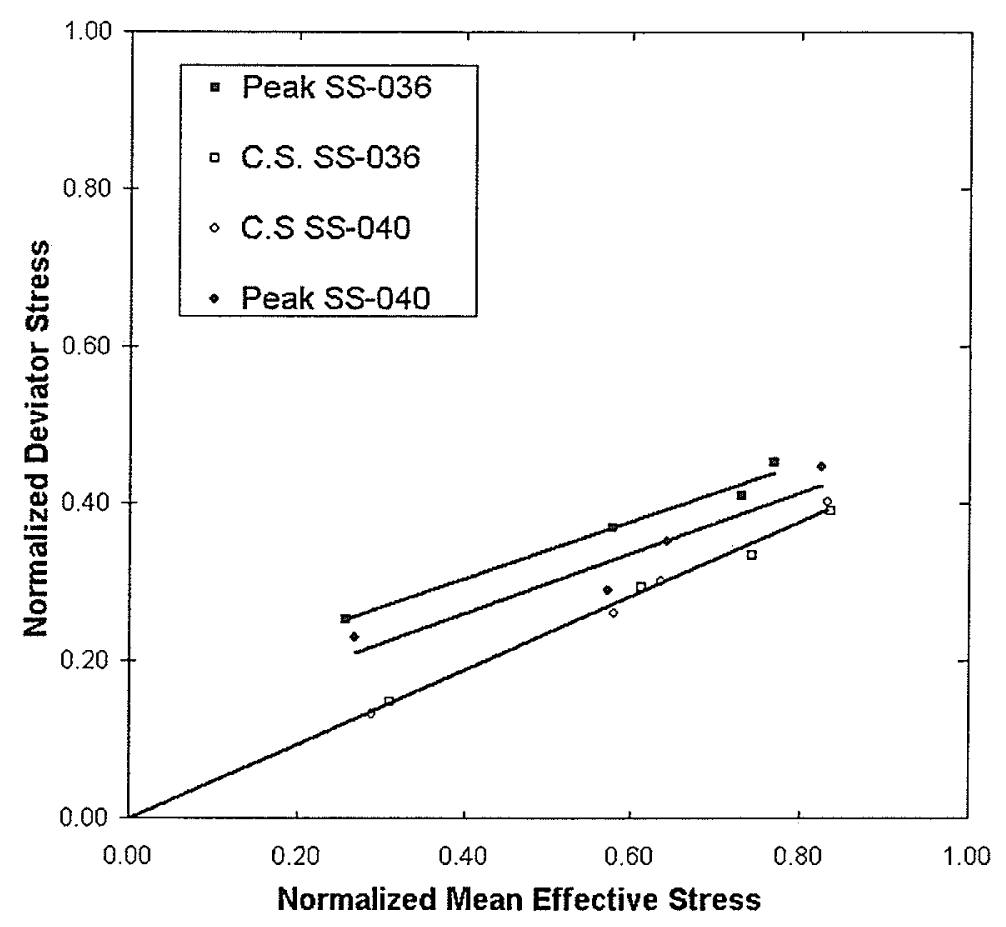

b) Normalized by Consolidation Pressure

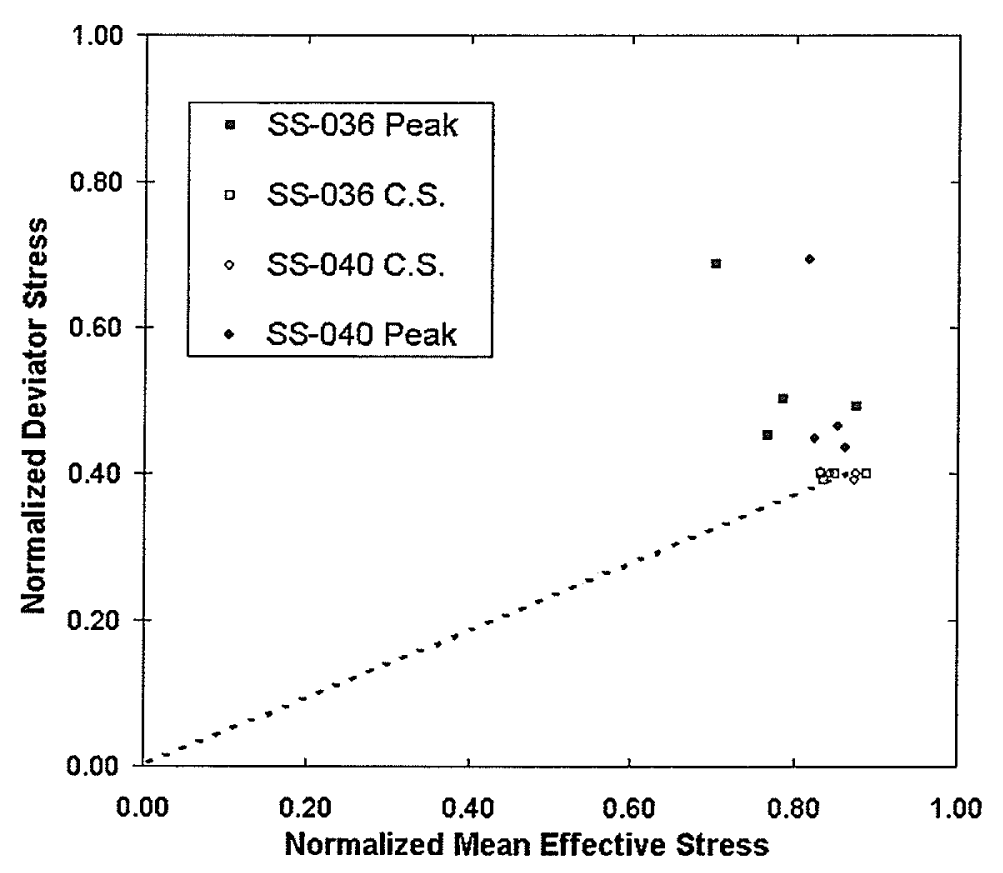

Figure 3.35. Normalized plots of deviator stress vs. mean effective stress for foundation material 


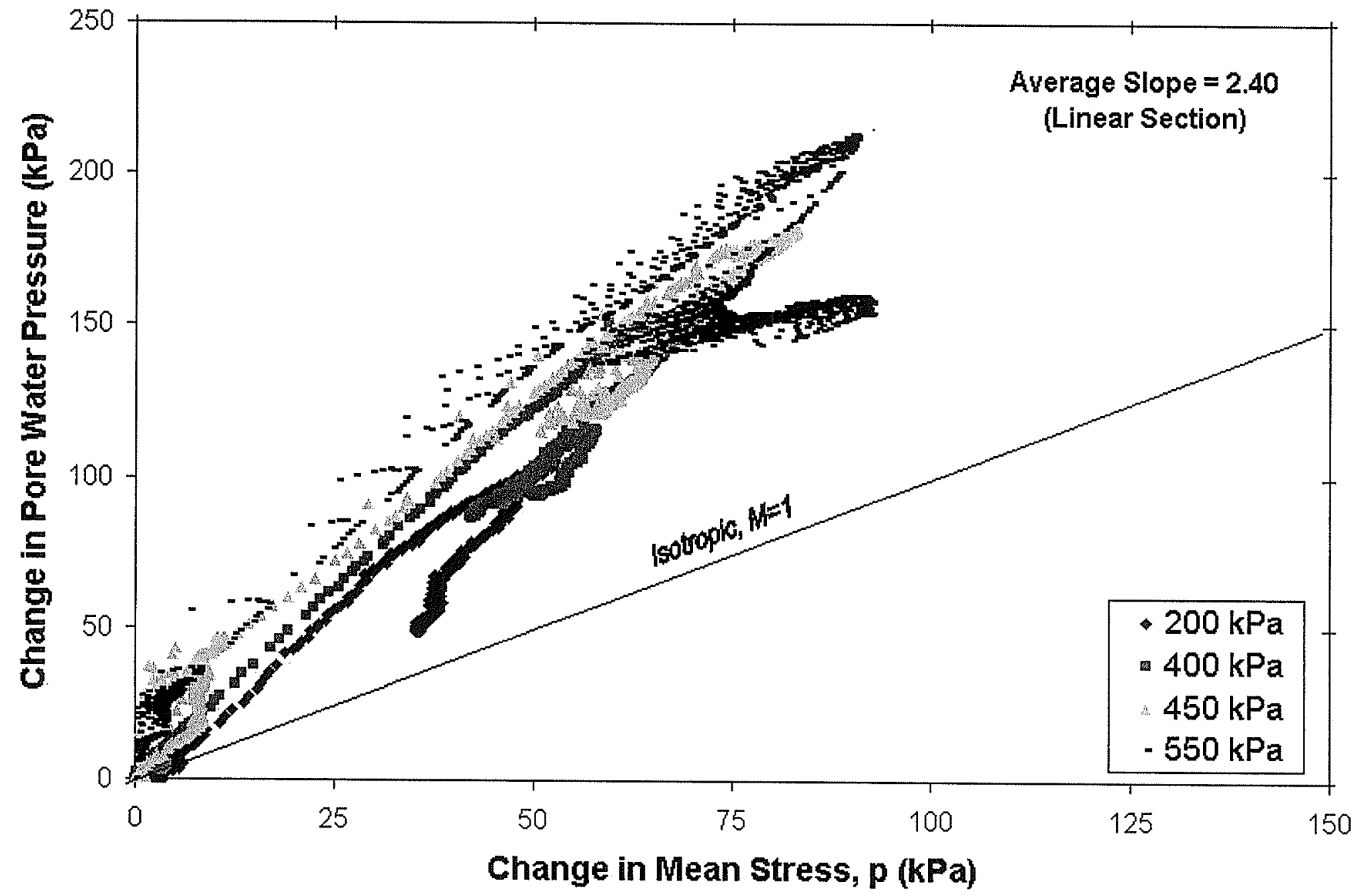

Figure 3.36. Change in pore water pressure vs. change in mean stress for foundation material at section SS-036 


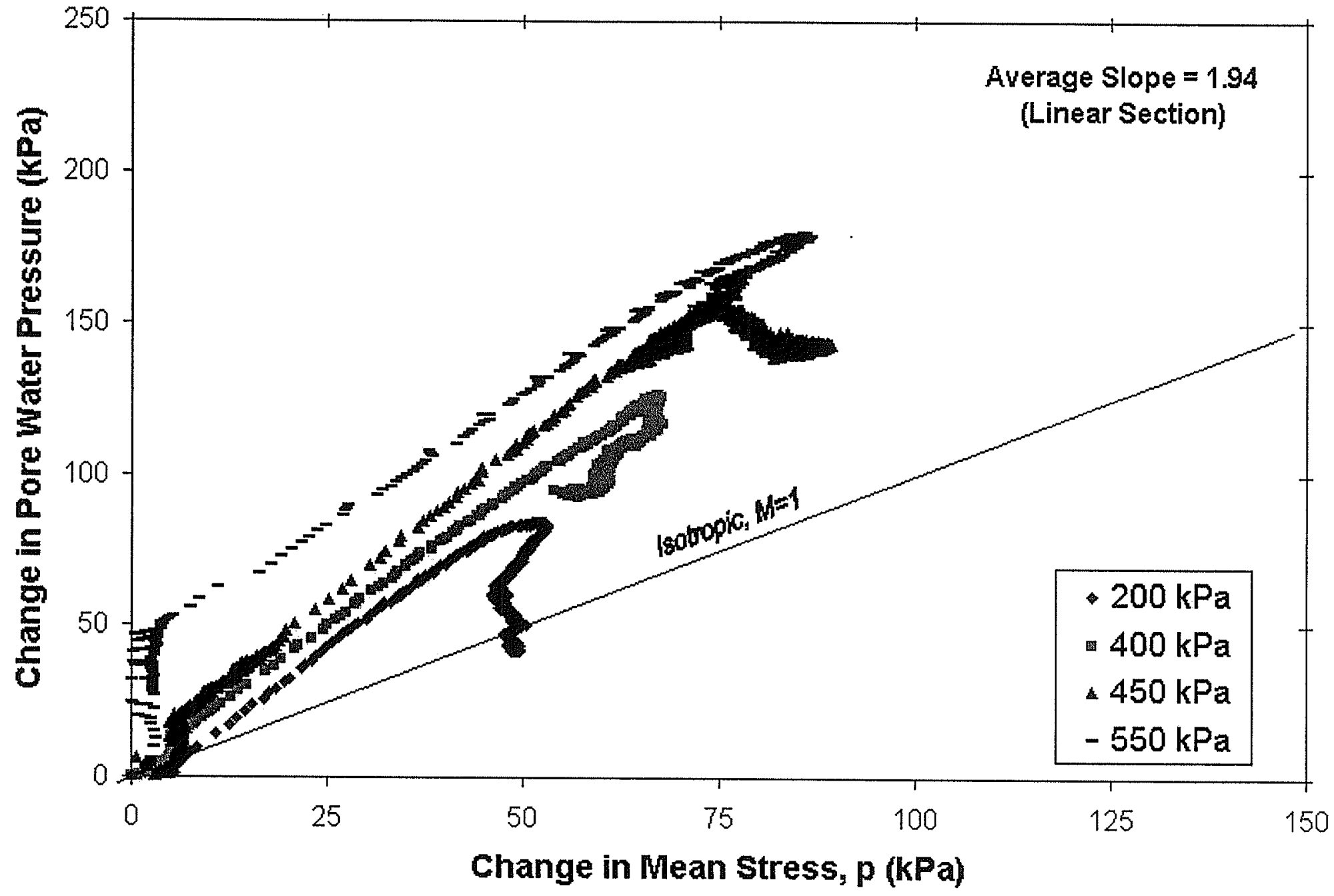

Figure 3.37. Change in pore water pressure vs. change in mean stress for foundation material at section SS-040 


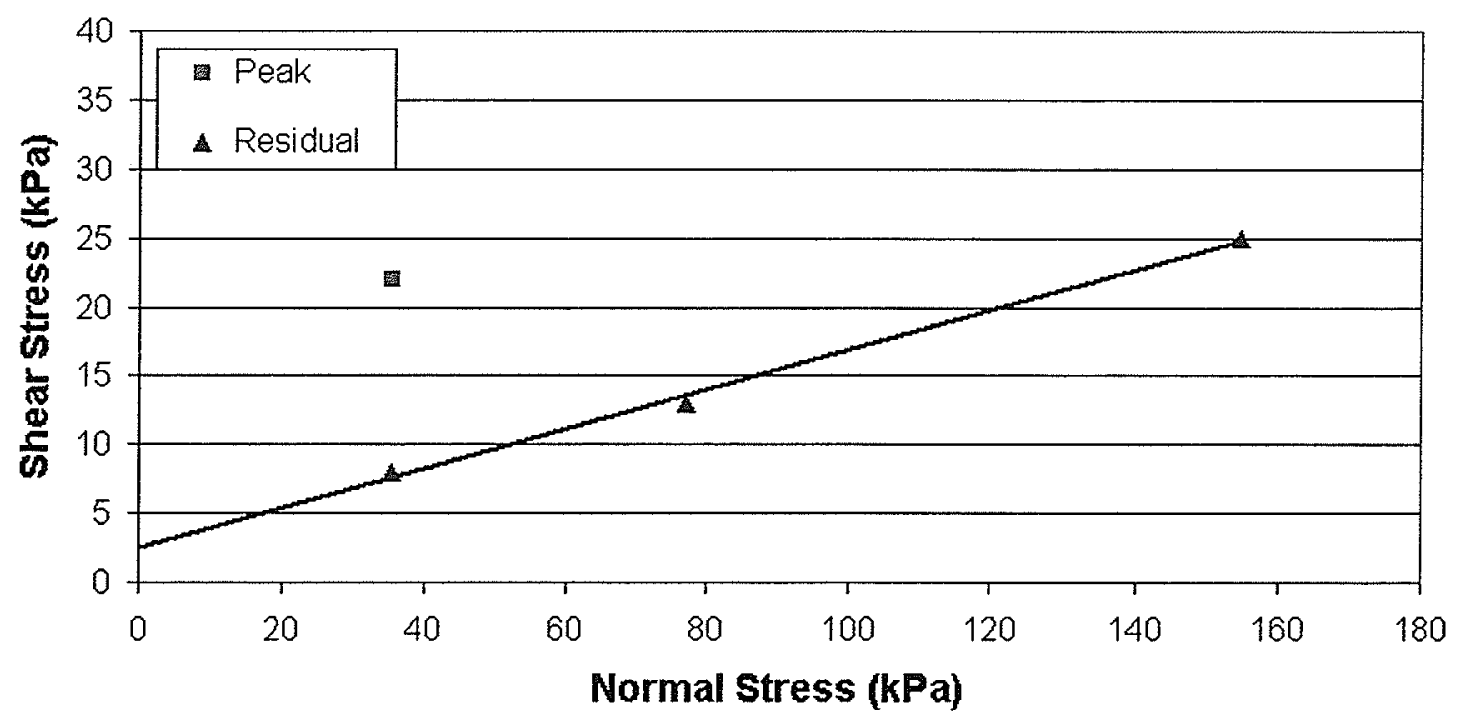

Figure 3.38. Direct shear test results for Sample 1 from section SS-036

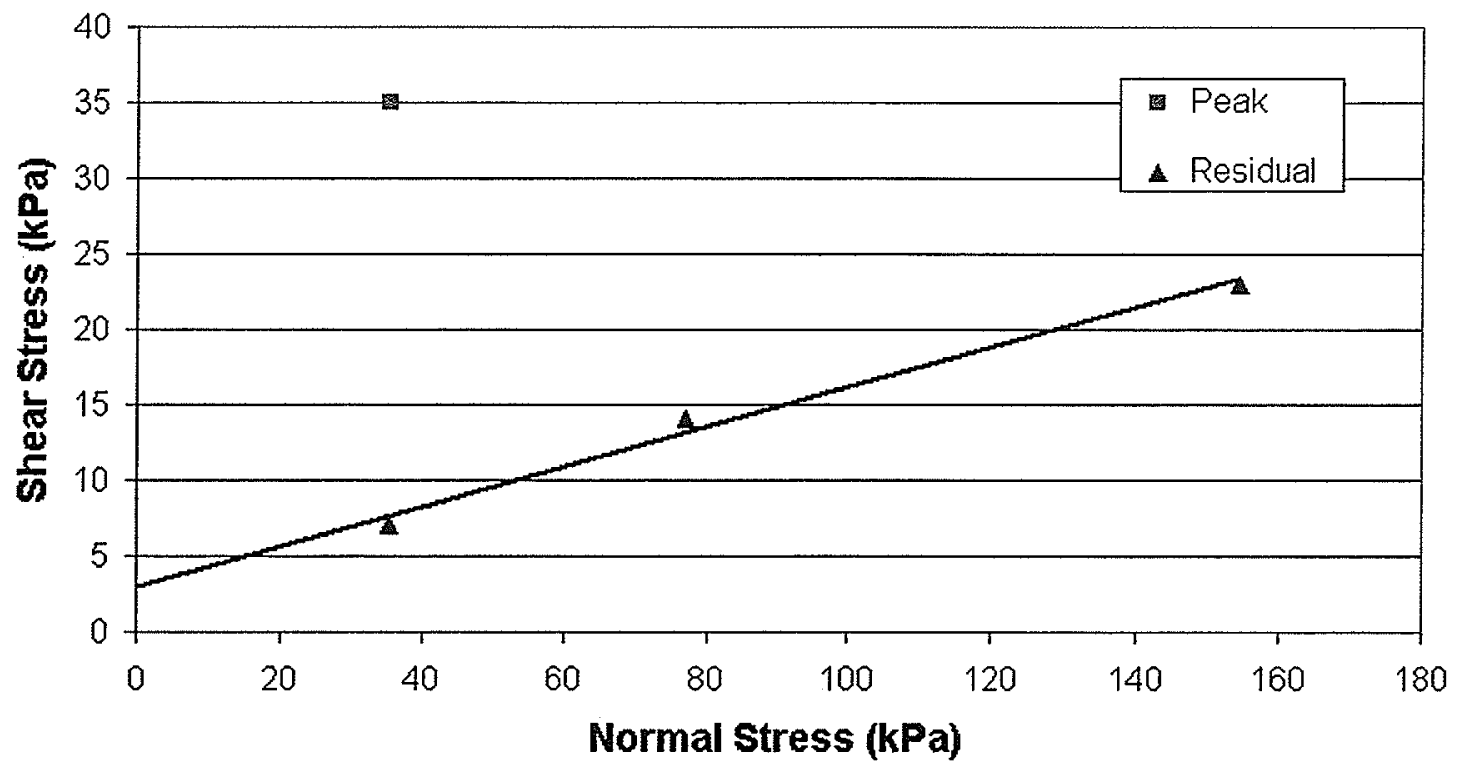

Figure 3.39. Direct shear test results for Sample 2 from section SS-040 


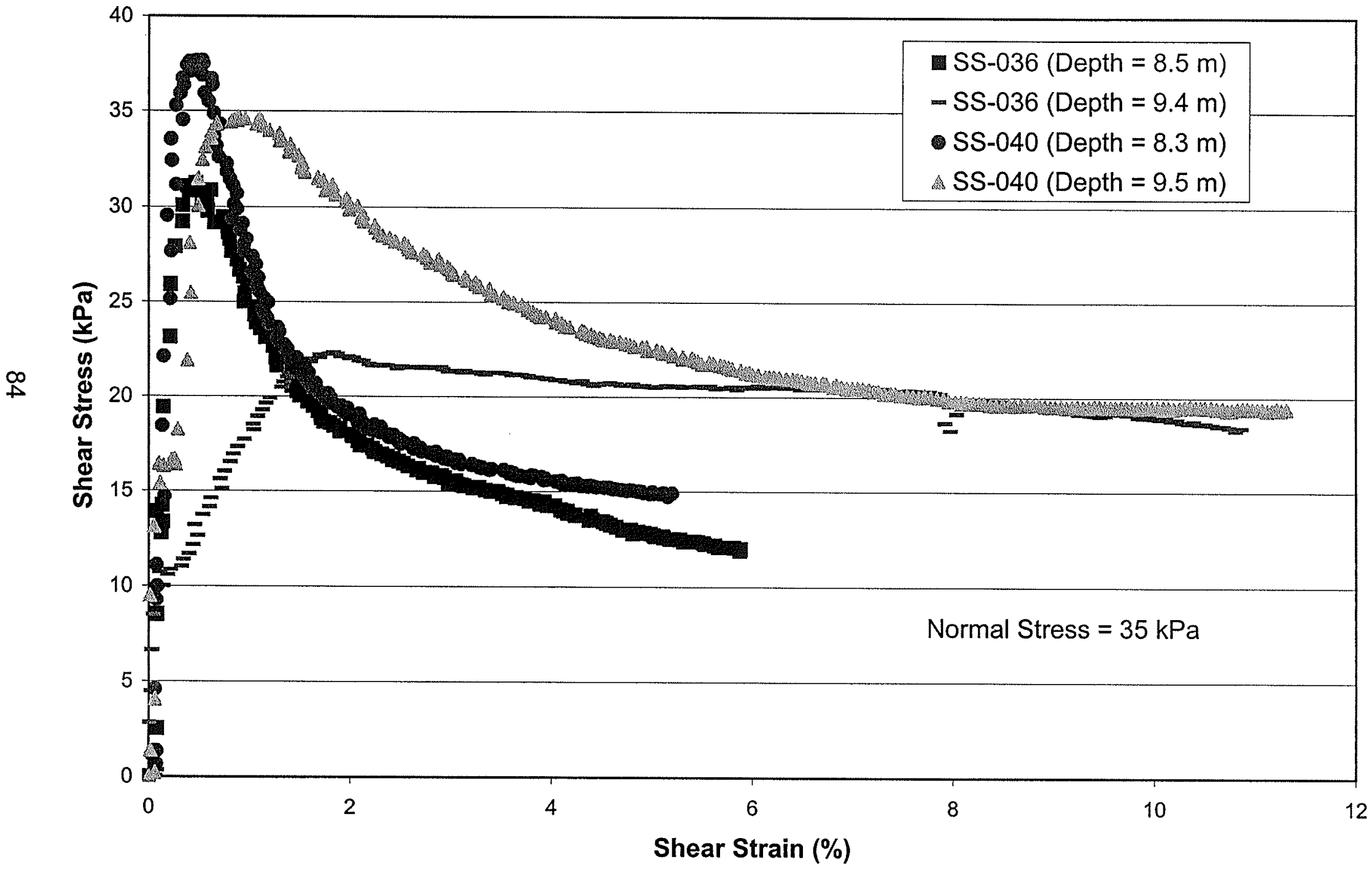

Figure 3.40. Initial direct shear tests on specimens 


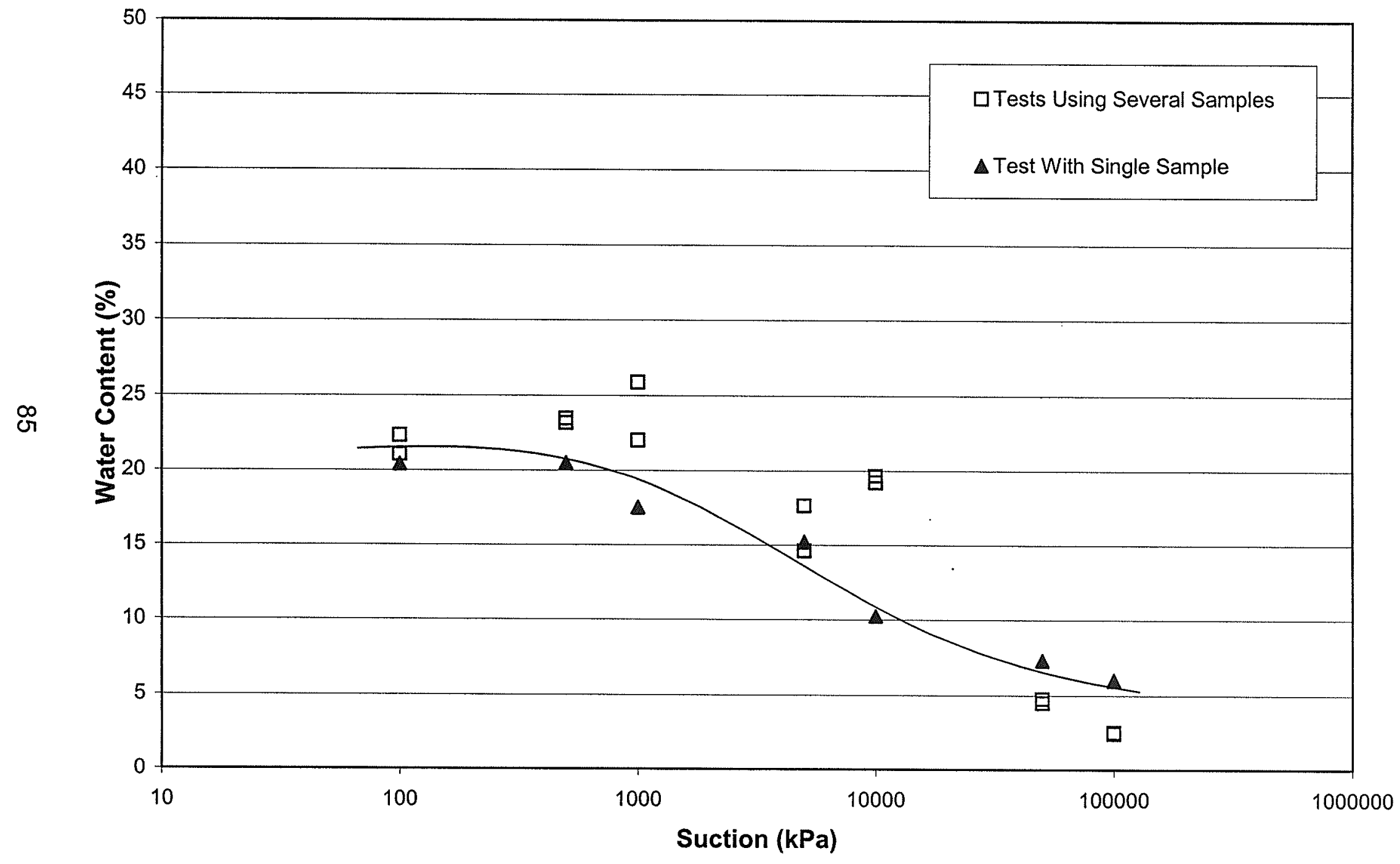

Figure 3.41. Soil water characteristic curves 


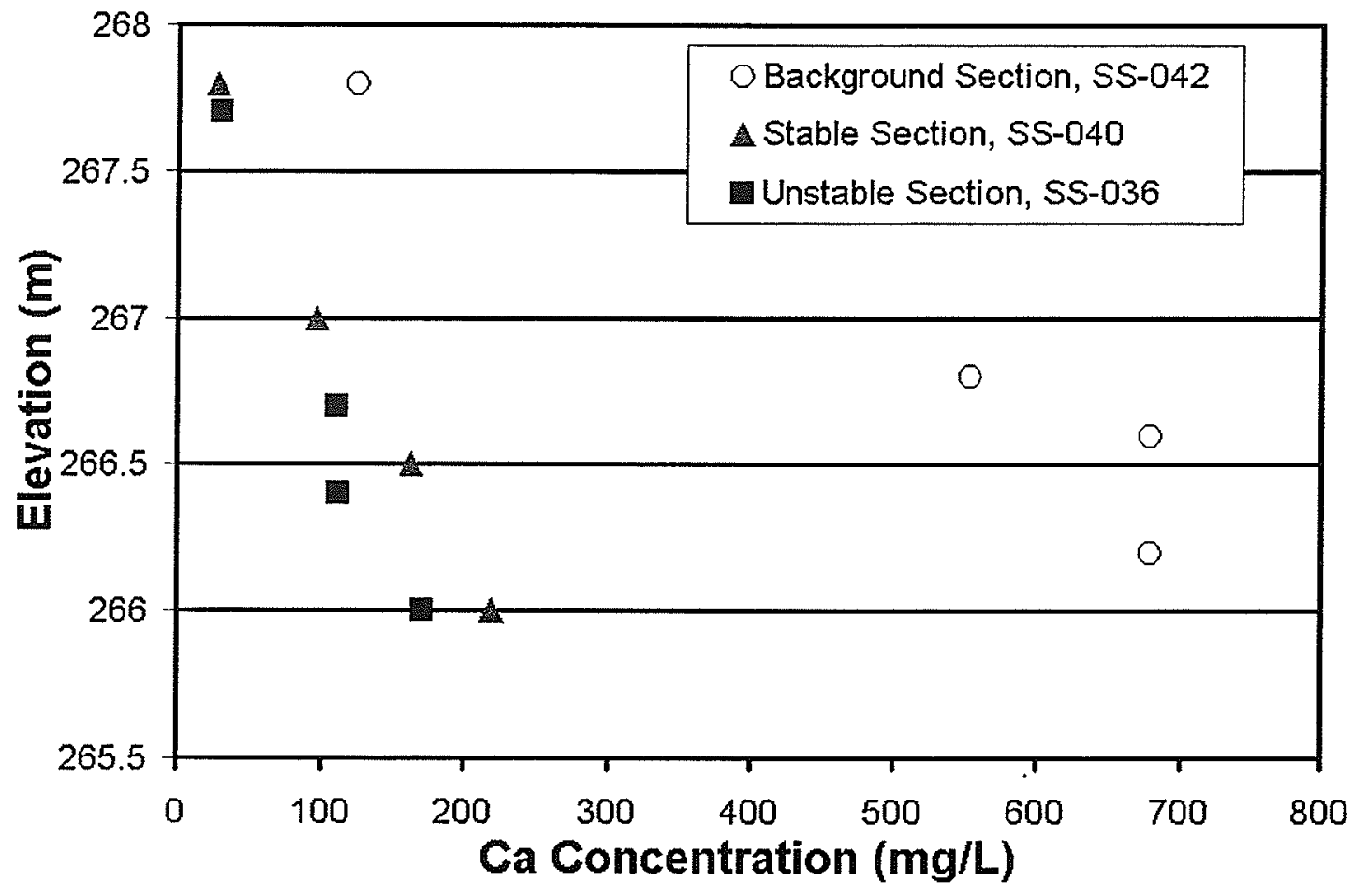

Figure 3.42. Calcium concentration vs. elevation

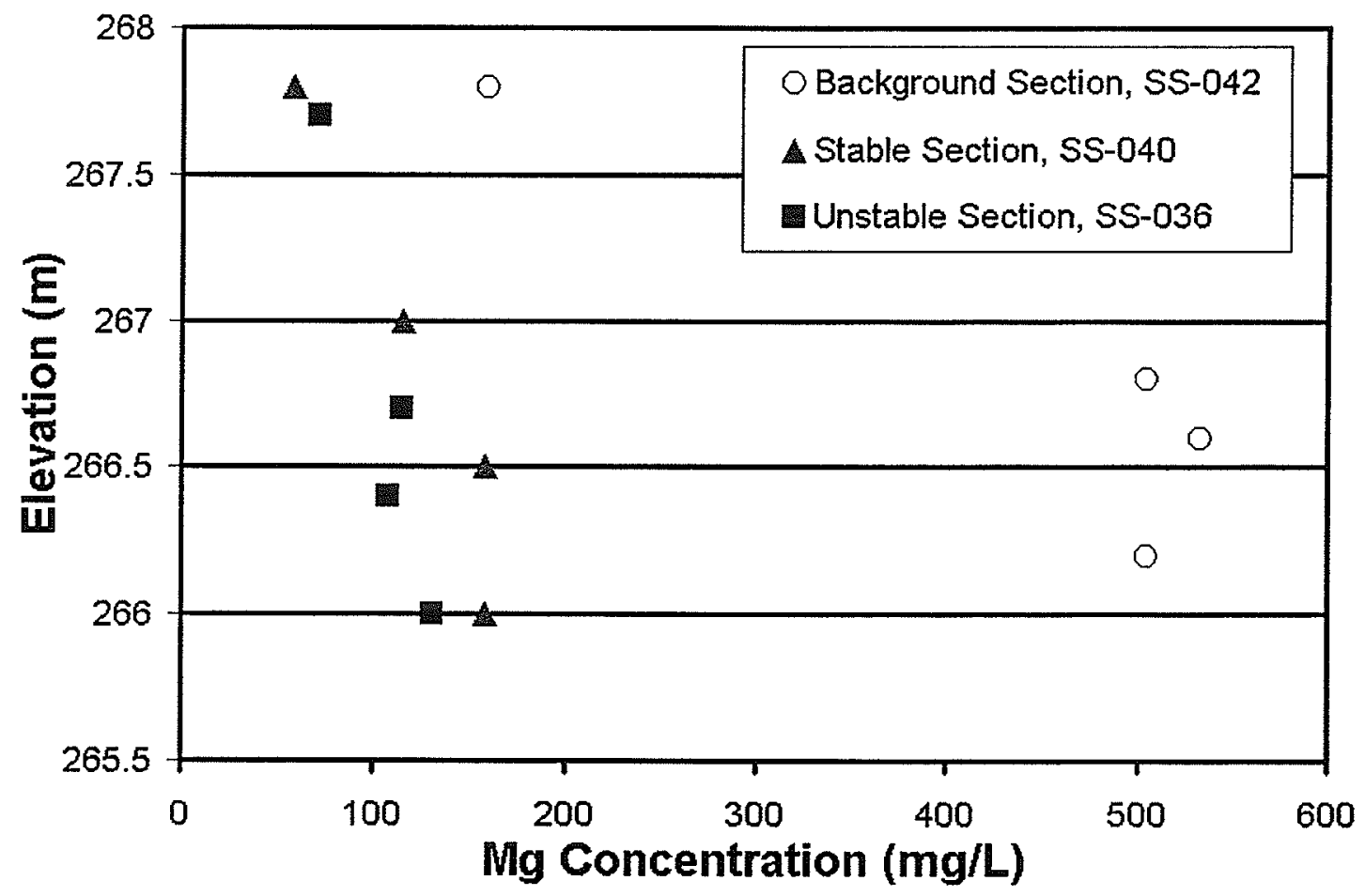

Figure 3.43. Magnesium concentration vs, elevation 


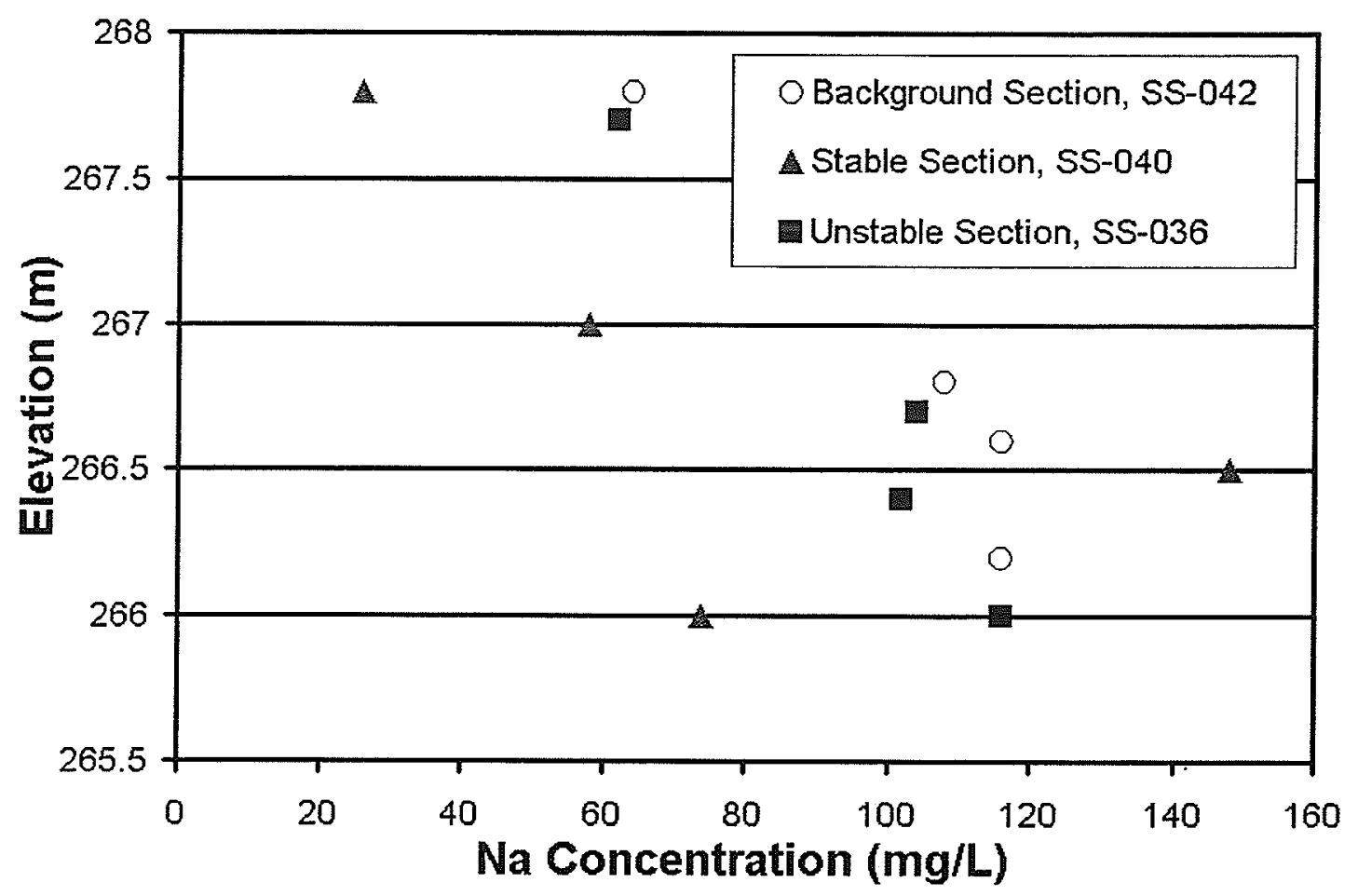

Figure 3.44. Sodium concentration vs. elevation

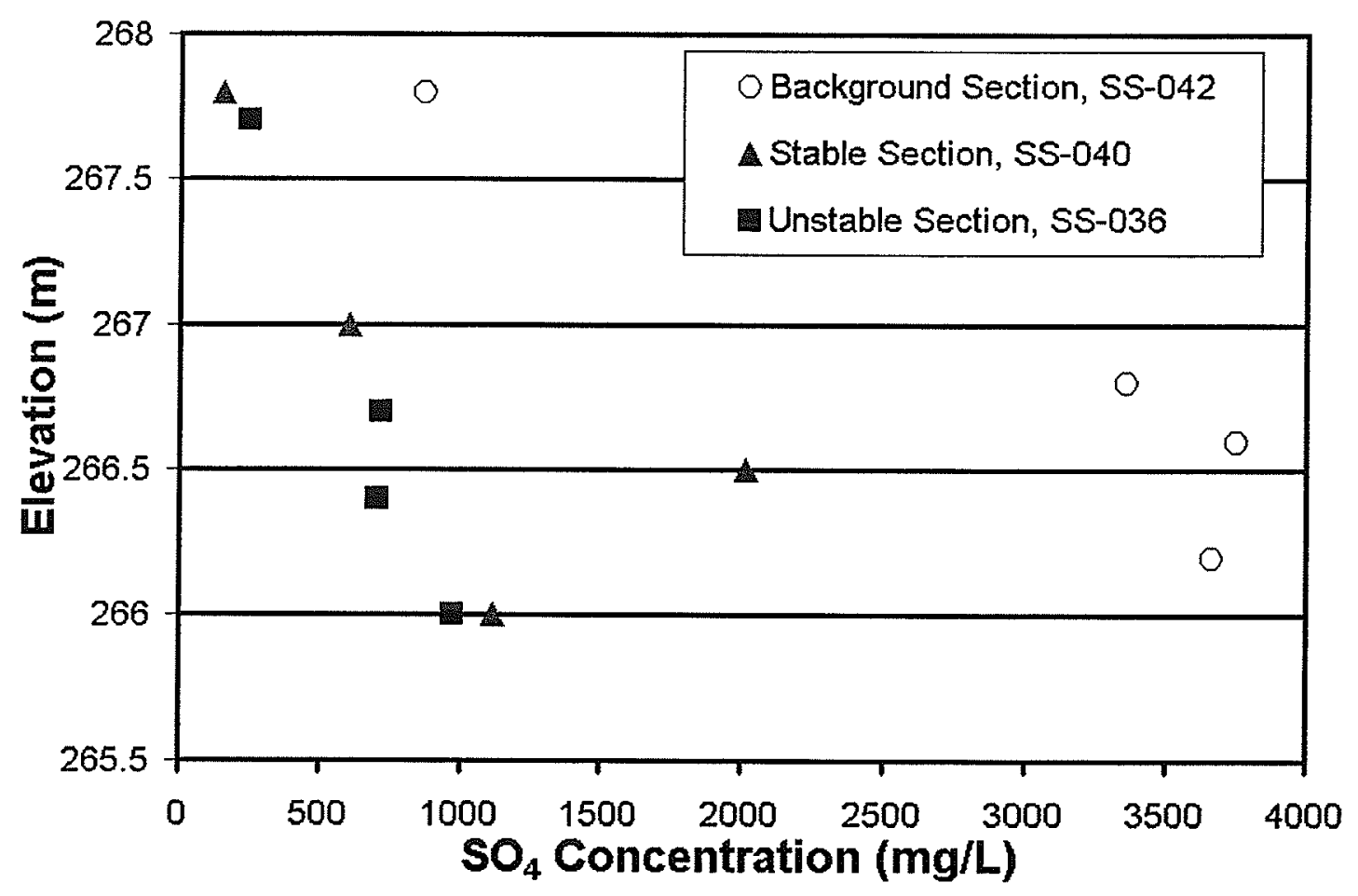

Figure 3.45. Sulphate concentration vs. elevation 


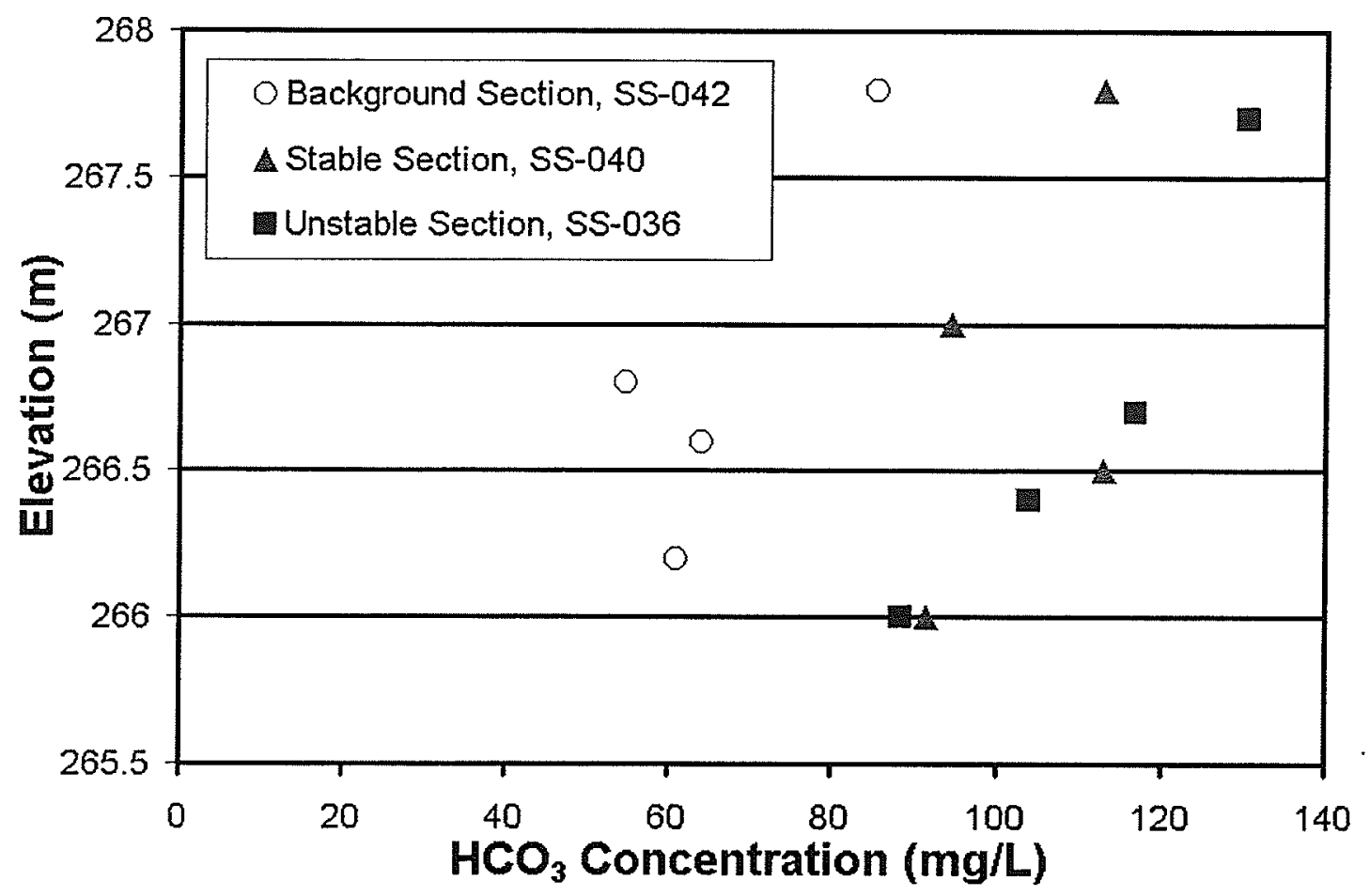

Figure 3.46. Bicarbonate concentration vs. elevation

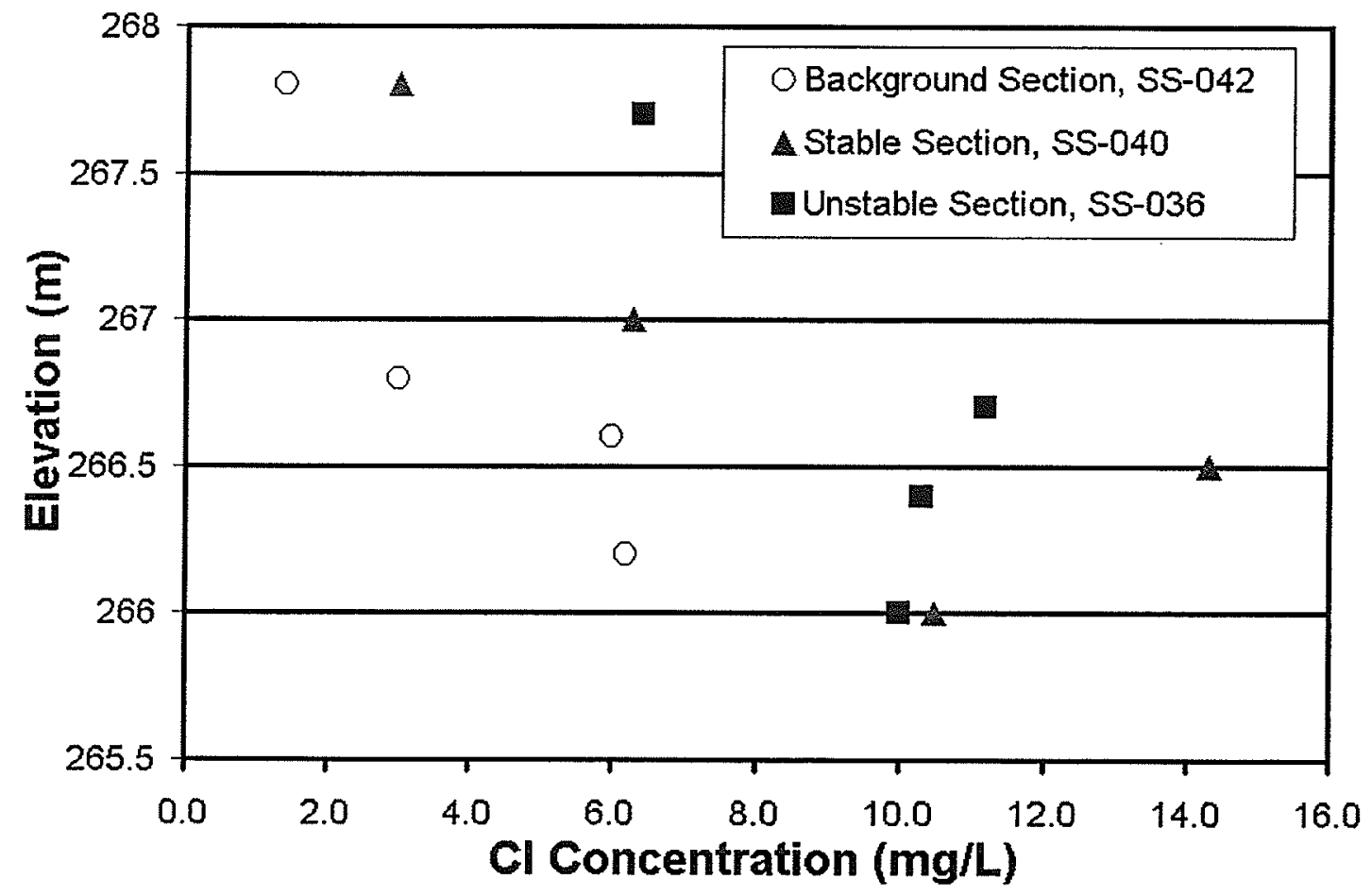

Figure 3.47. Chlorine concentration vs. elevation 


\section{Chapter 4 - Modeling of Seven Sisters Dykes}

\subsection{Introduction}

Modeling of the embankments at the Seven Sisters Generating Station was done using software created by Geo-Slope International Ltd. The basic governing equations and theory of the programs used are presented below.

Sequential seepage, stress-deformation, and slope stability modeling was used to determine the factor of safety of the embankments. The first step in the modeling took results from a steady state seepage analysis and input them into a slope stability analysis to determine the factor of safety. To remove the assumptions for the interslice forces in the previous slope stability analysis, a second step in the modeling used sequentially-coupled stress-deformation and seepage analyses as precursors to determining the factor of safety using the slope stability application.

\subsection{Computer Modeling Theory}

The following section describes some of the basic parts of finite element modeling followed by descriptions of each of the software programs and their basic governing equations. 


\subsubsection{Finite Element Modeling}

The finite element method is based on dividing a complicated domain into smaller and manageable pieces. These pieces form a mesh consisting of elements connected to each other at nodes. In finite element modeling, four main conditions need to be met:
1) Equilibrium condition
2) Compatibility condition
3) Constitutive relationship
4) Boundary conditions

The equilibrium condition is such that the analysis is able to converge to a solution without numerical instability occurring. The compatibility condition requires that there is compatibility between elements at the nodes and that there are no discontinuities within the mesh. The mesh for a finite element model should contain triangular and quadrilateral elements, preferably consisting of elements that are either right angle triangles or squares. When changing from coarse elements to finer elements or vice versa within a mesh, transitional elements should be used to maintain the compatibility requirement of the elements. The constitutive relationship defines the behavior of the materials in the model as accurately as possible. Boundary conditions specify areas at element nodes or on element edges where information is known about the 
model. When loading is applied, numerical techniques are used to determine the 'least energy' response of the domain.

\subsubsection{Seepage Modeling Theory}

The seepage modeling was performed using the finite element SEEP/W software. The program calculates the flow of water through saturated and unsaturated soil based on Darcy's Law shown in Equation 4.1.

$$
q=k i
$$

In this equation, $q$ is the specific discharge, $k$ is the hydraulic conductivity, and $i$ is the hydraulic gradient.

In SEEP/W the governing differential equation for the flow of water through an element is shown in Equation 4.2.

$$
\frac{\partial}{\partial x}\left(k_{x} \frac{\partial H}{\partial x}\right)+\frac{\partial}{\partial y}\left(k_{y} \frac{\partial H}{\partial y}\right)+Q=\frac{\partial \Theta}{\partial t}
$$

In this equation, $\mathrm{H}$ is total head, $\mathrm{k}_{\mathrm{x}}$ is hydraulic conductivity in $\mathrm{x}$-direction, $\mathrm{k}_{\mathrm{y}}$ is hydraulic conductivity in y-direction, $Q$ is the applied boundary flux, $\Theta$ is volumetric water content, and $\mathrm{t}$ is time. The equation implies that the flow into or out of an elemental volume at a certain point in time is equal to the change in volumetric water content. If the problem considered is steady state, time is neglected and the right side of Equation 4.2 becomes zero. 
In areas that may be unsaturated, the soil water characteristic curve can be input into the software. This is used to relate the negative pore water pressures to water content in the soil. Related to the soil water characteristic curve, and more important in obtaining better accuracy, a hydraulic conductivity function can be defined. This relates the hydraulic conductivity of a soil to the negative pore water pressure in the soil. By defining this curve, it is possible to determine flow at hydraulic pressures less than atmospheric in unsaturated regions where the hydraulic conductivity term in Darcy's Law is reduced from its saturated value.

In order to solve the model, at least one node must have its total head specified as a boundary condition. From this, the head of all other nodes can be determined in reference to the known head. If no head boundaries are input, the equations will become indeterminate, as there will be no flow into or out of the system.

\subsubsection{Stress-Deformation Modeling Theory}

The load-deformation modeling was performed using the finite element SIGMA/W software, which can be used for plain strain or axisymmetric problems using small displacement, small strain theory. The basic fundamental constitutive relationship used in the program is shown in Equation 4.3 (Figure 1).

$$
\sigma=E \varepsilon
$$


This equation indicates that the stress, $\sigma$, is related to the strain, $\varepsilon$, by the stiffness, E, of the material. For a two dimensional plane strain problem, the basic strain components are shown in the Equations 4.4 to 4.6.

$$
\begin{aligned}
& \varepsilon_{x}=\frac{\partial u}{\partial x} \\
& \varepsilon_{y}=\frac{\partial v}{\partial y} \\
& \gamma_{x y}=\frac{\partial u}{\partial y}+\frac{\partial v}{\partial x}
\end{aligned}
$$

In these equations, the $\varepsilon_{x}$ term is longitudinal strain in the x-direction, $\varepsilon_{y}$ is longitudinal strain in the y-direction, $\gamma_{x y}$ is the shear strain in the $x-y$ plane, and $u$ and $v$ are the displacement components related to the $x$ - and $y$-directions, respectively.

The program can perform an insitu analysis in order to compute initial stresses acting within the soil prior to any engineering work. The results of this analysis can then be input into a load-deformation analysis to account for stresses within the soil prior to the application of any loading.

When defining soil materials, different constitutive models can be used to best represent their stress-strain behavior. Several constitutive models are available in SIGMA/W, but only those used in this project will be discussed. The simplest type of constitutive model that can be used in the SIGMA/W program is the isotropic linear elastic model shown in Figure 4.1. In this model only two 
parameters are needed to relate the stresses to the strains. These are Young's Modulus, E, and Poisson's Ratio, $v$, as shown by Equation 4.7.

$$
\left\{\begin{array}{l}
\sigma_{x} \\
\sigma_{y} \\
\sigma_{z} \\
\tau_{x y}
\end{array}\right\}=\frac{E}{(1+v)(1-2 v)}\left[\begin{array}{cccc}
1-v & v & v & 0 \\
v & 1-v & v & 0 \\
v & v & 1-v & 0 \\
0 & 0 & 0 & \frac{1-2 v}{2}
\end{array}\right]\left\{\begin{array}{l}
\varepsilon_{x} \\
\varepsilon_{y} \\
\varepsilon_{z} \\
\gamma_{x y}
\end{array}\right\}
$$

In this equation, $\sigma_{x}, \sigma_{y}$, and $\sigma_{z}$ are stresses in the $x, y$, and $z$ directions, $\tau_{x y}$ is the shear stress in the $\mathrm{x}$-y plane, $\varepsilon_{x}, \varepsilon_{y}$, and $\varepsilon_{z}$ are the strains in the $\mathrm{x}, \mathrm{y}$, and $\mathrm{z}$ directions, and $\gamma_{x y}$ is the shear strain in the $x-y$ plane.

Another type of constitutive model that can be used in the SIGMA/W program is the elastic perfectly-plastic model shown in Figure 4.2. This describes the stress-strain relationship as being linearly elastic up to the yield point, followed by perfectly plastic behavior. In this model, the incremental strain past the yield point can be separated into an elastic and a plastic component as shown in Equation 4.8.

$$
\{d \epsilon\}=\left\{d \epsilon^{e}\right\}+\left\{d \epsilon^{p}\right\}
$$

In this equation, $\epsilon$ is total strain, $\epsilon^{e}$ is recoverable elastic strain, and $\epsilon^{\mathrm{p}}$ is nonrecoverable plastic strain.

A third type of constitutive model that can be used in the SIGMA/W program is the strain softening model as shown in Figure 4.3. This is based on a stress-strain curve made up of three linear portions, the first starting from zero 
stress up to the peak undrained shear strength. This is followed by a reduction in strength from peak to residual undrained shear strength, and finally the third portion is constant residual undrained shear strength with further straining. Based on Equation 4.9, the shear strength, $C_{s}$, is determined from the amount of total equivalent plastic strain.

$$
\mathrm{C}_{\mathrm{s}}= \begin{cases}\mathrm{C}_{\mathrm{u}} & \text { when } \epsilon_{\mathrm{p}}=0 \\ \mathrm{C}_{\mathrm{u}}-\operatorname{R} \epsilon_{\mathrm{p}} & \text { when } 0<\epsilon_{\mathrm{p}} \leq \epsilon_{\mathrm{pr}} \\ \mathrm{C}_{\mathrm{r}} & \text { when } \epsilon_{\mathrm{p}}>\epsilon_{\mathrm{pr}}\end{cases}
$$

In this equation, $\mathrm{C}_{\mathrm{u}}$ is peak undrained shear strength, $\mathrm{C}_{\mathrm{r}}$ is residual undrained shear strength, $\mathrm{R}$ is rate of softening, $\epsilon_{\mathrm{p}}$ is total equivalent plastic strain, and $\epsilon_{\mathrm{pr}}$ is plastic strain where the softening line intersects the residual line. In SIGMA/W, strain softening like that shown in Figure 4.3 is only available in a total stress format.

\subsubsection{Slope Stability Modeling Theory}

The computer program SLOPE/W was used to determine the factor of safety for slope stability. The program uses the procedures known as the General Limit Equilibrium method, based on the statics of a series of notional slices interpolated into the cross-section. The forces acting on a slice through a sliding mass are shown in Figure 4.4. This method comprises four parts:

1) The normal force, $P$, at the base of each slice is determined by the summation of forces in the vertical direction for each slice, 
2) The interslice normal force, E, of each slice is determined by summation of forces in the horizontal direction for each slice,

3) The moment equilibrium factor of safety is determined by summing moments about a common point for all slices, and

4) Summing forces in the horizontal direction for all slices is used to determine the force equilibrium factor of safety.

In this form, the problem is indeterminate. The factor of safety can only be determined by assuming the direction of the resultant interslice forces. Some of the assumptions for interslice forces used in different forms of the analysis are as follows:

1) The Ordinary method sets the interslice forces parallel to the base of each slice in turn and satisfies only moment equilibrium,

2) The Bishop method considers normal forces but not shear forces between slices and only satisfies moment equilibrium,

3) The Morgenstern-Price method uses a selected interslice force function and satisfies both force and moment equilibrium.

An alternative method for determining the factor of safety, which in this case is called the stability factor, is to use stresses computed using finite elements in a limit equilibrium framework. This method uses the $\sigma_{x}, \sigma_{y}$, and $\tau_{x y}$ stresses from SIGMAN modeling to determine the normal stress, $\sigma_{n}$, and mobilized shear stress, $\tau_{m}$, at the base center of each slice based on Equations 4.11 and 4.12 below. 


$$
\begin{gathered}
\sigma_{n}=\frac{\sigma_{x}+\sigma_{y}}{2}+\frac{\sigma_{x}-\sigma_{y}}{2} \cos 2 \theta+\tau_{x y} \sin 2 \theta \\
\tau_{m}=\tau_{x y} \cos 2 \theta-\frac{\sigma_{x}-\sigma_{y}}{2} \sin 2 \theta
\end{gathered}
$$

In these equations, $\sigma_{x}$ is the total stress in the x-direction at the base center, $\sigma_{y}$ is the total stress in the $y$-direction at the base center, $\tau_{x y}$ is the shear stress in $x-$ and $y$-directions at the base center, and $\theta$ is the angle measured from the positive $x$-axis to the line of application of the normal stress. The stability factor is determined from the ratio of the summation of the available shear strength to the summation of the mobilized shear stress along the slip surface.

Krahn (2001) discussed the disadvantages of limit equilibrium methods due to the lack of consideration of strain and displacement compatibility. Several advantages of doing a stability analysis using the stresses determined from a load-deformation analysis include:

1) No need to assume interslice forces

2) No iterative convergence problems since the stability factor is deterministic

3) Ground stresses in model are closer to reality

4) There is indirect consideration for stress concentrations and arching within the soil

Note however that these solutions must also make some assumptions, specifically the constitutive model that is used in the stress-deformation analysis. 


\subsection{Seepage Modeling}

\subsubsection{Seepage Model Parameters}

'Worst-case' Manitoba Hydro piezometer data were used to evaluate pore water pressures for the slope stability modeling. Vibrating wire piezometer readings had been taken at the site over a long period of time. These were used to obtain the phreatic surface and pore pressure distribution through the dykes using the SEEP/W finite element computer program from GEOSLOPE International Ltd.

The steady state seepage model was based on construction drawings for the embankment and the results of material testing that identified the zones of embankment and foundation materials. The mesh for the dykes was created using elements that were $0.5 \times 0.5 \mathrm{~m}$ in size, with a finer mesh of $0.25 \times 0.25 \mathrm{~m}$ used near the boundary of the dyke material and foundation material.

For boundary conditions, on the water side of the embankment the hydraulic head was set at an elevation of $274.25 \mathrm{~m}$. Based on previous records, this level appears to remain relatively constant. Due to a sand drain at the landside toe of the embankment and knowledge that the groundwater level is near the ground surface outside the embankment, the hydraulic head on the landside of the embankment was set to an elevation of $270 \mathrm{~m}$. 
In defining the material properties, the rip-rap shell was not considered a relevant material in the seepage modeling. Due to its high hydraulic conductivity, it would not significantly affect the heads and pore water pressures. The saturated hydraulic conductivities of the embankment and foundation material used in the model were taken from the laboratory testing presented in Section 3.3. To account for the unsaturated soil within the upper portion of the embankment, the unsaturated conductivity function acquired from SoilVision Systems Ltd. (Figure 3.13) was input into the model. The ratio of $k_{y} / k_{x}$ was assumed to be 1.0 for all materials used in the model. For most reasonable values of the ratio between vertical and horizontal hydraulic conductivity from laboratory tests (Section 3.4.3) this study found that the effect on the factor of safety was small.

\subsubsection{Seepage Model Results}

The results of the model showed the phreatic surface being near horizontal on the waterside of the embankment and then lowering down to the sand drain on the landside of the embankment. Figure 4.5 shows a typical pore water pressure distribution from the SEEP/W analysis. These values were input from SEEP/W to SLOPE/W to permit evaluation of effective stresses from gravity induced total stresses. 


\subsection{Stress-Deformation Modeling}

\subsubsection{Stress-Deformation Parameters}

The finite element program SIGMA/W from GEOSLOPE International Ltd. was used for the stress deformation analysis. The objective of this model was to show the impact of incorporating strain softening behavior of the foundation material on the stress distribution. These stresses were then input into the slope stability model, SLOPE/W. It should be noted that SIGMANW has only the capability of incorporating the strain softening behavior of the soil under undrained (total stress) conditions. This may not represent the long-term condition of the foundation.

An insitu analysis including the foundation soil and the existing dykes was first conducted to determine the stresses in the soil prior to heightening of the dykes. A second model used the stresses obtained from the insitu model and added three time-steps to simulate the construction of the embankment as it was built between 1947 and 1949. The mesh used in these models was identical to that used for the seepage analysis. This allowed results from both analyses to be used in the slope stability analysis. 
For the initial insitu analysis, the materials were modeled as linearly elastic, with values of $E$ determined from the triaxial testing described in Section 3.5 and an assumed Poisson's ratio $v$. The modeling parameters for the stressdeformation analysis are shown in Table 4.1. Modeling values for the rip-rap shell were taken from the literature for similar materials. Their effect is small. For analyzing the embankment and upper foundation, parameters were obtained from the CIU triaxial tests described in Section 3.5. For the upper foundation, a strain softening model was used, in which the $S_{u}$ (peak) in Table 4.1 represents the peak undrained shear strength of the soil and $S_{u}$ (residual) represents the residual undrained shear strength of the soil. A triaxial test on a specimen taken from the lower foundation soil showed similar behavior to the embankment material. The modeling parameters for these two materials were assumed to be identical.

The literature review emphasized that one of the main concerns for modeling embankments on soft ground was updating material nodes to account for deformations. SIGMA/W prevents this problem by allowing adjustment of the fill to the design elevation at the end of each time step. Since the dykes were built to an elevation of $276.25 \mathrm{~m}$, this option allowed this elevation to be reached at the final stage of construction. 


\subsubsection{Stress-Deformation Model Results}

Figure 4.6 shows a typical result from the SIGMAWW modeling. Results from modeling the construction of the embankment showed a maximum vertical deformation of $0.10 \mathrm{~m}$ for borehole SS-036 and $0.14 \mathrm{~m}$ for borehole SS-040. Maximum shear strains in the upper foundation ranged from approximately $2 \%$ to 4\%. Results from the triaxial tests indicated that these shear strains would be sufficient to induce softening in parts of the foundation soils.

\subsection{Slope Stability Modeling}

\subsubsection{Slope Stability Modeling Parameters}

GeoSlope SLOPE/W was used to determine the factor of safety at the two sections, SS-036 and SS-040, using a Morgenstern-Price solution with constant interslice force inclination. Pore water pressures were taken from the SEEP/W analysis discussed in Section 4.3. A second analysis that combined SEEP/W, SIGMANW, and SLOPE/W was conducted using the stresses obtained in the stress-deformation analysis discussed in Section 4.4. The objective of these analyses was to determine the corresponding safety factor at the unstable section (SS-036) and the stable section (SS-040). 
The geometry for each of the two sections was identical in each of the stress, seepage and stability models. From the laboratory soil identification discussed in Section 3.2, the transition from embankment to foundation material was taken at a depth of $8.0 \mathrm{~m}$ (Elevation $268 \mathrm{~m}$ ) at section SS-036. At section SS-040, changes in plasticity index suggested that the transition should be at approximately $7.5 \mathrm{~m}$ depth (Elevation $268.5 \mathrm{~m}$ ). Also based on the laboratory tests, the depth of the highly plastic foundation soil was determined to be approximately four meters at section SS-036 and three meters at section SS-040 beneath the dykes. These depths corresponded well with records of stripping of the upper soil during construction. In both sections, bedrock was set at $13 \mathrm{~m}$ depth.

Table 4.2 shows the strength parameters used in the modeling. For the foundation soil, the critical state ('large-strain') friction angle $\phi^{\prime}=13^{\circ}$ for borehole SS-036 and $\phi^{\prime}=14^{\circ}$ for borehole SS-040 were used, and a small cohesion of 5 $\mathrm{kPa}$ was also included. Previous work (Betke, 2001) indicated that a small effective cohesion from 0 to $10 \mathrm{kPa}$ was probably needed to obtain a safety factor close to unity (tests on Lake Agassiz clays in Winnipeg have indicated that they also have a small amount of cohesion). The analysis was also checked using residual strength parameters $c_{r}{ }^{\prime}=5 \mathrm{kPa}$ and $\phi_{r}{ }^{\prime}=9^{\circ}$ for the upper foundation in both sections. Parameters for the rip-rap shell were the same as those used for Seven Sisters dykes by Rivard and Lu (1978). The $\phi^{b}$ parameter for suction was assumed to be $12^{\circ}$ for the dyke material. A sensitivity analysis 
showed that in this case, the parameter had little effect on the safety factor for $7^{\circ} \leq \phi^{\mathrm{b}} \leq 25^{\circ}$

The dyke and the lower foundation clay at sections SS-036 and SS-040 were modeled by 'peak' strength parameters $\mathrm{c}^{\prime}=20 \mathrm{kPa}, \phi^{\prime}=23^{\circ}$ and $\mathrm{c}^{\prime}=$ $20 \mathrm{kPa}, \phi^{\prime}=24^{\circ}$, respectively, which are similar to those used in Rivard and Lu (1978).

\subsubsection{Slope Stability Model Results}

Table 4.3 shows safety factors obtained using various strength assumptions. Case 1 used pore water pressures from the seepage analysis in a Morgenstern-Price solution (constant interslice force function) with critical state strength parameters for the upper foundation clay (Table 4.2). Case 2 again took input from the seepage analysis and used a Morgenstern-Price solution, but this time with residual strength parameters in the upper foundation. Case 3 imported results from the seepage and stress-deformation analysis to establish the stress system in the soil. It then used critical state strength parameters for the upper foundation clay. The final case (Case 4) again imported results from the seepage and stress-deformation analysis, but now used residual strength parameters in the upper foundation clay. Figures 4.7 and 4.8 show typical results for critical slip surfaces, phreatic surfaces, and safety factors for Case 4 at Sections SS-036 and SS-040 respectively. 
Additional computations to examine the sensitivity of the solutions to various input parameters showed that cohesion in the upper foundation had a more significant effect on safety factor than cohesion in the dyke material. Similarly, changing the angle of shearing resistance had more effect in the foundation material than in the dyke.

Table 4.3 shows that (1) Generalized Limit Equilibrium using the Morgenstern-Price solution and (2) solutions that incorporated stresses using FEM (from SIGMA/W) into the slope stability solution, produce very similar results. This is supported by Krahn (2001) who showed that for deep slip surfaces, the finite element and limit equilibrium normal stress distributions are alike and therefore give similar factors of safety. Cases 1 and 3 in Table 4.3 used critical state strengths in the upper foundation clay. (Here, we assume that 'critical state' strength is essentially the same as 'post-peak' strength and 'Undrained Strength at Large Strains', USALS.) The results show safety factors of around 1.15 at the unstable section SS-036 and 1.22 at the currently stable section SS-040.

While there are some differences in the calculated safety factor at the unstable and stable sections, it is not felt that the differences are themselves sufficient to be definitive. With these levels of safety factor, it is likely that creep shear straining has occurred over time since construction. The foundation clay at Seven Sisters is markedly strain softening as determined from laboratory testing 
and the residual friction angle (approximately $9^{\circ}$ ) is lower than the critical state angle $\left(14^{\circ}\right)$. Table 4.3 shows that if the upper foundation clay experiences progressive straining so that it should be modeled by the residual friction angle, then instability will occur at both sections.

Similar modeling was undertaken to confirm this method of stability analysis by calibrating with the analysis done by Rivard and Lu (1978) at Seven Sisters. The model again included a sequentially coupled seepage analysis and load deformation analysis input into the slope stability analysis. Soil parameters specified by Rivard and Lu were used in the model, with unspecified parameters assumed to be the same as those used in the model described in Sections 4.3, 4.4 , and 4.5 .

Results of the model gave a similar factor of safety as that in the paper, although the computed slip surface did not reach the glacial till or bedrock as indicated by Rivard and Lu. The question then arises why does the normally consolidated strength indicated by Rivard and Lu not provide a factor of safety of 1.0 in the slope stability modeling done in Section 4.5 ? The most obvious difference between the cross-section used by Rivard and Lu and that based on soil identification in this project is that the height of the dyke used by Rivard and Lu is $5.1 \mathrm{~m}$ compared to approximately $8.0 \mathrm{~m}$ observed in the soil identification in this project. Therefore the slip surface has a greater amount of stronger dyke material to overcome to become unstable, compared to the weaker foundation 
soil. Rivard and Lu also assumed the normally consolidated foundation soil to have no cohesion. As indicated earlier, Winnipeg clays have been found to have a small cohesion. Also the depth of the foundation clay differs from $4.5 \mathrm{~m}$ in Rivard and Lu compared to 2.5 to $4 \mathrm{~m}$ observed in this analysis. 
Table 4.1. Stress-deformation modeling parameters

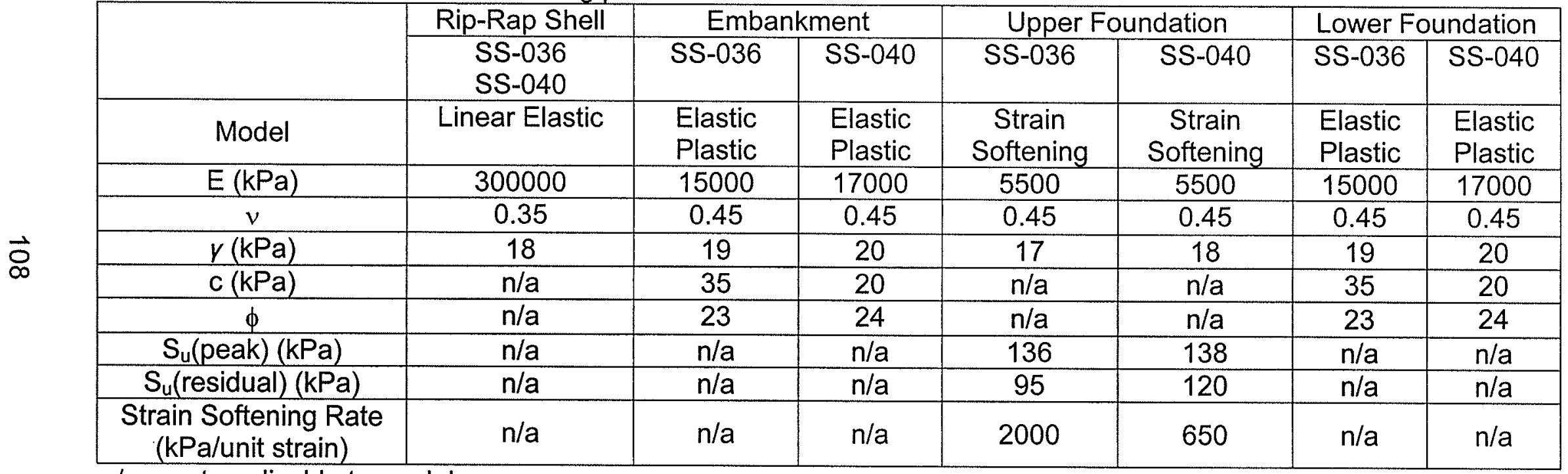

n/a - not applicable to model 
Table 4.2. Slope stability modeling parameters

\begin{tabular}{|c|ccc|ccc|}
\hline & \multicolumn{3}{|c|}{ SS-036 } & \multicolumn{3}{c|}{ SS-040 } \\
\cline { 2 - 7 } & $\begin{array}{c}V \\
\left(\mathrm{kN} / \mathrm{m}^{3}\right)\end{array}$ & $\begin{array}{c}\mathrm{c}^{\prime} \\
(\mathrm{kPa})\end{array}$ & $\phi^{\prime}$ & $\begin{array}{c}V \\
\left(\mathrm{kN} / \mathrm{m}^{3}\right)\end{array}$ & $\begin{array}{c}\mathrm{c}^{\prime} \\
(\mathrm{kPa})\end{array}$ & $\phi^{\prime}$ \\
\hline $\begin{array}{c}\text { Rip-rap Shell } \\
\text { Dyke }\end{array}$ & 18 & 0 & 35 & 18 & 0 & 35 \\
$\begin{array}{c}\text { Upper } \\
\text { Foundation } \\
\text { Lower }\end{array}$ & 19 & 20 & 23 & 20 & 20 & 24 \\
Foundation & 17 & 5 & 13 & 18 & 5 & 14 \\
\hline
\end{tabular}

Table 4.3. Slope stability modeling results

\begin{tabular}{|c|c|c|}
\hline Analysis Method & SS-036 & SS-040 \\
\hline Case 1 & 1.16 & 1.23 \\
\hline Case 2 & 0.97 & 0.98 \\
\hline Case 3 & 1.15 & 1.21 \\
\hline Case 4 & 0.97 & 1.01 \\
\hline
\end{tabular}




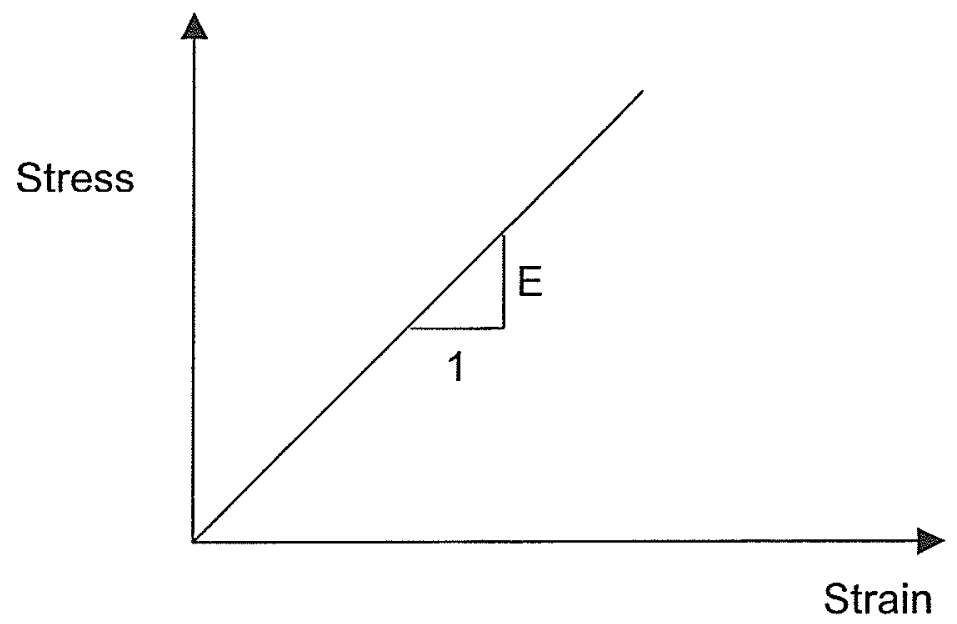

Figure 4.1. Linear elastic constitutive model

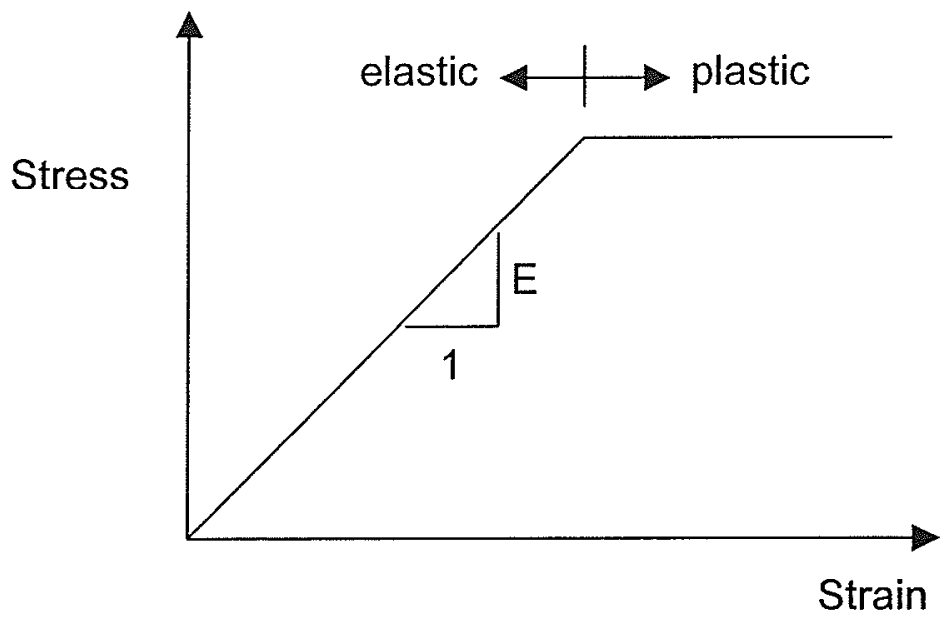

Figure 4.2. Elastic perfectly-plastic constitutive model

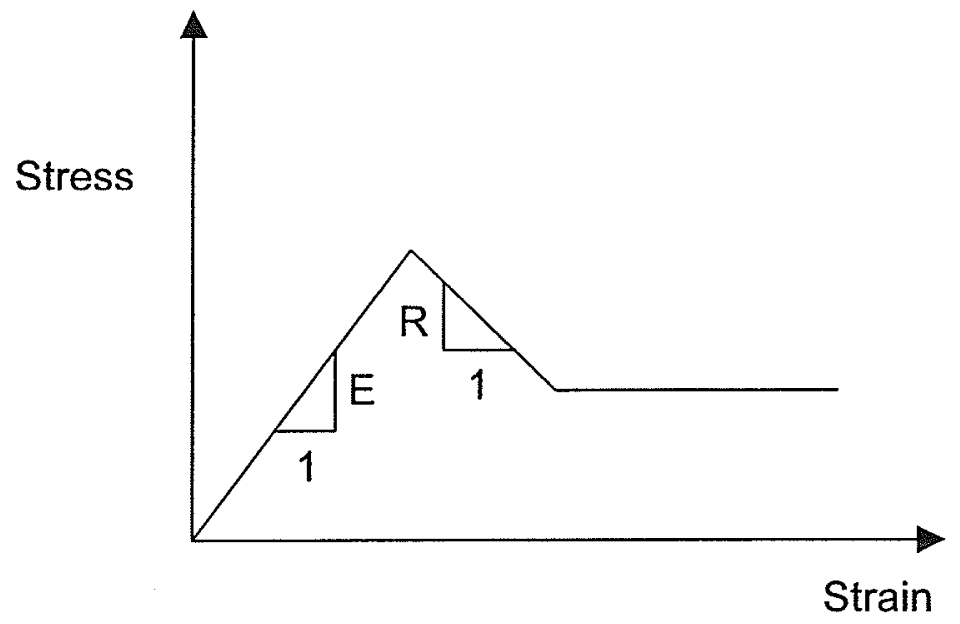

Figure 4.3. Strain softening constitutive model 


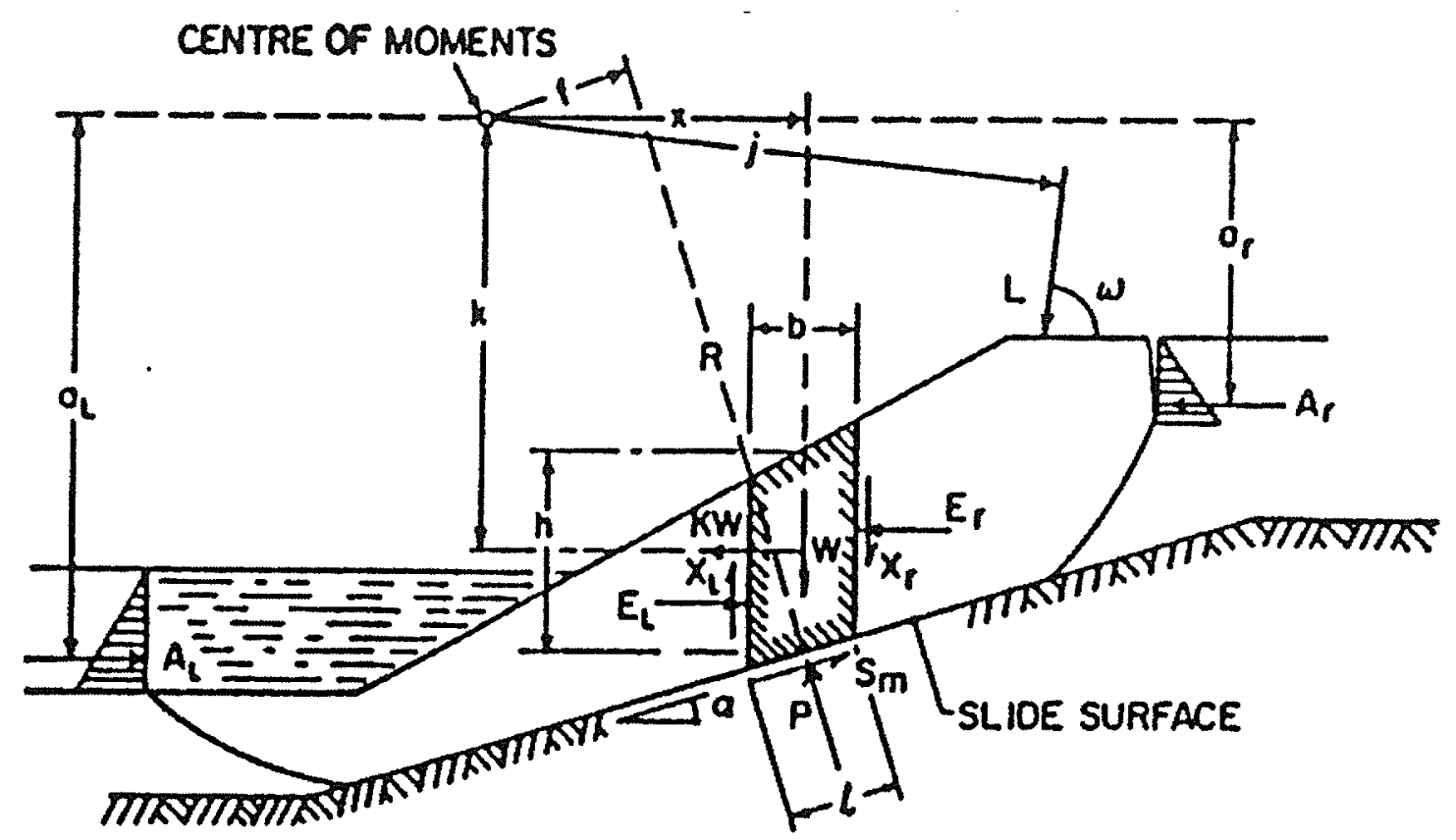

Figure 4.4. Forces acting on slide mass and slice within slide mass (from Fredlund and Krahn, 1977) 


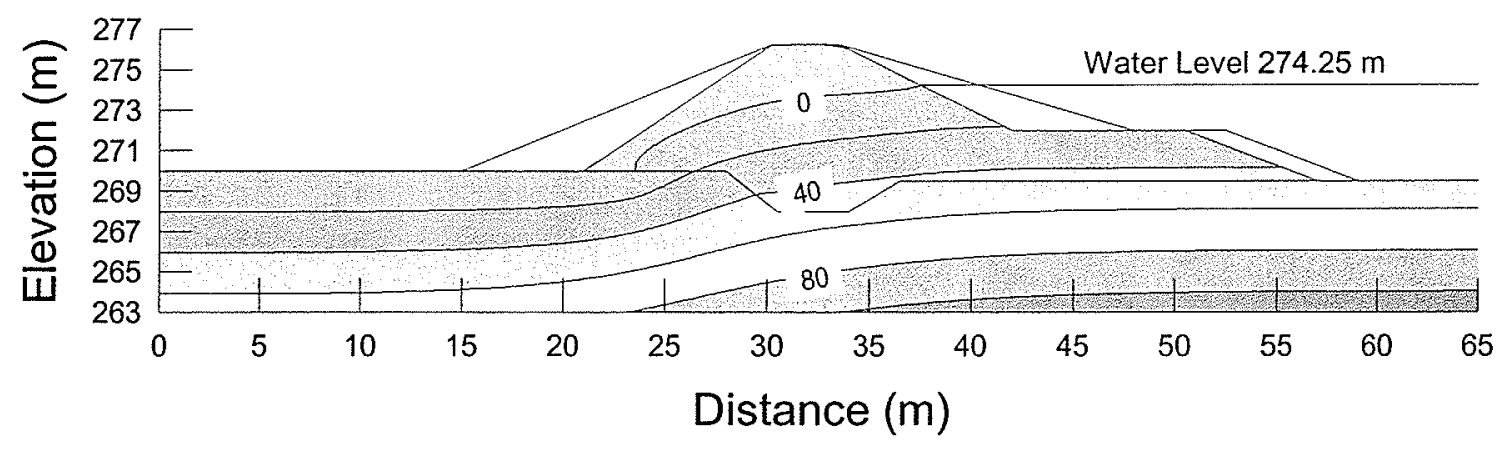

Figure 4.5. Modeled pore water pressure distribution (in $\mathrm{kPa}$ ) through section SS-036 of dykes

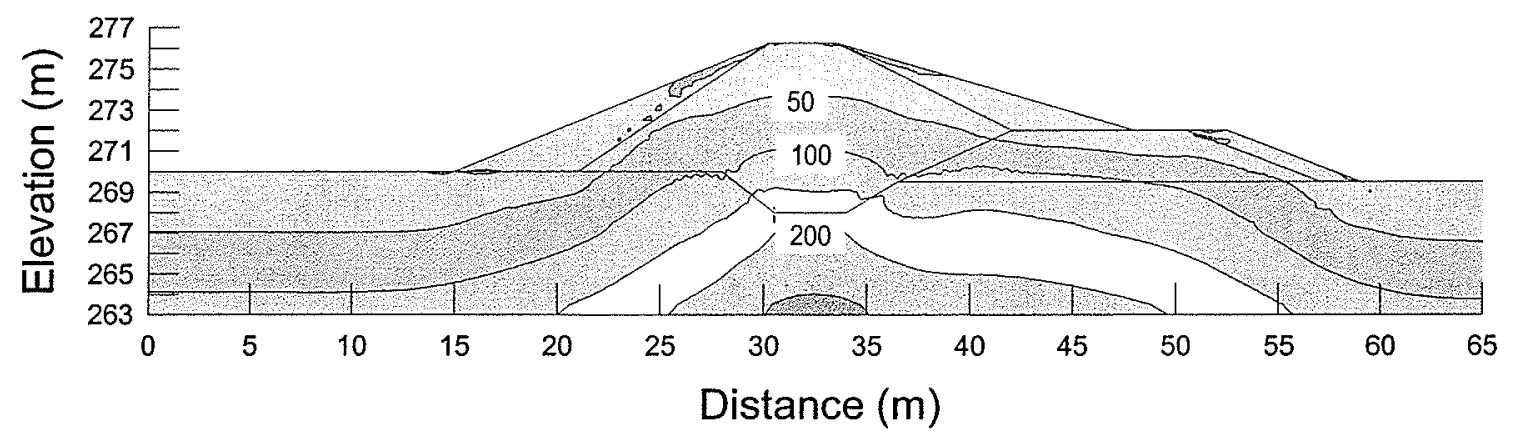

Figure 4.6. Modeled vertical stress distribution (in $\mathrm{kPa}$ ) through section SS036 of dykes 


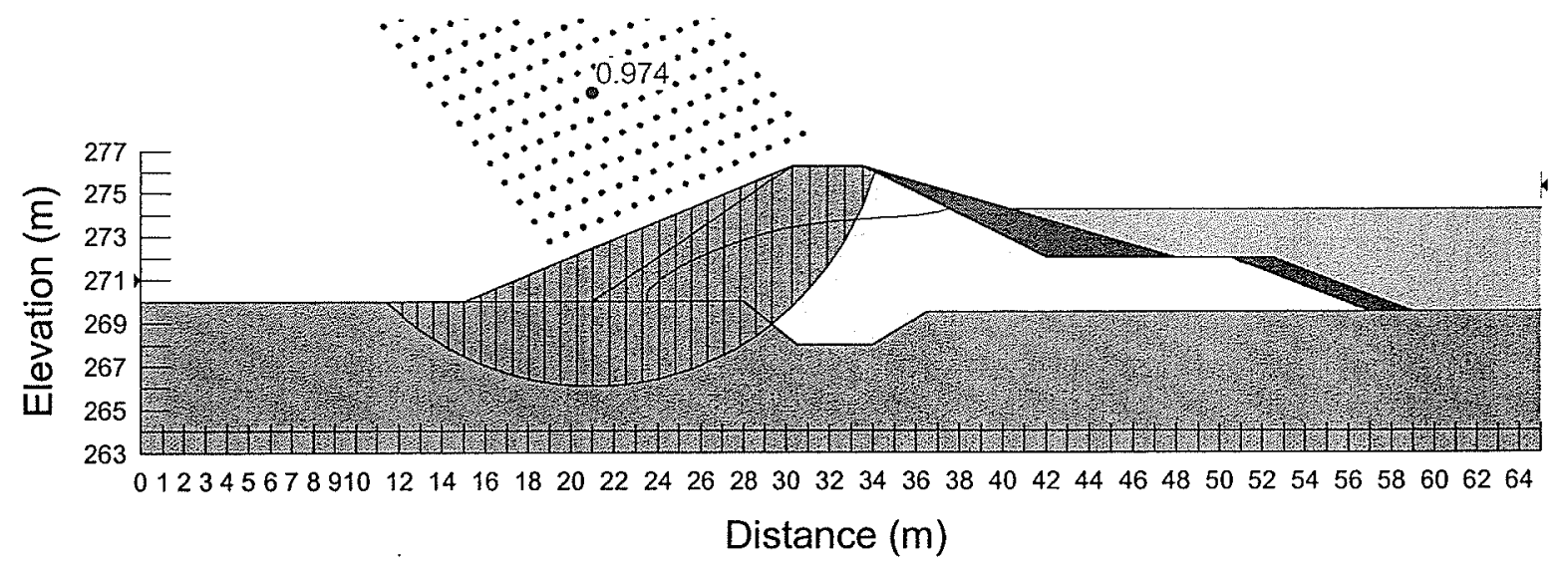

Figure 4.7. Slope stability results at section SS-036 with stress-deformation analysis and residual strength parameters in upper foundation

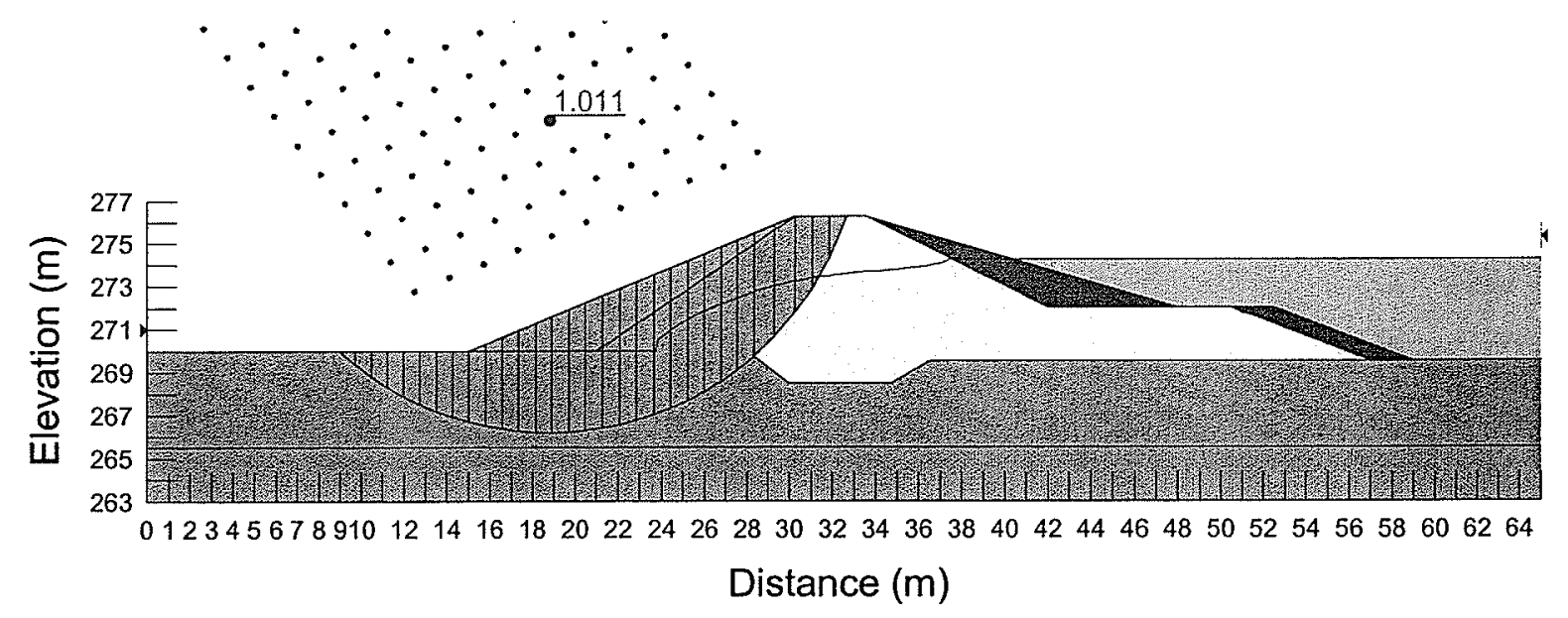

Figure 4.8. Slope stability results at section SS-040 with stress-deformation analysis and residual strength parameters in upper foundation 


\section{Chapter 5 - Summary of Results and Conclusions}

\subsection{Summary of Results}

The investigation of the dykes at the Seven Sisters Generating Station included laboratory testing and modeling at two cross-sections. One section had experienced previous instability and the second had remained stable.

An extensive laboratory testing program was undertaken to characterize the soil and determine parameters for its compressibility and strength. The soil parameters provided a comparison of the two sections and were also used in computer modeling. Testing was also done on pore fluid obtained from soil samples from the two sections and from a third background section.

The laboratory testing on samples of the foundation soil showed it to be markedly strain softening, indicating possible loss of cementation bonding of the soil or a soil that had previously been cemented and from which, leaching had removed some of the cementation bonds. The strain softening indicates that progressive failure is likely. This may be the cause of the irregular timing of instabilities at some sections of the dykes since their heightening over fifty years ago. Comparisons of the two sections showed greater brittleness and anisotropy at section SS-036 than SS-040. 
The pore fluid chemistry testing indicated quite marked differences between the background section and the two sections beneath the dykes. The significant reduction in calcium and sulfate in the sections beneath the dykes indicate that there is likely a leaching of gypsum from the soil. This leaching likely changes the soil in an unfavorable manner towards reduced stability. Seepage rates through the foundation soils will almost certainly be non-uniform as a result of minor irregular differences in silt lenses, sand partings, etc. This means that the rate of leaching out of cementing agents such as gypsum or calcite will also be irregular along the length of the dykes. Some sections will weaken more quickly than others. This suggests a possible mechanism why instabilities have appeared at different sections over a period of many years.

The stress-deformation modeling of the dykes at Seven Sisters indicated that the foundation soil has probably reached strains at which considerable strain softening would occur. Results also showed that there is marginal stability using normally consolidated strengths in the highly plastic foundation soil. At residual strengths, instability would occur.

In 1997 Manitoba Hydro performed cone penetration tests at several sections along the dykes on both the waterside and landside of the crest. Observations made from these tests indicate that at the unstable section (SS036), the sleeve friction in the highly plastic foundation soil was similar at both the waterside and landside of the dyke. At the stable section (SS-040), the 
sleeve friction in the highly plastic foundation soil on the waterside of the dykes was slightly lower than at the landside. At other sections investigated along the dykes, it is generally seen that the friction on the waterside is slightly lower than on the landside, but differences between stable and unstable sections are not as clearly seen as those from sections SS-036 and SS-040.

Of the possible triggers presented in the literature review, many can now be further discussed. Cyclic pore pressure variation within the dykes is likely not a factor as historical records from Manitoba Hydro show that the forebay elevation is held relatively constant. Excess pore water pressures along weak seams may be possible due to stress transfer associated with plastic strain softening and low hydraulic conductivity of the foundation soil. This has an effect of higher pore water pressures during strain softening. The generation of excess pore water pressures due to the breaking down of the clay structure is possible at the Seven Sisters site. This mechanism was found to rapidly cause a progressive failure even when drained conditions occurred for a long period of time.

\subsection{Conclusions}

Based on the results discussed earlier, the following conclusions can be made about the stability of the dykes at Seven Sisters. 
1) Laboratory testing on the highly plastic foundation soil beneath the dykes has indicated markedly strain softening stress-strain behavior. The brittleness of this soil is likely caused by a quasi-stable structure, which, when disturbed by straining, causes a reduction in strength.

2) Laboratory testing at the unstable section and the stable section indicates some differences between the sections, but these differences are relatively small. Plasticity indices in the foundation soil show slightly higher values in the unstable section than in the stable section. Also, triaxial testing indicated the unstable section was more brittle and more anisotropic than the stable section.

3) Pore fluid chemistry testing from a background (unloaded) section, an unstable section, and a stable section provided results that clearly indicate considerable differences in cation and anion concentrations. The calcium and sulphate concentrations were lower in the sections beneath the dykes relative to the background section. It appears that there is gypsum dissolution caused by slow seepage beneath the dykes.

4) Modeling of the dykes indicated that using critical state strengths for the foundation of the dykes provided only marginal stability and that a further reduction in strength would produce instability. The reduction in strength could be related to shear strains that cause strengths to decrease below critical state, 
probably accentuated by the leaching of cementation bonds. Therefore with strengths decreasing below critical state as shown by triaxial testing (Section 3.5), instability could occur at a point when strengths are between critical state and residual.

It appears that the dykes at Seven Sisters have been stable for over fifty years due to a microstructure of the soil that originally contained some cementation bonding. Based on the pore fluid chemistry testing, the bonding is likely due to the presence of gypsum. Shear straining and leaching of the gypsum since the dykes were heightened is believed to have led to instability of some sections of the dykes. The depth of the foundation may also contribute to the instability of certain sections.

Based on the work presented in this thesis, the hypothesis that changes in soil chemistry triggers delayed instabilities is supported. Comparison of the sections beneath the dykes to the section away from the dykes showed changes in pore fluid chemistry. This indicates that seepage is affecting the soil chemistry in the highly plastic foundation soil, causing an increased interparticle repulsion and reduction in strength. 


\subsection{Recommendations for Further Work}

Manitoba Hydro engineers have engaged in ongoing studies to identify critical locations of possible slope instability in the land-side of the dykes. None of the earlier slope instabilities penetrated across the crest into the wet-side of the dykes, and in no case was there a loss of water. Instrumentation has been added to monitor the situation and berms have also been constructed in a proactive manner at locations where instability has not occurred, but where the potential for slope instability was believed to be high. Training of site staff for monitoring and surveillance of the dykes was also undertaken. Further studies such as presented in this thesis were carried out in addition to previous studies carried out by Manitoba Hydro.

Three topic areas have been identified that would probably benefit from additional study.

1) The effect on soil properties of the highly plastic foundation soil due to the changes in soil chemistry. As there is a significant difference in the pore fluid chemistry between the background section and sections beneath the dykes, the effect of these changes on strength of the soil needs to be quantified to truly understand their impact on the stability of the dykes. In particular, the preliminary suggestion in this thesis that the softening results from leaching of gypsum needs to be confirmed. 
2) The time dependent nature of previous instabilities suggests some non-uniformity in the foundation soils, possibly as a result of local layering of silts or sands. This possibility should be examined through an extensive series of CPTU tests that include estimates of the insitu horizontal hydraulic conductivity, $k_{h}$. Also temperature measurement in the foundation can be used to identify zones of high permeability.

3) It is somewhat disturbing that the slope analyses of the 'stable' and 'unstable' sections produce closely similar results. This may result from the relatively simplistic total stress strain softening constitutive model in SIGMA/W. Further work should be done to incorporate anisotropy and provide a better constitutive model for the softening of the foundation soil. 


\section{References}

Armstrong, R. 2001. Horizontal and vertical hydraulic conductivity comparisons of highly plastic clay. Undergraduate Co-op Report, University of Manitoba.

ASTM. 2000a. Standard test methods for liquid limit, plastic limit, and plasticity index of soils. American Society for Testing and Materials, Philadelphia, Pa., D4318-98, pp. 546-558.

ASTM. 2000b. Standard test methods for particle-size analysis of soils. American Society for Testing and Materials, Philadelphia, Pa., D422-63, pp. 10-17.

ASTM. 2000c. Standard test methods for measurement of hydraulic conductivity of saturated porous materials using a flexible wall permeameter. American Society for Testing and Materials, Philadelphia, Pa., D5084-90, pp. 985-992.

ASTM. 2000d. Standard test methods for one-dimensional consolidation properties of soils. American Society for Testing and Materials, Philadelphia, Pa., D2435-96, pp. 228-237. 
ASTM. 2000e. Standard test methods for consolidated undrained triaxial compression test for cohesive soils. American Society for Testing and Materials, Philadelphia, Pa., D4767-95, pp. 882-895.

ASTM. 2000f. Standard test methods for direct shear test of soils under consolidated drained conditions. American Society for Testing and Materials, Philadelphia, Pa., D3080-98, pp. 324-329.

Bailey, W.A. 1965. The effect of salt content on the consolidation behavior of saturated remolded clays. United States Army Engineer Waterways Experiment Station, Vicksburg, Miss., Contract Report 3-101.

Balasubramonian, B.I. 1972. Swelling of compaction shale. Ph.D. dissertation, Department of Civil Engineering, University of Alberta, Edmonton.

Barbour, S.L. and Fredlund, D.G. 1989. Physico-chemical state variable for clay soils. In Proceedings, $12^{\text {th }}$ International Conference of Soil Mechanics and Foundation Engineering, Rio de Janeiro, Brazil, vol. 3, pp. 1839-1843.

Barbour, S.L. and Yang, N. 1993. A review of the influence of clay-brine interactions on the geotechnical properties of Ca-montmorillonitic clayey soils from western Canada. Canadian Geotechnical Journal, 30: 920-934. 
Berger, L. 1951. Stability analysis of actual slides. Doctor's Thesis, Northwestern University, Evanston, Illinois.

Betke, J. 2001. Selection of cohesion and friction parameters for slope stability analysis in fissured plastic clays. Undergraduate thesis, Civil Engineering, University of Manitoba.

Bjerrum, L. 1967. Progressive failure in slopes of overconsolidated plastic clay and clay shales. The Third Terzaghi Lecture, Miami 1966. ASCE Proceedings, Vol. 93, No. SM5, p.3-49.

Bjerrum, L. 1969. Discussion of main session 5, stability of natural slopes and embankment foundations. $7^{\text {th }}$ International Conference on Soil Mechanics and Foundation Engineering, Mexico City, Mexico, Vol. iii, pp. 377-414.

Boone, Storer J. and Lutenegger, Alan J. 1997. Carbonates and cementation of glacially derived cohesive soils in New York State and southern Ontario. Canadian Geotechnical Journal, 34: 534-550.

Burland, J.B., Rampello, S., Georgiannou, V.N., and Calabresi, G. 1996. A laboratory study of the strength of four stiff clays, Geotechnique, 46(3): 491-514. 
Casagrande, A. 1959. An unsolved problem of embankment stability on soft ground. Procedure to the $1^{\text {st }}$ Pan-American Conference on Soil Mechanics, Mexico City.

Chai, J.C. and Bergado, D.T. 1993. Some techniques for finite element analysis of embankments on soft ground. Canadian Geotechnical Journal, 30: 710-719.

Davis, J.F., Bannatyne, B.B., Barry, G.S., and McCabe, H.R. 1962. Geology and Mineral Resources of Manitoba. Province of Manitoba Department of Mines and Natural Resources.

Dounias, G.T., Potts, D.M., and Vaughan, P.R. 1988. Finite element analysis of progressive failure: Two case studies. Computers and Geotechnics, 6: 155-175.

Fredlund, D.G and Krahn, J. 1977. Comparison of slope stability methods of analysis. Canadian Geotechnical Journal, 14: 429-439.

Fredlund, D. G., Xing, A., and Huang, S. 1994. Predicting the permeability function for unsaturated soils using the soil-water characteristic curve. Canadian Geotechnical Journal, 31: $533-546$. 
Garinger, B., Graham, J., and Alfaro, M. 2001a. Seven Sisters laboratory testing summary report. Report to Manitoba Hydro.

Garinger, B., Graham, J., and Alfaro, M. 2001b. Seven Sisters oedometer testing report. Report to Manitoba Hydro.

Garinger, B., Alfaro, M., Graham, J., and Dubois, D. 2001c. Stability of dykes at Seven Sisters Generating Station. $54^{\text {th }}$ Canadian Geotechnical Conference, Calgary, Alberta, pp. 259-265.

Garinger, B., Man, A., Alfaro, M., Graham, J., Goh, T., and Dubois, D. 2002. Physico-chemical investigation of the foundation at Seven Sisters Dykes. Submitted for $55^{\text {th }}$ Canadian Geotechnical Conference, Niagara Falls, Ontario.

Graham, J., Oswell, J.M., and Gray, M.N. 1992. The effective stress concept in saturated sand-clay buffer. Canadian Geotechnical Journal, 29: 10331043.

Hawkins, A.B. and McDonald, C. 1992. Decalcification and residual shear strength reduction in Fuller's Earth Clay. Géotechnique, 42(3): 453-464. 
Krahn, John. 2001. The limits of limit equilibrium analysis. R.M. Hardy Keynote Address. $54^{\text {th }}$ Canadian Geotechnical Conference, Calgary, Alberta, pp. $1-18$.

Lacerda, Willy A. 1989. Fatigue of residual soils due to cyclic pore pressure variation. Discussion. Proceedings of the $12^{\text {th }}$ International Conference on Soil Mechanics and Foundation Engineering. Rio de Janeiro, pp. 3085-3087.

Lambe, T.W. 1960. A mechanistic picture of shear strength in clay. In Proceeding of ASCE Research Conference on the Shear Strength of Cohesive Soils, Boulder, Colo., June 15-16. University of Colorado, Soil Mechanics and Foundation Division. American Society of Civil Engineers, New York. pp. 555-580.

La Rochelle, P., Trak, B., Tavenas, F., Roy, M. 1974. Failure of a test embankment on a sensitive Champlain clay deposit. Canadian Geotechnical Journal, 11: $142-164$.

Lefebvre, G. and La Rochelle, P. 1974. The analysis of two slope failures in cemented Champlain clays. Canadian Geotechnical Journal, 11: 89 - 108. 
Leonards, G. A. 1958. Report on Fourth Int. Conf., ASCE, Soil Mechanics and foundation Division Activities, May 1958, pp. 1958-10-8.

Leonards, Gerald A. 1982. Investigation of failures. Journal of the Geotechnical Engineering Division ASCE, 108(2): 187-246.

Leroueil, Serge, Tavenas, Francois, Brucy, Francoise, La Rochelle, Pierre, and Roy, Marius. 1979. Behavior of destructured natural clays. Journal of the Geotechnical Engineering Division ASCE, 105(6): 759-778.

Liu, V.P.H and Dubois, D.P. 1996. Seven Sisters Generating Station dykes risk analysis. $49^{\text {th }}$ Canadian Geotechnical Conference. St. John's, Newfoundland, pp. 351-360.

Mayer-Oakes, W. (Ed.) 1967. Life, land, and water. Proc. 1966 Conf. On Environmental Studies on glacial Lake Agassiz region, Univ. Manitoba Press, Winnipeg.

Mayne, P.W. and Kulhawy, F.H. 1982. $K_{0}-$ OCR relationships in soil. Journal of the Geotechnical Engineering Division ASCE, 108(6): 851-872.

Mitchell, J.K. 1993. Fundamentals of soil behavior. $2^{\text {nd }}$ ed. John Wiley \& Sons, Inc., New York. 
Peterson, R. 1957. Stability of earth dykes, Seven Sisters Falls Project. P.F.R.A. Engineering Services, Saskatoon, Saskatchewan.

Peterson, R., Iverson, N.L., and Rivard, R.J. 1957. Studies of several dam failures on clay foundations. Proceedings of the 4th International Conference on Soil Mechanics and Foundation Engineering. London, England, pp. 348-352.

Peterson, R., Rivard, P.J., Jasper, J.L., Iverson, N.L. 1960. Limitations of laboratory shear strength in evaluating stability of highly plastic clays. In Proceeding of ASCE Research Conference on the Shear Strength of Cohesive Soils, Boulder, Colo., June 15-16. University of Colorado, Soil Mechanics and Foundation Division. American Society of Civil Engineers, New York. pp. 765-791.

Rivard, P.J. and Lu, Y. 1978. Shear strength of soft fissured clay. Canadian Geotechnical Journal, 15(3): 382-390.

Skempton, A.W. 1964. Long-term stability of clay slopes. Géotechnique, 14(2): 77-103. 
Smith, R.E. and Ehrlich, W.A. 1967. Soils of the Lac du Bonnet Area. Manitoba Soil Survey. Report No. 15.

Teller, J.T. 1976. Lake Agassiz deposits in the main offshore basin of southern Manitoba. Canadian Journal of Earth Sciences, 13: 27-43.

Teller, J.T., and Clayton, Lee. 1983. Glacial Lake Agassiz: The Geological Association of Canada Special Paper 26.

Yuen, K., Graham, J. and Janzen, P. 1998. Weathering-induced fissuring and hydraulic conductivity in a natural plastic clay. Canadian Geotechnical Journal 35: 1101-1108. 